\title{
Advancing our understanding of animal dispersal and functional connectivity in human-altered landscapes: conceptual considerations and their empirical and simulation-based demonstration
}

\author{
DISSERTATION \\ to attain the doctoral degree (Dr. rer. nat.) \\ of the Faculty of Forest Sciences and Forest Ecology \\ Georg-August-Universität Göttingen
}

\author{
Submitted by \\ Femke Jantina Pflüger \\ born on the $14^{\text {th }}$ October 1982 in Fritzlar
}

Göttingen, October 2019 
1. Referee: Prof. Dr. Niko Balkenhol

2. Referee: Prof. Dr. Matthias Waltert

Date of oral examination: $17^{\text {th }}$ December 2019 


To my parents. 



\section{Abstract}

Dispersal, the movement from a natal site to a new breeding site, is a key process in ecology and evolution. By determining the dynamics and distribution of populations and gene flow among them, dispersal is essential for species persistence, especially for species in human-dominated landscapes threatened by habitat loss and fragmentation.

Effective conservation management requires on one side an in-depth understanding of individual dispersal behavior and on the other side indicators that reliably specify negative environmental effects on dispersal prior to extinction. However, simplified assumptions are made on the behavioral process of dispersal and on the complexity of environmental influences. This could lead to false or incomplete conclusions to what extent the landscape is influencing dispersal and resulting distributions of populations and genetic variation. The thesis therefore deals with an integration of behavioral ecology into analyses on landscape-dispersal pattern relationships and examines the potential of reliable early-warning indicators for conservation.

After a general introduction into the research context in chapter 1, resource selection functions and resemblance measures are used to illustrated in chapter 2 how different environmental factors are shaping the distribution of reintroduced brown bears (Ursus arctos) in the Central European Alps. Local habitat suitability and habitat similarity are important drivers of brown bear settlement, suggesting that testing different hypothesis on how the environment influences individual dispersal behavior at the three different stages of dispersal (emigration, movement and immigration) is vital for correctly identifying environmental predictors of population distribution.

Chapter 3 deals with the conceptual and analytical integration of several environmental factors that are important for the behavioral process of dispersal in landscape genetic studies. A combined integration of local and intervening environmental factors can be feasible by using metapopulation connectivity indices, which allows to evaluate their relative importance in shaping 
resulting genetic pattern. The consideration of several environmental factors in landscape genetic studies could allow a comprehensive evaluation of landscape effects on dispersal and resulting distribution of populations and genetic variation.

Individual-based simulations are used in chapter 4 to examine the development of genetic variation and population abundance during continuous habitat loss. Genetic diversity, genetic differentiation and population abundance exhibit non-linear responses to habitat loss with rapid changes beyond critical tipping points of habitat amount. Since the negative effects of habitat loss manifest first in genetic data before detectable changes in population abundance occur, genetic data could serve as an early warning indicator of upcoming species extinction in conservation.

Chapter 5 summarizes and discusses the main findings of this work with respect to the current research context. The results of this work can enhance the understanding and prediction of dispersal in heterogeneous and human-modified landscapes and contribute to the protection of species threatened by habitat loss and fragmentation. 


\section{Zusammenfassung}

Abwanderung, definiert als die Bewegung eines Individuums von seinem Geburtsort zu einem neuen Ort, an dem es sich niederlassen und fortpflanzen kann, ist ein wichtiger Bestandteil ökologischer und evolutionärer Prozesse. Indem es die Dynamik und Verbreitung von Populationen und genetischer Vielfalt beeinflusst, trägt das Abwandern von Individuen entscheidend zur Arterhaltung bei, insbesondere in Arten, die in anthropogenen Landschaften leben und durch den Verlust und die Fragmentierung ihres Lebensraums bedroht sind.

Die erfolgreiche Erhaltung einer Art erfordert zum einen ein umfassendes Verständnis von dem zugrundliegenden Verhaltensprozess der Abwanderung und zum anderen verlässliche Indikatoren, die den negativen Einfluss von Lebensraumverlust und Fragmentierung frühzeitig anzeigen. In vielen Studien, die sich mit dem Einfluss von Landschaftscharakteristiken auf die Abwanderung befassen, werden jedoch meist vereinfachte Annahmen hinsichtlich des Abwanderungsprozesses und der Komplexität an Landschaftseinflüsse gemacht. Das kann dazu führen, dass fehlerhafte oder unvollständige Schlussfolgerungen darüber getroffen werden, inwieweit die Landschaft einen Einfluss auf die Abwanderung und die daraus resultierende Verbreitung von Populationen und genetischer Vielfalt hat.

Die Dissertation befasst sich daher einerseits mit der Integration verhaltensökologischer Aspekte in Analysen, welche die kausale Beziehung zwischen Landschaftscharakteristiken und Abwanderung untersuchen. Andererseits umfasst die Arbeit die Bewertung von alternativen Frühwarnindikatoren und wie diese im Artenschutz praktische Anwendung finden könnten.

Nach einer generellen Einleitung in das Forschungsthema in Kapitel 1, zeigt Kapitel 2 unter Verwendung von Ressourcenselektionsfunktionen und Ähnlichkeitsmaßen, wie die Verbreitung von wiedereingeführten Braunbären (Ursus arctos) in den zentral-europäischen Alpen durch verschiedene Landschaftsfaktoren beeinflusst wird. Die Qualität eines Lebensraumes sowie ähnliche Landschaftsbedingungen wie am Geburtsort sind wichtige Faktoren für 
die Entscheidung eines Braunbären, sich an einem neuen Ort niederzulassen. Die Ergebnisse zeigen, dass es wichtig ist, verschiedene Hypothesen über den Einfluss der Landschaft in Abhängigkeit von den drei einzelnen Phasen der Abwanderung (Emigration, Bewegung, Immigration) zu testen, um die entscheidenden Landschaftsfaktoren zu identifizieren, die die Verbreitung einer Art bestimmen.

Kapitel 3 befasst sich mit der konzeptionellen und analytischen Integration von verschiedenen Landschaftsfaktoren basierend auf den drei Phasen der Abwanderung in landschaftsgenetischen Studien. Lokale Landschaftsfaktoren sowie Faktoren, die sich zwischen dem Geburtsort und dem neuen Ort befinden, können gemeinsam in Metapopulationskonnektivitäts-Indizes integriert werden, wodurch deren relativer Einfluss auf die resultierende Verbreitung genetischer Vielfalt bestimmt werden kann. Die Berücksichtigung mehrerer Landschaftseinflüsse in der Landschaftsgenetik könnte somit eine gesamtheitliche Bewertung darüber erlauben, wie die Abwanderung und Verbreitung von Individuen und ihrem genetischen Material von der Landschaft beeinflusst wird.

In Kapitel 4 werden Individuen-basierte Simulationen verwendet, um die zeitliche Entwicklung von genetischer Vielfalt und Abundanz unter kontinuierlichem Lebensraumverlust zu untersuchen. Genetische Diversität, genetische Differenzierung sowie Abundanz zeigen ein nicht-lineares Verhalten gegenüber dem Verlust an Lebensraum, bei dem es zu rapiden Veränderungen nach Erreichen eines kritischen Schwellenwertes kommt. Da sich die negativen Effekte von Lebensraumverlust zuerst in den genetischen Daten manifestieren bevor Effekte auf die Abundanz detektiert werden können, könnten genetische Daten verlässliche Frühwarnindikatoren für bevorstehende Aussterbeprozesse darstellen und die Effektivität von Arterhaltungsmaßnahmen erhöhen.

Kapitel 5 diskutiert zusammenfassend die Ergebnisse der einzelnen Kapitel unter Bezugnahme des aktuellen Forschungsstandes. Die Ergebnisse dieser Arbeit können dazu beitragen, Abwanderungsverhalten in heterogenen und anthropogenen Landschaften umfassender zu verstehen und vorherzusagen sowie dem Aussterben von Arten entgegenzuwirken, die aufgrund von Verlust und Veränderung ihres Lebensraumes bedroht sind. 


\section{Contents}

\begin{tabular}{llr}
\hline & General introduction & 2
\end{tabular}

The importance of dispersal . . . . . . . . . . . . . . . . . . . 2

Threats to dispersal . . . . . . . . . . . . . . . 3

Understanding dispersal and resulting dispersal pattern . . . . . . . . 3

Understanding dispersal using landscape genetics . . . . . . . . . . . 6

Estimating extinction risk . . . . . . . . . . . . . . 7

Aim of the thesis . . . . . . . . . . . . . . . . . 9

Structure of the thesis . . . . . . . . . . . . . . . . . 9 9

2 The influence of habitat suitability, habitat similarity and landscape resistance on brown bear (Ursus arctos) dispersal in the

Central-European Alps 16

Introduction . . . . . . . . . . . . . . . . . . . . . 17

Methods . . . . . . . . . . . . . . . . . . . . 20

Study area . . . . . . . . . . . . . . . . . 20

Brown bear data . . . . . . . . . . . . . . 20

Environmental data . . . . . . . . . . . . . . 22

Study design and statistical analysis . . . . . . . . . . . 23

Habitat suitability model . . . . . . . . . . . . . . . . . . 25

Measuring habitat similarity . . . . . . . . . . . . . . 25

Measuring habitat reachability . . . . . . . . . . . . 26

Results. . . . . . . . . . . . . . . . . . . . . 28

Habitat suitability . . . . . . . . . . . . . . . . . . . 28

Habitat similarity . . . . . . . . . . . . . . . . . . . . . . . 29

Habitat reachability . . . . . . . . . . . . . . . . . . 32

Discussion . . . . . . . . . . . . . . . . . . . . . . . . . 33

The importance of local environmental factors for dispersal . . . 34

The importance of in-between environmental factors for dispersal 37 
Dispersal and habitat selection of Trentino brown bears . . . . . 38

Limitations . . . . . . . . . . . . . . . . . . . . . . . . 39

Conclusions . . . . . . . . . . . . . . . . . . 40

Appendix A2.1: Supplemental material . . . . . . . . . . . . . . 50

3 A plea for simultaneously considering matrix quality and local environmental conditions when analyzing landscape impacts on effective dispersal $\quad 54$

Introduction . . . . . . . . . . . . . . . . . . . . . 55

Rethinking environmental effects on dispersal . . . . . . . . . . . . . 57

Environmental influences on emigration . . . . . . . . . . . . 58

Environmental influences on transience . . . . . . . . . . . 58

Environmental influences on immigration . . . . . . . . . . . 59

Simultaneous consideration of landscape resistance and local environ-

mental conditions . . . . . . . . . . . . . . . . . 61

Step 1: Quantify matrix quality among sampling locations . . . 61

Step 2: Quantify local environmental conditions and convert them into meaningful variables . . . . . . . . . . . 61

Step 3: Combine landscape resistances and local environmental variables . . . . . . . . . . . . . . . . . . 63

Evaluating the relative importance of local environmental conditions and matrix quality . . . . . . . . . . . . . . . 65

An illustration using simulated data . . . . . . . . . . . 66

Relevance of simultaneous analyses for landscape genetic inferences . 69

Effects of density-dependent dispersal on source-sink and range dynamics ....................... 69

Effects of NHPI on corridor functionality . . . . . . . . . . 70

Conclusions and suggestions for future research . . . . . . . . . . 71

Appendix A3.1: Simulation details . . . . . . . . . . . . . 80

4 Habitat loss causes non-linear genetic erosion in specialist $\begin{array}{lr}\text { species } & 86\end{array}$

Introduction . . . . . . . . . . . . . . . . . . . . . . . . . . 87

Methods . . . . . . . . . . . . . . . . . . . . . . . . . . . . 89

Simulation experiments . . . . . . . . . . . . . . 89

Population genetic simulation . . . . . . . . . . . . . . 91

Sampling . . . . . . . . . . . . . . . . . . . . 92

Quantifying genetic variation . . . . . . . . . . 93 


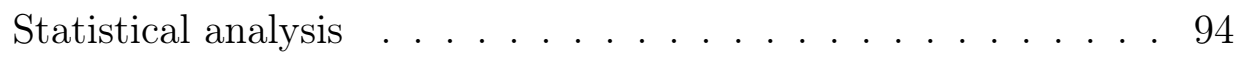

Results. . . . . . . . . . . . . . . . . . . . . 94

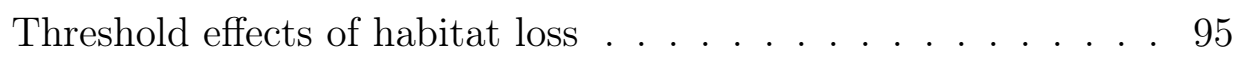

Temporal metric behavior after habitat loss stopped . . . . . . . 96

Effects of simulation parameters . . . . . . . . . . . . 100

Discussion . . . . . . . . . . . . . . . . . . . . . . . 101

Non-linear responses . . . . . . . . . . . . . . . . . . . . . . 102

Consistency of abundance vs. genetic variation. . . . . . . . . 104

Genetic diversity vs. differentiation . . . . . . . . . . . . . 105

Legacy effect after stopping habitat loss _ . . . . . . . . . 106

Potential conservation application . . . . . . . . . . . . . 107

Conclusions . . . . . . . . . . . . . . . . . . . . . . . . 109

Appendix A4.1: ODD protocol and supplemental material . . . . . . 114

5 General discussion 130

Environmental drivers of individual dispersal . . . . . . . . . . . . 130

Integrating dispersal behavior into landscape genetics . . . . . . . . 132

Detecting negative landscape effects on dispersal. . . . . . . . . . . 133

Outlook . . . . . . . . . . . . . . . . . . . . . . . . 133 



\section{CHAPTER 1}

\section{General introduction}

\section{The importance of dispersal}

Dispersal is the permanent movement of an individual from a natal site to a first breeding site or potential breeding site, which is often termed 'natal dispersal' (Greenwood 1980). For animals that actively decide to disperse, dispersal can also be defined as the departure from the natal habitat, the subsequent search for and the settlement within new habitat (Clobert et al., 2001). When an individual reproduces after dispersal, it is described as 'effective dispersal' (Greenwood, 1980), defining dispersal also as any movement of individuals with potential consequences for gene flow across space (Ronce, 2007).

Dispersal is a key driver of ecological and evolutionary processes (e.g., Wright, 1943; Hanski, 1998; Ronce, 2007; Lowe and Allendorf, 2010) and is acting on several temporal and spatial scales. It has important implications for the survival, growth and reproduction of individuals (Doligez and Pärt, 2008. Green and Hatchwell, 2018). It influences the composition, structure and dynamics of populations and communities (Hanski and Gilpin, 1997), and finally the evolution, geographical distribution and persistence of species (Slatkin, 1987; Bell and Gonzalez, 2011). Dispersal allows species to spread and colonize new habitat in response to environmental change (Berg et al., 2010; Thompson and Gonzalez, 2017), which can decrease extinction risks and balances the loss of other populations (Hanski and Gilpin, 1997, Hanski, 1998). Populations can also be rescued from extinction when individuals move into declining populations (Brown and Kodric-Brown, 1977). Dispersal enables gene flow between populations and determines genetic variation (Bohonak, 1999), which 
is important for adaptation to changing environmental conditions and persistence within changed environments (Lande and Shannon, 1996, Berg et al. 2010). Consequently, restrictions to dispersal can have profound effects on the amount and distribution of species and genetic variation, and ultimately on their future fate, especially in human-altered and degraded landscapes.

\section{Threats to dispersal}

Human-induced habitat loss and alteration has led to a decreased movement potential of many species worldwide (Bischof et al., 2017; Tucker et al., 2018). Within the last two centuries the amount of natural habitat has dramatically declined (Haddad et al. 2015) and more than 50\% of the earth's surface have been transformed by humans (Barnosky et al., 2012, Watson et al., 2016). Roughly one million species are threatened by extinction (Díaz et al., 2019), some of them living in small habitat remnants embedded in human-modified landscapes that constrain movement, and thus gene flow among populations (Fahrig and Merriam, 1985, Andreassen et al., 1998; Tischendorf and Fahrig, 2000). Small and isolated populations show increased extinction probabilities, because they are vulnerable to demographic variability, inbreeding risk and environmental stochasticity (Shaffer, 1981; Frankham, 2005).

Regarding the ongoing biodiversity crisis, understanding how individuals disperse in heterogeneous landscapes is essential for predicting the impact of environmental change on populations and for devising effective conservation schemes, such as effective landscape planning, wildlife protection and management or human wildlife conflict mitigation (Travis et al., 2013; Wall et al., 2014; Tucker et al., 2018).

\section{Understanding dispersal and resulting dispersal pattern}

In the past years, a multitude of different methodological and conceptual advancements have been suggested to improve our understanding of dispersal. Advancing tracking technology can provide us with large amounts of fine-scale location data (Cagnacci et al. 2010), facilitating the examination of dispersal. By equipping animals with GPS radio-collars and following them over a certain period of time, we are able to gain detailed information about why, how, when and where individuals allocate in space and time and respond to their environment (Nathan et al., 2008). Genetic data can be used to measure effective dispersal that in combination with high resolution environmental data make 
landscape genetics a promising research field to provide detailed insights into the causes and consequences of dispersal in heterogeneous landscapes. It has also been realized that individuals move for particular reasons and select their new place to live non-randomly (Burt, 1943, Clobert et al. 2001), highlighting the importance of individual behavior for interpreting dispersal pattern.

From a behavioral ecological perspective, dispersal is defined as a behavioral process involving three successive dispersal stages called 'emigration', 'movement' and 'immigration' (Clobert et al., 2001; Matthysen, 2012). All of these stages are influenced by fitness cost and benefits resulting from kin competition, inbreeding (avoidance) and spatiotemporally varying environments (Hamilton and May, 1977; Gandon, 1999; Bonte et al., 2012). On the stage of emigration or departure, individuals leave their natal home range due to local negative fitness effects such as competition over resources or inbreeding. Increasing local population densities or sexual maturity are possible mechanisms initiating emigration (Pusey, 1987; Matthysen, 2005). In the transience or movement stage, individuals move through the landscape and search for new potential sites to settle, which is directly affecting fitness due to mortality risk or energetic expenses (Bonte et al. 2012). In the last stage of immigration or settlement, the individual establishes a new home range where it can live permanently and reproduce, which again depend on local conditions.

According to these three stages, environmental factors that are important for individual dispersal decisions on each dispersal stage are likely different (Matthysen, 2012) (Fig. 1.1). Specifically, local habitat for resource use within individual home ranges (i.e., natal and new established home range) must contain suitable components that are relevant for the survival of the individual itself and its offspring, e.g. access to food, water, or shelter, or low human disturbances (Holt and Barfield, 2001, Stamps, 2001). In addition, familiar environmental cues that the individual experienced in the natal site can influence dispersing individuals to select similar habitat when settling in new areas (e.g., Mabry and Stamps, 2008, Larue et al., 2018), a behavioral mechanism that is called 'natal habitat preference induction' (NHPI, Davis and Stamps, 2004). The movement stage is essentially influenced by the environmental factors experienced between natal and new site (also called the 'landscape matrix'), expecting individuals to prefer habitat that is least costly to cross and to select movement paths accordingly (Adriaensen et al., 2003). Thus, at the individual level, behavioral decisions on the three stages of dispersal are affected by complex interactions between the individual's fitness and 
several environmental factors (Clobert et al., 2009; Matthysen, 2012), which in sum determine observed dispersal pattern at the population and community level.

Studies that examine landscape effects on dispersal pattern often make simplified assumptions on the underlying dispersal process. Despite the knowledge that dispersal encompasses three interrelated stages, it is often integrated as one single parameter. Consequently, only environmental factors relevant for this single stage (i.e., either local or landscape-wide factors) are included and related to dispersal pattern. However, although a detailed study of dispersal for many species can be challenging, the incorporation of incomplete dispersal assumptions may yield inaccurate predictions on dispersal, potentially leading to ineffective conservation management Bowler and Benton, 2005). In order to gain a comprehensive understanding of landscape effects on dispersal and resulting dispersal pattern (e.g., distribution of species or genetic variation), we have to acknowledge landscape influences on the whole behavioral process of dispersal.

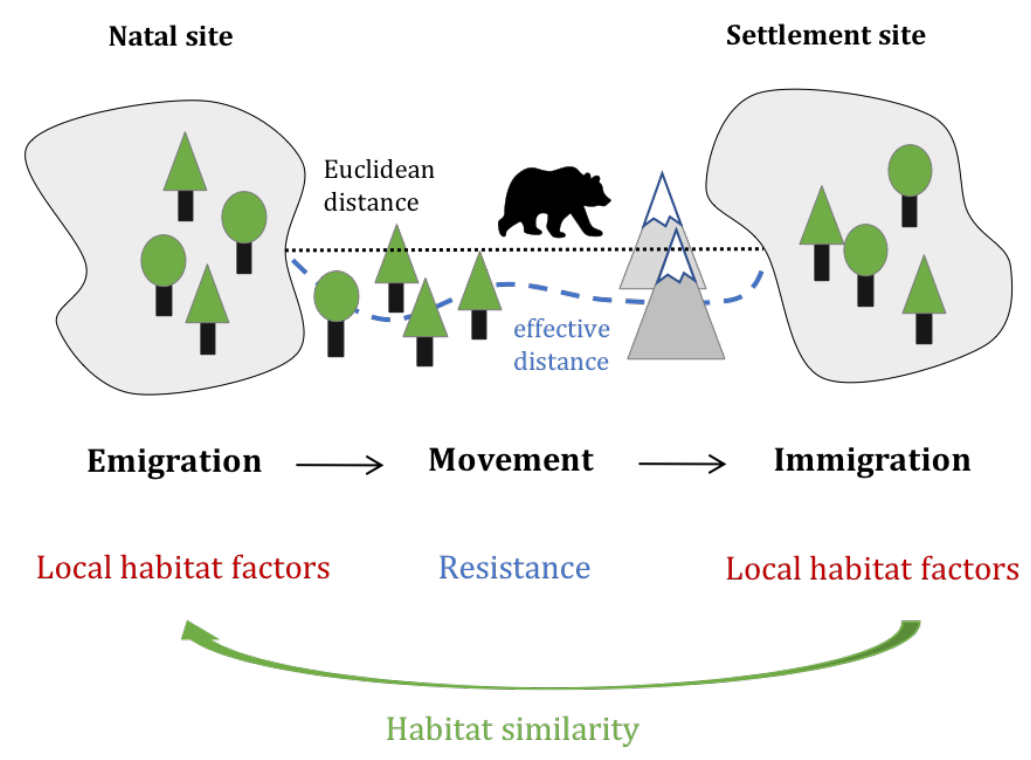

Figure 1.1: The three interrelated dispersal stages of emigration, movement and immigration and stage-dependent environmental local and landscape-wide factors. Euclidean distances (black dotted line) reflects the geographical distance between populations or individuals, which are often used in population genetics. Effective distances (blue broken line) used in landscape genetics account for intervening landscape effects, which influence navigation and path selection during movement. 


\section{Understanding dispersal using landscape genetics}

Landscape genetics holds a great potential for understanding environmental effects on dispersal and for predicting its ecological and evolutionary consequences, because genetic data reflects effective dispersal, i.e. movements that resulted in successful reproduction. Landscape genetics is defined as an interdisciplinary "[...] research that combines population genetics, landscape ecology, and spatial analytical techniques to explicitly quantify the effects of landscape composition, configuration, and matrix quality on microevolutionary processes such as gene flow, drift and selection, using neutral and adaptive genetic data" (Balkenhol et al., 2016).

However, a major limitation of landscape genetic analyses is that they only measure landscape effects of the intervening landscape matrix (e.g., Cushman and Lewis, 2010; Reding et al., 2013, Graves et al., 2014), and thus, solely consider the movement stage of dispersal. Inferences on landscape effects on effective dispersal usually are drawn by relating genetic distances of individuals or populations to so-called 'effective' distances (Storfer et al., 2007). Genetic distances are population- or individual-based measurements of genetic differentiation, i.e., genetic variation among populations or individuals (Storfer et al. 2010). Effective distances account for the impacts of intervening environmental factors, such as mountains, rivers and forests that influence navigation and path selection during movement and thus, differ from straight-line geographical distances (i.e., Euclidean distance) used in population genetics (Fig. 1.1).

Effective distances are estimated from resistance surfaces (for an example see Fig. A3.1), which themselves are created from raster GIS layers that represent different landscape components, for example vegetation type, elevation or anthropogenic factors (Sawyer et al., 2011). Resistance surfaces are grid-based spatial cost layers whose grid values represent the willingness of an individual to move through certain habitat, the physiological cost and/or the reduction in survival of traversing the habitat (Zeller et al., 2012). Through statistically correlating or regressing genetic distances to effective distances, the effects of landscape variables on genetic variation can be explicitly tested and quantified (Storfer et al., 2007).

Effective distances between populations or individuals such as least cost distances or resistance distances based on circuit theory Adriaensen et al. 2003; McRae, 2006, Pinto and Keitt, 2009) that reflect movement in response to the landscape, might be more meaningful than simple straight-line distances. However, local environmental factors that are relevant for the emigration or 
immigration stage of dispersal are rather neglected in landscape genetic studies, but can have an important influence on the amount and distribution of genetic variation (e.g., Geffen et al., 2004; Busch et al., 2009; Roy et al., 2012).

The missing link between local and landscape-wide environmental factors severely limits the ability to fully elucidate the effects of heterogeneous landscapes on effective dispersal using landscape genetic approaches. However, incorporating and combining local and landscape-wide environmental factors in landscape genetic studies would acknowledge the behavioral processes underlying dispersal, which could in turn enhance our ability to interpret the dispersal pattern we observe. Regarding the threat of habitat alteration and loss of functional connectivity (i.e., gene flow via dispersal), a deep understanding on how individuals respond to their environment is essential to predict future dispersal pattern of populations and communities under environmental change (Bro-Jørgensen et al., 2019; Wittemyer et al., 2019).

\section{Estimating extinction risk}

In order to protect populations and species that are threatened by habitat loss and isolation, we also have to identify when populations in fragmented habitats are at risk of going extinct. For this, early-warning indicators have been proposed, which identify negative environmental effects before populations are forced across critical thresholds or 'tipping-points' beyond which rapid extinction and potentially irreversible regime shifts can occur (Barnosky et al. 2012 , Pardini et al. 2017). For example, 'habitat thresholds', i.e., the maximum value of habitat loss that a species can tolerate before it is threatened by extinction, are often used to define habitat conservation targets (McAlpine et al. 2007; Rompré et al., 2010; Hoek et al., 2015). These simple habitat thresholds are appealing, because they do not require actual field data and the amount of habitat within a landscape can easily be estimated from digital maps or remote sensing data. However, these threshold values are often derived from single species and can be inaccurate or misleading Johnson, 2013; Lindenmayer and Luck, 2005). They also do not provide any actual evidence of habitat loss effects, which is often needed to convince stakeholders and policy-makers to invest in conservation actions. Sophisticated early-warning indicators of imminent species decline (e.g., Dakos et al., 2012; Scheffer et al., 2009) could be used as an alternative to simple habitat threshold rules, but they require longterm demographic monitoring data that are difficult and expensive to obtain in most applied settings. Thus, early warning indicators that both, reliably 
indicate negative effects of habitat loss and are preferably straight-forward to acquire, are currently lacking.

Genetic diversity and differentiation, i.e. genetic variation within and among populations, are profoundly affected by habitat loss and fragmentation (Templeton et al., 1990; Young et al., 1996), making genetic data a potential alternative solution. It is usually assumed that negative habitat effects take time to manifest in genetic data, rising the question whether populations persist long enough to detect observable changes in genetic variation (e.g., Keyghobadi, 2007). Contrary, it has also been suggested that populations are not driven to extinction before genetic effects impact them (e.g., Spielman et al., 2004). We actually do not know how genetic variation develops over time during ongoing habitat loss and whether critical tipping points exist in genetic data.

The evaluation whether genetic data can serve as an early warning indicator requires the identification of general principles in genetic responses during habitat loss. For this, genetic monitoring over several generations is needed, which can be difficult to obtain in empirical studies, especially for long-living species. Spatially explicit, individual-based models (IBM) could overcome this limitation, since they are able to simulate dynamics of thousands autonomous individuals during landscape change over long periods of time (Epperson et al., 2010; McLane et al., 2011; Grimm et al., 2017). In such models, individuals (i.e., model entities) can be equipped with certain attributes (e.g., sex or genotype), which are then placed in a spatially explicit, heterogeneous environment. This environment is represented by a grid where cells contain different landscape characteristics (e.g., habitat vs. non-habitat), which can be altered over time. By defining specific rules of movements (e.g., distance or probability) or reproduction (e.g., reproductive rate or rule of inheritance), individuals move through the artificial landscape and reproduces with other individuals, leading to the development of new individuals with own attributes (e.g., recombined genotypes). When the simulation proceeds from initial habitat conditions, i.e., populations within continuous and unaltered landscapes, it is possible to directly study the influence of ongoing habitat loss on resulting dispersal pattern.

Although simulations inherently make simplified assumptions on complex ecological processes (Grimm and Railsback, 2005, Landguth et al., 2016), they have a high potential for identifying general principles of habitat loss effects on abundance and genetic variation, which could allow the evaluation of 
their applicability as an early-warning indicator of imminent species decline.

\section{Aim of the thesis}

The overall aim of this thesis is to integrate individual dispersal behavior into research on environmental effects on animal populations. It deals with the varying effects of landscape heterogeneity on individual dispersal, how considering a combination of different dispersal components and environmental effects can help to interpret observed dispersal patterns, and how negative effects of habitat loss and fragmentation can be detected in different resulting dispersal patterns.

\section{Structure of the thesis}

The thesis is subdivided into three main chapters that all deal with environmental influences on dispersal and resulting patterns of gene flow, population distribution and population persistence.

Chapter 2 illustrates that different environmental factors are influencing movement and settlement stages of dispersal in a reintroduced brown bear (Ursus arctos) population in the Central European Alps. The results suggest that testing different hypothesis on how the environment influences individual dispersal behavior at the three different stages of dispersal is essential for correctly identifying environmental predictors of population distribution.

Chapter 3 demonstrates how a more dispersal process-oriented evaluation of environmental effects can be implemented into landscape genetic studies. It shows that local and landscape-wide environmental factors can be combined in metapopulation connectivity indices, allowing to examine the relative importance of different environmental influences for observed genetic patterns.

Chapter 4 closes with an assessment of genetic consequences of restricted dispersal of specialist species in fragmented landscapes over time using individual-based simulations. The results suggest that, similar to population abundance, habitat loss and fragmentation can lead to sudden, non-linear declines in genetic variation and that genetic effects can precede the effects on population abundance. This suggests that genetic data has the potential to detect indirect effects of landscape-wide habitat loss before direct effects on the size of a population become apparent, which makes genetic data a valuable early-warning indicator for practical conservation. 
Chapter 5 summarizes and discusses the findings of chapter 2 - 4 and provides an outlook on the integration of individual behavior into studies examining landscape effects on dispersal. 


\section{References}

Adriaensen, F., Chardon, J. P., De Blust, G., Swinnen, E., Villalba, S., Gulinck, H., and Matthysen, E. (2003). The application of 'least-cost' modelling as a functional landscape model. Landscape and Urban Planning, 64(4):233-247.

Andreassen, H. P., Hertzberg, K., and Ims, R. A. (1998). Space-use responses to habitat fragmentation and connectivity in the root vole Microtus oeconomus. Ecology, 79(4):12231235 .

Balkenhol, N., Cushman, S., Storfer, A., and Waits, L. (2016). Landscape genetics: concepts, methods, applications. Wiley-Blackwell, West Sussex.

Barnosky, A. D., Hadly, E. A., Bascompte, J., Berlow, E. L., Brown, J. H., and et al. (2012). Approaching a state shift in Earth's biosphere. Nature, 486(7401):52-58.

Bell, G. and Gonzalez, A. (2011). Adaptation and evolutionary rescue in metapopulations experiencing environmental deterioration. Science, 332(6035):1327-1330.

Berg, M. P., Toby Kiers, E., Driessen, G., van der Heijden, M., Kooi, B. W., Kuenen, F., Liefting, M., Verhoef, H. A., and Ellers, J. (2010). Adapt or disperse: Understanding species persistence in a changing world. Global Change Biology, 16(2):587-598.

Bischof, R., Steyaert, S. M., and Kindberg, J. (2017). Caught in the mesh: roads and their network-scale impediment to animal movement. Ecography, 40(12):1369-1380.

Bohonak, J. A. (1999). Dispersal, Gene Flow, and Population Structure. The Quarterly Review of Biology, 74(1):21-45.

Bonte, D., Van Dyck, H., Bullock, J. M., Coulon, A., Delgado, M., and et al. (2012). Costs of dispersal. Biological Reviews of the Cambridge Philosophical Society, 87(2):290-312.

Bowler, D. E. and Benton, T. G. (2005). Causes and consequences of animal dispersal strategies: relating individual behaviour to spatial dynamics. Biological Reviews of the Cambridge Philosophical Society, 80(2):205-225.

Bro-Jørgensen, J., Franks, D. W., and Meise, K. (2019). Linking behaviour to dynamics of populations and communities: application of novel approaches in behavioural ecology to conservation. Philosophical Transactions of the Royal Society B: Biological Sciences, 374(1781):20190008.

Brown, J. and Kodric-Brown, A. (1977). Turnover Rates in Insular Biogeography: Effect of Immigration on Extinction. Ecology, 58(2):445-449.

Burt, W. H. (1943). Territoriality and Home Range Concepts as Applied to Mammals. Journal of Mammalogy, 24(3):346-352.

Busch, J. D., Waser, P. M., and Dewoody, J. A. (2009). The influence of density and sex on patterns of fine-scale genetic structure. Evolution, 63(9):2302-2314.

Cagnacci, F., Boitani, L., Powell, R. A., and Boyce, M. S. (2010). Animal ecology meets GPS-based radiotelemetry: A perfect storm of opportunities and challenges. Philosophical Transactions of the Royal Society B: Biological Sciences, 365(1550):2157-2162. 
Clobert, J., Danchin, E., Dhondt, A., and Nichols, J. (2001). Dispersal. Oxford.

Clobert, J., Le Galliard, J.-F., Cote, J., Meylan, S., and Massot, M. (2009). Informed dispersal, heterogeneity in animal dispersal syndromes and the dynamics of spatially structured populations. Ecology Letters, 12(3):197-209.

Cushman, S. A. and Lewis, J. S. (2010). Movement behavior explains genetic differentiation in American black bears. Landscape Ecology, 25(10):1613-1625.

Dakos, V., Carpenter, S. R., Brock, W. A., Ellison, A. M., Guttal, V., and et al. (2012). Methods for detecting early warnings of critical transitions in time series illustrated using simulated ecological data. PLoS ONE, 7(7):e41010.

Davis, J. M. and Stamps, J. A. (2004). The effect of natal experience on habitat preferences. Trends in Ecology and Evolution, 19(8):411-416.

Díaz, S., Settele, J., Brondízio, E., Ngo, H. T., Guèze, M., and et al. (2019). IPBES (2019): Summary for policymakers of the global assessment report on biodiversity and ecosystem services of the Intergovernmental Science-Policy Platform on Biodiversity and Ecosystem Services. IPBES secretariat, Bonn, Germany.

Doligez, B. and Pärt, T. (2008). Estimating fitness consequences of dispersal: a road to 'know-where'? Non-random dispersal and the underestimation of dispersers' fitness. Journal of Animal Ecology, 77(6):1199-1211.

Epperson, B. K., McRae, B. H., Scribner, K., Cushman, S. A., Rosenberg, M. S., and et al. (2010). Utility of computer simulations in landscape genetics. Molecular Ecology, 19(17):3549-3564.

Fahrig, L. and Merriam, G. (1985). Habitat patch connectivity and population survival. Ecology, 66(6):1762-1768.

Frankham, R. (2005). Genetics and extinction. Biological Conservation, 126(2):131-140.

Gandon, S. (1999). Kin competition, the cost of inbreeding and the evolution of dispersal. Journal of Theoretical Biology, 200(4):345-364.

Geffen, E., Anderson, M. J., and Wayne, R. K. (2004). Climate and habitat barriers to dispersal in the highly mobile grey wolf. Molecular Ecology, 13(8):2481-2490.

Graves, T., Chandler, R. B., Royle, J. A., Beier, P., and Kendall, K. C. (2014). Estimating landscape resistance to dispersal. Landscape Ecology, 29(7):1201-1211.

Green, J. P. and Hatchwell, B. J. (2018). Inclusive fitness consequences of dispersal decisions in a cooperatively breeding bird, the long-tailed tit (Aegithalos caudatus). Proceedings of the National Academy of Sciences of the United States of America, 115(47):12011-12016.

Greenwood, P. (1980). Mating systems, philopatry and dispersal in birds and mammals. Animal Behaviour, 28:1140-1162.

Grimm, V., Ayllón, D., and Railsback, S. F. (2017). Next-Generation Individual-Based Models Integrate Biodiversity and Ecosystems: Yes We Can, and Yes We Must. Ecosystems, 20(2):229-236. 
Grimm, V. and Railsback, S. F. (2005). Individual-based Modeling and Ecology. Princeton University Press.

Haddad, N. M., Brudvig, L. A., Clobert, J., Davies, K. F., Gonzalez, A., and et al. (2015). Habitat fragmentation and its lasting impact on Earth's ecosystems. Science Advances, 1(2):e1500052.

Hamilton, W. and May, R. (1977). Dispersal in stable habitats. Nature, 269:578-581.

Hanski, I. (1998). Metapopulation dynamics. Nature, 396:41-49.

Hanski, I. A. and Gilpin, M. E. (1997). Metapopulation Biology: Ecology, Genetics, and Evolution. Academic Press, San Diego, California.

Hoek, Y. V. D., Zuckerberg, B., Manne, L. L., van der Hoek, Y., Zuckerberg, B., and Manne, L. L. (2015). Application of habitat thresholds in conservation: Considerations, limitations, and future directions. Global Ecology and Conservation, 3:736-743.

Holt, R. and Barfield, M. (2001). On the relationship between the ideal free distribution and the evolution of dispersal. In Clobert, J., Danchin, E., Dhondt, A. A., and Nichols, J. D., editors, Dispersal., pages 83-95. Oxford University Press, New York.

Johnson, C. J. (2013). Identifying ecological thresholds for regulating human activity: Effective conservation or wishful thinking? Biological Conservation, 168:57-65.

Keyghobadi, N. (2007). The genetic implications of habitat fragmentation for animals. Canadian Journal of Zoology, 85(10):1049-1064.

Lande, R. and Shannon, S. (1996). The role of genetic variation in adaptation and population persistence in a changing environment. Evolution, 50(1):434-437.

Landguth, E., Cushman, S. A., and Balkenhol, N. (2016). Simulation modeling in landscape genetics. In Balkenhol, N., Cushman, S. A., Storfer, A., and Waits, L. P., editors, Landscape genetics: concepts, methods, applications, chapter 6, pages 101-113. WileyBlackwell, West Sussex.

Larue, B., Côté, S. D., St-Laurent, M. H., Dussault, C., and Leblond, M. (2018). Natal habitat preference induction in large mammals - Like mother, like child? Ecology and Evolution, 8(24):12629-12640.

Lindenmayer, D. B. and Luck, G. (2005). Synthesis: Thresholds in conservation and management. Biological Conservation, 124(3):351-354.

Lowe, W. H. and Allendorf, F. W. (2010). What can genetics tell us about population connectivity? Molecular Ecology, 19(15):3038-3051.

Mabry, K. and Stamps, J. (2008). Dispersing brush mice prefer habitat like home. Proceedings of the Royal Society B: Biological Sciences, 275:543-548.

Matthysen, E. (2005). Density-dependent dispersal in birds and mammals. Ecography, $3: 403-416$. 
Matthysen, E. (2012). Multicausality of dispersal: a review. In Clobert, J., Baguette, M., Benton, T., and Bullock, J., editors, Dispersal Ecology and Evolution, pages 3-18. Oxford University Press, Oxford.

McAlpine, C., Rhodes, J., Peterson, A., Possingham, H., Callaghan, J., Curran, T., Mitchell, D., and Lunney, D. (2007). Planning guidelines for Koala conservation an recovery: $A$ guide to best planning practice. Brisbane.

McLane, A. J., Semeniuk, C., McDermid, G. J., and Marceau, D. J. (2011). The role of agentbased models in wildlife ecology and management. Ecological Modelling, 222(8):15441556.

McRae, B. (2006). Isolation by resistance. Evolution, 60(8):1551-1561.

Nathan, R., Getz, W., Revilla, E., Holyoak, M., Kadmon, R., Saltz, D., and Smouse, P. (2008). A movement ecology paradigm for unifying organismal movement research. Proceedings of the National Academy of Sciences of the United States of America, 105(49):19052-19059.

Pardini, R., Nichols, E., and Püttker, T. (2017). Biodiversity response to habitat loss and fragmentation. Reference Module in Earth Systems and Environmental Sciences, pages $1-11$.

Pinto, N. and Keitt, T. H. (2009). Beyond the least-cost path: Evaluating corridor redundancy using a graph-theoretic approach. Landscape Ecology, 24(2):253-266.

Pusey, A. E. (1987). Sex-biased dispersal and inbreeding avoidance in birds and mammals. Trends in Ecology and Evolution, 2(10):295-299.

Reding, D. M., Cushman, S. A., Gosselink, T. E., and Clark, W. R. (2013). Linking movement behavior and fine-scale genetic structure to model landscape connectivity for bobcats (Lynx rufus). Landscape Ecology, 28(3):471-486.

Rompré, G., Boucher, Y., Bélanger, L., Côté, S., and Robinson, W. D. (2010). Conserving biodiversity in managed forest landscapes: The use of critical thresholds for habitat. Forestry Chronicle, 86(5):589-596.

Ronce, O. (2007). How Does It Feel to Be Like a Rolling Stone? Ten Questions About Dispersal Evolution. Annual Review of Ecology, Evolution, and Systematics, 38(1):231253 .

Roy, J., Yannic, G., Côté, S. D., and Bernatchez, L. (2012). Negative density-dependent dispersal in the American black bear (Ursus americanus) revealed by noninvasive sampling and genotyping. Ecology and Evolution, 2(3):525-537.

Sawyer, S. C., Epps, C. W., and Brashares, J. S. (2011). Placing linkages among fragmented habitats: do least-cost models reflect how animals use landscapes? Journal of Applied Ecology, 48(3):668-678.

Scheffer, M., Bascompte, J., Brock, W. A., Brovkin, V., Carpenter, S. R., and et al. (2009). Early-warning signals for critical transitions. Nature, 461(7260):53-59.

Shaffer, M. L. (1981). Minimum population sizes for species conservation. BioScience, $31(2): 131-134$. 
Slatkin, M. (1987). Gene flow and the geographic structure of natural populations. Science, 236:787-792.

Spielman, D., Brook, B. W., and Frankham, R. (2004). Most species are not driven to extinction before genetic factors impact them. Proceedings of the National Academy of Sciences of the United States of America, 101(42):15261-15264.

Stamps, J. (2001). Habitat selection by dispersers: integrating proximate and ultimate approaches. In Clobert, J., Danchin, E., Dhondt, A. A., and Nichols, J. D., editors, Dispersal, pages 230-242. Oxford University Press, New York.

Storfer, A., Murphy, M., Evans, J., Goldberg, C., Robinson, S., Spear, S., Dezzani, R., Delmelle, E., Vierling, L., and Waits, L. (2007). Putting the "landscape" in landscape genetics. Heredity, 98(3):128-142.

Storfer, A., Murphy, M. a., Spear, S. F., Holderegger, R., and Waits, L. P. (2010). Landscape genetics: where are we now? Molecular Ecology, 19(17):3496-3514.

Templeton, A. R., Shaw, K., Routman, E., and Davis, S. K. (1990). The Genetic Consequences of Habitat Fragmentation. Annals of the Missouri Botanical Garden, 77(1):13-27.

Thompson, P. L. and Gonzalez, A. (2017). Dispersal governs the reorganization of ecological networks under environmental change. Nature Ecology and Evolution, 1(0162).

Tischendorf, L. and Fahrig, L. (2000). On the usage and measurement of landscape connectivity. Oikos, 90:7-19.

Travis, J. M., Delgado, M., Bocedi, G., Baguette, M., Bartoń, K., Bonte, D., and et al. (2013). Dispersal and species' responses to climate change. Oikos, 122(11):1532-1540.

Tucker, M. A., Böhning-Gaese, K., Fagan, W. F., Fryxell, J. M., Van Moorter, B., and et al. (2018). Moving in the Anthropocene: Global reductions in terrestrial mammalian movements. Science, 359(6374):466-469.

Wall, J., Wittemyer, G., Klinkenberg, B., and Douglas-Hamilton, I. (2014). Novel opportunities for wildlife conservation and research with real-time monitoring. Ecological Applications, 24(4):593-601.

Watson, J. E., Shanahan, D. F., Di Marco, M., Allan, J., Laurance, W. F., Sanderson, E. W., Mackey, B., and Venter, O. (2016). Catastrophic Declines in Wilderness Areas Undermine Global Environment Targets. Current Biology, 26(21):2929-2934.

Wittemyer, G., Northrup, J. M., and Bastille-Rousseau, G. (2019). Behavioural valuation of landscapes using movement data. Philosophical Transactions of the Royal Society B: Biological Sciences, 374(1781):20180046.

Wright, S. (1943). Isolation by distance. Genetics, 28:114-138.

Young, A., Boyle, T., and Brown, T. (1996). The population genetic consequences of habitat fragmentation for plants. Trends in Ecology and Evolution, 11(10):413 - 418.

Zeller, K. A., McGarigal, K., and Whiteley, A. R. (2012). Estimating landscape resistance to movement: a review. Landscape Ecology, 27(6):777-797. 
CHAPTER 2

\title{
The influence of habitat suitability, habitat similarity and landscape resistance on brown bear (Ursus arctos) dispersal in the Central-European Alps
}

\begin{abstract}
Understanding environmental effects on dispersal is important to predict species distributions and population persistence under changing habitat conditions, especially for animals living in human-modified landscapes. Environmental effects can act on any of the three stages of dispersal, i.e., on emigration, movement and settlement. However, most studies only consider environmental effects on one of these stages when investigating the factors that shape observed dispersal patterns. Using a 17-year data set of GPS-movement and occurrence data, we tested different environmental influences on movement and settlement decisions of dispersers in a reintroduced brown bear (Ursus arctos) population in the Central-European Alps. Specifically, we tested for the effects of habitat suitability, habitat similarity and habitat reachability on the establishment of post-dispersal bear home ranges. We found that brown bear settlement was well explained by habitat suitability and similarity, indicating that these two factors are important determinants for the expansion of the reintroduced population. The preference for habitat similarity also gives support for natal habitat preference induction in brown bears. In contrast, the reachability of habitat did not influence brown bear dispersal patterns, and bears were not strongly affected by environmental factors during the move-
\end{abstract}


ment stage. Overall, our study shows that considering individual behavioral responses to local and landscape-wide factors during different stages of dispersal is essential for interpreting landscape effects on observed dispersal patterns. The identification of the correct drivers of dispersal will be important to enable range expansions and persistence of the reintroduced brown bear population.

Keywords: dispersal behavior, resource selection function, step selection function, natal habitat preference induction, species reintroduction, brown bears

\section{Introduction}

Dispersal is a key process in ecology and evolution, as it influences individual fitness (Doligez and Pärt, 2008, Green and Hatchwell, 2018), dynamics and genetics of single populations (Slatkin, 1987; Templeton et al., 1990) as well as metapopulations (Hanski and Gilpin, 1997; Brown and Kodric-Brown, 1977), and distributional ranges of species (Kirkpatrick, Mark \& Barton, 1997, Shigesada and Kawasaki, 2002). Due to its importance in eco-evolutionary processes, a detailed understanding of the factors driving dispersal is important to explain and predict the viability and distribution of species facing environmental changes, especially in species threatened by habitat loss and habitat fragmentation.

Dispersal is a life history trait that is shaped by fitness costs and benefits resulting from spatiotemporally varying environments, intraspecific competition and inbreeding avoidance (Hamilton and May, 1977; Gandon, 1999 Bonte et al., 2012). Thus, the dispersal patterns we observe, such as the distribution of species or genetic variation, often result from complex processes involving several behavioral mechanisms (Matthysen, 2012) at three different and consecutive dispersal stages, i.e., emigration, transience and immigration (Baguette et al., 2007; Ronce, 2007; Clobert et al., 2009). In the first stage of emigration (or 'departure'), individuals leave their current location to avoid local fitness costs or to obtain fitness benefits elsewhere, for example by seeking areas with reduced competition for resources or between kin. During transience (or 'movement'), an animal has to decide where to move (e.g. direction and distances) and how to move there (e.g., navigation and movement path selection; Nathan et al. 2008). In this second stage, movements are influenced by perceived predation risks, energetic expenses or physical limitations experienced during dispersal (Bonte et al., 2012, Benoit et al., 2019). Finally, in 
the immigration (or 'settlement') stage, an individual either stays at the new location or moves on, depending on the fitness prospects under the current local conditions.

Environmental characteristics play an important role in determining and shaping dispersal (Baguette et al., 2013, Cote et al., 2017). For example, local habitat suitability can influence emigration and settlement (Bowler and Benton, 2005; Clobert et al., 2009), because dispersing animals are generally more likely to leave less suitable habitats with limited resources, high intra-specific competition or inbreeding risk (Bonte et al., 2008; Mathieu et al., 2010). Dispersing individuals should prefer to settle in habitat of high suitability, which provides sufficient resources for survival and reproduction (Fretwell and Lucas, 1969, VanDerWal et al., 2009). Dispersers can also be influenced by past experiences. Familiar environmental cues that the individual experienced prior to emigration in its natal range, can lead to preferences for similar attributes at the settlement stage (e.g., Mabry and Stamps, 2008; Merrick and Koprowski, 2016); a behavioral mechanism that is called 'habitat imprinting' or 'natal habitat preference induction' (NHPI, Davis and Stamps, 2004). Selecting similar habitat during dispersal could be beneficial as it can reduce search time for finding new, suitable habitat (Stamps et al. 2009) or enhance survival probability due to improved resource acquisition (Hoppitt et al., 2008, Stamps and Davis, 2006). Finally, landscape conditions encountered during dispersal movements can also influence dispersal (Wiens, 2001). Specifically, dispersal movements are influenced by landscape resistance, which represents the willingness of an organism to move through certain habitat, the physiological cost and/or the reduction in survival of traversing the habitat (Zeller et al., 2012). For example, landscape characteristics that increase mortality risk, such as anthropogenic infrastructures (e.g. settlements, roads), can lead to avoidance or movement restrictions (Bischof et al., 2017; Tucker et al., 2018), and thus, prevent reachability of certain areas for dispersing individuals.

Thus, the local environment, such as habitat suitability, habitat similarity, and the environmental conditions between sites that determine habitat reachability, affect individual dispersal behavior in different ways and differ in their relative importance for the three stages of dispersal (Matthysen, 2012). Even though these impacts jointly shape the dispersal pattern we observe in nature, studies that consider more than one type of environmental influence on dispersal or incorporate more than one dispersal stage are rare (e.g., Squires et al. 2013). Many studies focus either on local conditions such as habitat 
suitability or habitat similarity and relate them to settlement (e.g., VanDerWal et al., 2009, Selonen and Hanski, 2012, Merrick and Koprowski, 2016), or they focus on whether landscape resistance is constraining dispersal and gene flow among populations (e.g., Cushman and Lewis, 2010, Reding et al., 2013; Graves et al., 2014). However, the incorporation of different environmental factors that are important for individual dispersal could improve the interpretation of dispersal pattern we observe.

Here, we tested environmental influences on both, dispersal movements and settlement decisions using brown bears (Ursus acrtos) in the Central Alps as a case study. The brown bear population in the Alps experienced a drastic decline due to human persecution and habitat alteration within the last two centuries Mustoni et al., 2003). In order to save the relict and isolated population from extinction, bears from the Slovenian segment of the Dinaric population were translocated in Trentino, Italy, between 1999 and 2002 (Fig. 2.1), were few autochthonous bears of the Alpine population still survived (Mustoni et al. 2003). The current population in the Central Alps is entirely derived from the released animals and has grown and expanded into parts of the former range since the translocation, but the population is still demographically isolated (De Barba et al., 2010; Groff et al., 2018). Although male-biased dispersal from Trentino to the Dinaric population and vice versa has recently resulted in a partial overlap, it did not result in gene flow between the two bear populations (De Barba et al., 2013).

The Alpine ecosystem has long been shaped by anthropogenic activities and is a mosaic of natural and human dominated environments. Human presence and activities have major effects on bear ecology, behavior and survival (Zedrosser et al., 2011; Penteriani et al., 2018) and constitute a significant cause of mortality in the study population (Tenan et al. 2016). This might pose a main challenge to dispersal and establishment of connectivity (Tuomainen and Candolin, 2011; Proctor et al. 2012) with the Dinaric population, which is considered crucial for long term-viability of the bear population in the Alps (De Barba et al., 2010; Boitani et al., 2015). Thus, understanding how the environment is shaping individual dispersal is particularly important for this reintroduced population, in order to inform management actions for its conservation.

Using a 17-year data set, we tested for the impact of habitat suitability, habitat similarity and habitat reachability on observed dispersal patterns in this bear population. We predicted that brown bear settlement is influenced 
by habitat suitability, so that home ranges established after dispersal have higher suitability than expected under random settlement. Second, we predicted that natal habitat preference induction influences settlement decisions of dispersing bears, so that bears select home ranges that are environmentally more similar to their mother's range. Third, we predicted that the resistance of the landscape influences dispersal movements of bears, so that areas have varying probabilities of being reached by dispersing bears, which influences the location of post-dispersal home ranges. Considering multiple types of environmental influences on observed dispersal patterns in brown bears should improve our understanding of species-specific dispersal patterns in a humanmodified landscape.

\section{Methods}

\section{Study area}

Between 1999 and 2002 ten brown bears were translocated from Slovenia and released in the eastern part of Trentino, Italy, (Mustoni et al., 2003). At the end of 2017, the population was estimated to 52-63 individuals Groff et al. 2018). Today, the majority of the population still resides in the territory of Trentino, but a number of individuals moved to adjacent provinces or crossed the national borders of other countries (Tosi et al., 2015, Groff et al., 2018, LCIE, 2018). Based on this current distribution, our study area encompassed $158,690.7 \mathrm{~km}^{2}$ in the Alps covering the central-eastern Alpine region of Italy, the eastern part of Switzerland, and the entire German and most of the Austrian alpine regions (Fig. 2.1). Elevation in the this area ranges from $0 \mathrm{~m}$ to 3,914 $\mathrm{m}$ above sea level (a.s.l.) (Mustoni et al., 2003). Forests cover $44 \%$ of the study area (Table A2.1). Urban areas and human activities including agriculture, livestock grazing, tourism, and transportation infrastructures are diffuse and fragment the natural landscape (Table A2.1). Detailed information on the reintroduction area in Trentino, such as human population or infrastructure densities and vegetation and faunal composition can be found in Preatoni et al. (2005), Peters et al. (2015) and Tosi et al. (2015).

\section{Brown bear data}

We used location data of 48 brown bear individuals (24 females, 24 males) collected between 2001 and 2017 in Trentino, Italy and adjacent regions in the Alps. This data set consisted of three not mutually exclusive subsets, 


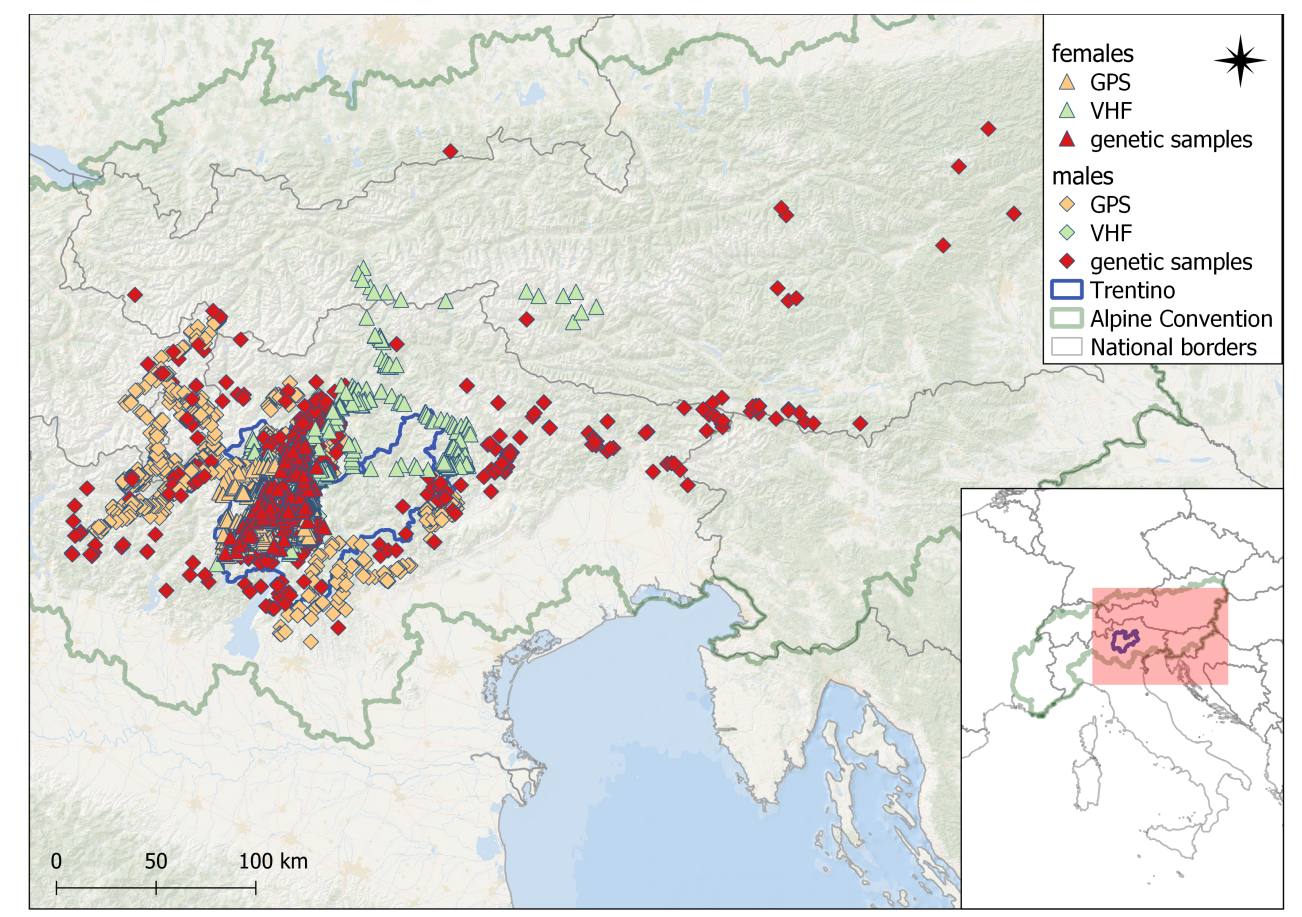

Figure 2.1: Relocation data (GPS and VHF data, and genetic monitoring samples) of female and male brown bears (Ursus arctos) collected in Trentino, and adjacent regions in the Central-European Alps between 2001 and 2017.

i.e. Global Positioning System (GPS) data of 15 animals (10 females, 5 males) from 2006-2017, Very High Frequency (VHF) data of 8 individuals (6 females, 2 males) from 2001-2008, and data from genetic monitoring of 46 individuals (22 females, 24 males) collected between 2002-2016. 19 individuals were present in two data subsets, and two individuals were present in all three subsets. Brown bear reintroduction and capturing, and data collection methods were previously described in detail (Mustoni et al., 2003, Preatoni et al., 2005; De Barba et al., 2010; Groff et al., 2018). VHF and GPS data were obtained from bears captured and collared with permission of the Italian Ministry of the Environment.

For GPS data, individuals were fitted with Vectronic GPS-GMS collars (Vectronic Aerospace GmbH, Berlin, Germany). The median fix rate of GPS data was approximately one hour. Similar to Peters and colleagues (2015), GPS collars were resampled to a two-hour sampling interval. Individuals tagged with Very High Frequency (VHF; MOD 505 radio collar, Telonics Inc., Mesa, Arizona 85204, USA) radio collars were triangulated twice a day (Preatoni et al., 2005). For telemetry data (GPS, VHF) we excluded the hibernation period (December to March) and also the first year of available VHF data. This is because VHF collars were employed on the founding individuals 
(i.e., first reintroduced individuals) and movements in the first year after this initial release unlikely reflect typical habitat use of brown bears in the region. Genetic monitoring data collection was based on systematic and opportunistic sampling of organic material (hairs, scats, saliva and tissues) in the field (Groff et al., 2018). DNA obtained from the samples was analyzed to derive individual bear profiles, their sex, and the pedigree of the population (De Barba et al. 2010; Groff et al., 2018), so that we could reliably identify mother-offspring pairs and their locations in the landscape.

Using these pairs, we defined dispersal as the relocation of an individual from its natal habitat (i.e., the home range of the mother while rearing the offspring) to a different, potentially unfamiliar area where a new home range is established (Howard, 1960, Greenwood, 1980). Since the average age of young brown bears that leave the natal site is 2 years (Dahle and Swenson, 2003a; Støen, 2005, Støen et al., 2006), we assumed individuals older than 2 years as capable to establish their own home range. Dispersal distance was measured as the straight-line distance between the center of the mother range and the center of the home range area established by the offspring after 2 years of age. We termed these newly established ranges 'settlement areas' and calculated them as the $50 \%$ Minimum Convex Polygon (50\% MCP), which is often referred to as the core area, i.e. an area of intense use (Burt, 1943, Kaufmann, 1962; Pusey, 1987). We used core areas instead of home ranges (i.e., $95 \% \mathrm{MCP}$ ), since core areas probably contain important resources for survival of the individual or its offspring, and thus, could be of high relevance for the individual's decision where to place the settlement area in the landscape.

\section{Environmental data}

Our analyses included environmental covariates based on previous studies on brown bear habitat selection in Trentino (Peters et al. 2015). We used a combination of digital data layers to characterize brown bear habitat. We reclassified CORINE Land Cover 2012 classifications at $100 \mathrm{~m}$ resolution into 11 classes (see Table A2.1). Land cover maps were complemented with a distance to main roads layer (motorways, trunks, primary and secondary roads; OpenStreetMap), and a raster for elevation, aspect and slope that we obtained from a digital elevation model (DEM; U.S. Geological Survey) at $10 \mathrm{~m}$ resolution. We rasterized or aggregated all other maps to the same resolution of the land cover raster (100 x $100 \mathrm{~m})$. 


\section{Study design and statistical analysis}

We applied a used-available design that compares the usage of resources to their availability and tests whether certain resources are used at significantly different proportions than expected under non-selective use (Manly et al., 2002). We used this framework to compare actual home ranges established by bears after dispersal ('used') to alternative ranges in our study area ('available'). A detailed description and illustration of this framework is presented in Figure 2.2. We then determined whether actual settlement areas were significantly more suitable, more similar, and more reachable than the alternative settlement areas that the bears could have chosen. Specifically, to establish alternative settlement areas, we shifted and rotated actual settlement ranges 25 times randomly around the center of the natal site (i.e., the home range of the mother) with distances drawn from the empirical distribution of sex-specific dispersal distances and angles drawn from an uniform distribution between $-\pi$ and $\pi$. We treated females and males separately throughout the analysis due to different life history traits influencing spatial behavior (Rode et al. 2006; Zedrosser et al., 2007). For each sex and site (ie., actual or random settlement area), we calculated $95 \%$ bootstrap confidence intervals (CI) of the mean difference for each environmental factor. We used Wilcoxon tests to assess whether habitat suitability, similarity and reachability were significantly larger for actual settlement areas compared to alternative settlement areas. If so, our predictions about environmental impacts on brown bear dispersal patterns would be supported.

For all three analytical steps (similarity, suitability, reachability) we included a quadratic term for elevation and distance to roads to allow for nonlinear relationships and centered these variables by subtracting the mean. Aspect (in radians) was decomposed in northness and eastness by applying the cosine and sine function, respectively.

We tested for collinearity between environmental variables using the Pearson's correlation coefficient threshold of $|\mathrm{r}|>0.7$ (Dormann et al., 2013) and retained variables below this threshold in the analysis. All data processing and statistical analysis was performed using $R$ software ( $R$ Development Core

Team, 2019) and environmental layers were processed in QGIS (3.4, QGIS Development Team, 2009). 


\begin{tabular}{|c|c|}
\hline Question & Methods / Analysis \\
\hline \multirow{3}{*}{$\begin{array}{l}\text { 1. Do bears choose } \\
\text { settlement areas based on } \\
\text { habitat suitability? }\end{array}$} & $\begin{array}{l}\text { Resource selection function (individuals within home ranges); } \\
\text { compare used (black filling) vs. available (no filling) resources (left) }\end{array}$ \\
\hline & $\begin{array}{l}\text { Suitability map (predicted probability of bear presence) for each } \\
\text { individual (right) }\end{array}$ \\
\hline & $\begin{array}{l}\text { Comparison of suitability of real (Ind. A) and random (R) } \\
\text { settlement areas (right) }\end{array}$ \\
\hline \multirow{2}{*}{$\begin{array}{l}\text { 2. Do bears choose } \\
\text { settlement areas based on } \\
\text { habitat similarity? }\end{array}$} & $\begin{array}{l}\text { Extract covariates (see Table A2.1) from natal (M), settlement (Ind. } \\
\text { A) and random (R) areas }\end{array}$ \\
\hline & $\begin{array}{l}\text { Compare covariates of mother-offspring and mother-random } \\
\text { pairings (i.e., calculate environmental distance, ED) }\end{array}$ \\
\hline
\end{tabular}

$\begin{array}{ll}\begin{array}{l}\text { 3. Do bears choose } \\ \text { settlement areas based on } \\ \text { habitat reachability? }\end{array} & \begin{array}{l}\text { Define and use long-distance movements (top 5\% of individual } \\ \text { step lengths) }\end{array} \\ & \begin{array}{l}\text { Step selection function; used steps (bold line) vs. random (light } \\ \text { line) (left) } \rightarrow \text { predicted probability of bear movement } \\ \text { Translate probability into resistance map (right) }\end{array} \\ & \begin{array}{l}\text { Least cost path (LCP) comparison between natal-settlement and } \\ \text { natal-random settlement areas (right) }\end{array}\end{array}$

\section{Study design}
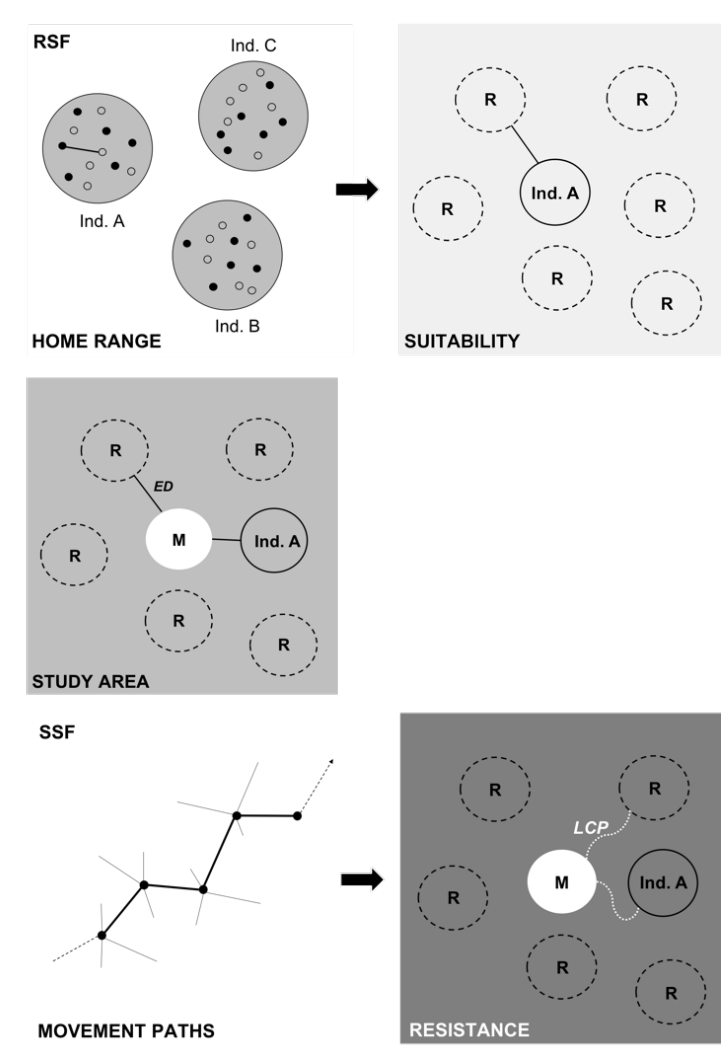

Figure 2.2: Study design and methods of the three analytical steps used to examine the influence of habitat suitability, habitat similarity and habitat reachability on brown bear distribution in the Central Alps (question 1-3). We applied an used-available design and tested whether certain resources are used at significantly different proportions than expected under non-selective (i.e., random) use. Environmental variables were compared between settlement areas of individual offspring (e.g., Ind. A), the natal range of the mother (M) and alternative (random) areas $(\mathrm{R})$. Random areas were created by shifting and rotating the settlement area of each offspring 25 times randomly around the center of the settlement site (question 1) or natal site (question 2) with distances drawn from the empirical distribution of sex-specific dispersal distances and angles drawn from an uniform distribution between $-\pi$ and $\pi$. For each used step (question 3) 10 random steps were generated. The line within each schematic figure indicate which level (i.e., individual locations or core areas) was compared. 


\section{Habitat suitability model}

To determine habitat suitability for brown bears, we applied resource selection functions (RSF; Boyce et al., 2002), i.e., logistic regressions, to female and male brown bear locations. We sampled availability within 95\% Minimum Convex Polygons and generated a set of random locations equal in number to the sample of used locations for each individual. We used a generalized linear mixed model (GLMM, Bolker et al., 2009) with a binomial response and a logistic link function, and used elevation, slope, aspect, landcover type, and distance to roads as covariates. For landcover, coniferous forest was used as reference category. As brown bear individuals show individual-specific variation in space use and movement (Leclerc et al., 2016, Hertel et al., 2019), we included random effects on the slopes of continuous variables (Muff et al., 2020). Since the biological relevance of selected landscape variables for the reintroduced brown bear population in Trentino was already tested before (Peters et al., 2015) and the number of covariates generally increases model performance (Zeller et al. 2017), we used a full model, which we tested against a null model (i.e., intercept - only model). We compared the full and null models based on their Akaike's information criterion ( $\triangle \mathrm{AIC}$, Burnham and Anderson, 2002).

We created individual suitability surfaces and parameterized the predicted probability of bear presence to the study area. For each individual $i$ we calculated the suitability $\left(S_{i}\right)$ of each cell $(j)$ as

$$
S_{i j}=\sum \beta_{i k} z_{j k}
$$

where $\beta_{i k}$ are the selection coefficients for the $i$-th individual, and $z_{j k}$ is the $k$ th environmental covariate. We used a linear stretch to rescale RSF predicted values between 0 and 1 (Johnson et al., 2004). Although the intercept affects the fixed effects, it is considered meaningless in a used-available design and is commonly dropped from the analysis (Muff et al., 2020).

For each settlement area, we extracted suitability values from each cell of the suitability surface and compared the mean suitability of the real settlement areas to the mean suitability of random ranges (Fig. 2.2, Fig. $2.3 \mathrm{~A})$.

\section{Measuring habitat similarity}

To test whether settlement decisions of brown bear offspring were dependent on habitat characteristics experienced in the natal range, we compared settle- 
ment areas of offspring and available (i.e., alternative) settlement areas to the range of the mother. For each range, we extracted the environmental variables from all cells, calculated the proportion of each land cover class and the mean of the continuous variables. We then estimated the multivariate Euclidean distance between environmental variables of the mother and offspring ranges, and between mother and random ranges (Fig. 2.2, Fig. 2.3B). The Euclidean distance is a proxy of environmental dissimilarity where a value of 0 indicates low dissimilarity (i.e., high similarity) and a value of 1 indicates high dissimilarity (i.e., low similarity) (see also Piper et al., 2013; Merrick and Koprowski, 2016).

As for habitat suitability, we compared the mean intra-individual environmental distance of mother-offspring pairings with mean expected environmental distances of mother-random pairings. We also repeated the above comparisons for each variable separately (i.e., by calculating univariate Euclidean distances) in order to assess which environmental variables were more similar between natal and settlement sites, and therefore, contribute most to NHPI. Since there might be some overlap between settlement sites and natal sites of philopatric females, we tested whether similarity between natal and settlement sites was simply due to spatial autocorrelation of the environment (e.g., overlapping mother-offspring ranges are more similar environmentally only because they are closer in space and hence, the environment). For this, we correlated environmental distances among range pairs against the spatial distances among these pairs. A significantly positive relationship between these two distances would indicate that ranges that are spatially close are also close in terms of environmental space, which would make a clear identification of NHPI difficult.

\section{Measuring habitat reachability}

Identifying actual dispersal paths can be challenging, because of limited data availability and the difficulty to clearly separate dispersal from other (e.g., long and directed) movements. Relocations observed during long movements can contain actual dispersal movements, but also other movements within and outside of the home range, such as exploratory or inter-patch movements. Although these movements are not dispersal per se, they can provide useful information on how movement during dispersal can be influenced by the environment (Vasudev et al., 2015). We used a data-driven approach and assigned GPS relocations of individuals to "dispersal-like" movements by using a step- 
length threshold. We estimated step lengths between consecutive steps and used the top five percent of individual step lengths as a cut-off value for long movements. For each step (i.e., 'used' resource), we generated 10 random steps (i.e., 'available' resource). For the random steps we sampled step lengths from a Gamma distribution and turning angles from a von Mises distribution fitted to the empirical distribution of step length and turning angles, respectively, using the amt package for $\mathrm{R}$ (Signer et al., 2019). We grouped the data by sex and conducted step selection functions (SSF; e.g., Thurfjell et al., 2014), i.e., conditional logistic regression, for females and males, respectively. We used the same covariates as for the RSF, but we did not include individuals as a random factor due to small number of movement steps. We also used coniferous forest as reference category, which was omitted from the analysis, because in conditional logistic regression, there is no model intercept (Zeller et al., 2014).

We created probability surfaces by parameterizing the predicted probability of bear movement across a cell for the entire study area (Eq. 1). We scaled estimates of movement probability to a range of 0 and 1, where 0 reflects low probability and 1 high probability of the cell being used during movements. Probability maps for females and males, respectively, were then transformed into resistance layers by using different transformation functions (Eq. 2). Suitability was translated into resistance as

$$
R=100-99 \frac{1-\exp (-c h)}{1-\exp (-c)}
$$

where $R$ is the resistance, $h$ the probability surface and $c$ the rescaling parameter determining the gradual change in resistance (or friction) values when the probability of using a cell for movement declines (Trainor et al., 2013). Values near 1 indicate low resistance and values near 100 high resistance to movement. We used linear $(c=0.25)$ and negative exponential $(c=8,16,32)$ transformations, where the latter allows more flexible selection of intermediate suitable habitat during movements, which was observed in recent studies (e.g., Mateo-Sánchez et al., 2015; Gastón et al., 2016; Keeley et al., 2016). We used GRASS (GRASS Development Team, 2017) in R with the package rgrass 7 (Bivand, 2018) to generate least-cost paths (LCP) between the centroid of natal and settlement areas and compared them to alternative least-cost paths between the natal and alternative settlement areas (Fig.2.2, Fig. 2.2C). These least-cost paths represent the movements of individuals that follow a route with low cumulative costs between natal and new ranges Adriaensen 
et al. 2003). The cumulative costs of the predicted least-cost paths were corrected for path length, because longer paths often accumulate greater costs than shorter paths, even if they cross only low resistance habitat (Etherington and Holland, 2013). We also translated the predicted habitat suitability using all relocations (RSF, see above) into resistances and estimated LCP in order to compare the cumulative costs with those estimated on the resistance layers based on movement behavior (SSF).

\section{Results}

Overall we had 29,304 relocations of 48 brown bear individuals (GPS locations: 19,174 ( $\mathrm{n}=15$ individuals), VHF: 6,303 $(\mathrm{n}=8)$, genetic samples: 3,827 (n $=46)$ ) of which were 17,637 female relocations (GPS: 11,099 $(\mathrm{n}=10)$, VHF: $5,142(\mathrm{n}=6)$, genetic samples: $1,126(\mathrm{n}=22))$ and 11,937 male relocations (GPS: 8,075 $(\mathrm{n}=5)$, VHF: 1,161 $(\mathrm{n}=2)$, genetic samples: 2,701 $(\mathrm{n}=24)$. The mean size ( $\pm \mathrm{SD}$ ) of $50 \%$ MCPs for females was $119.46 \pm 512.3 \mathrm{~km}^{2}$ and for males $408.77 \pm 637.15 \mathrm{~km}^{2}$. Dispersal distances $( \pm \mathrm{SD}$ ) for female offspring were on average $7.49 \pm 4.77 \mathrm{~km}$ and for male offspring $31.03 \pm 27.29 \mathrm{~km}$.

\section{Habitat suitability}

All environmental covariates had a correlation coefficient of smaller 0.7 in absolute terms; the highest correlations coefficient of 0.42 was observed between elevation and distance to roads. Full models fitted the data better than null models (intercept - only model, $\Delta$ AIC females: 6988, $\Delta$ AIC males: 4440 ).

Both male and female bears were highly selective in their habitat use as almost all covariates were significant in the RSF (Table 2.1, left panel). Selectivity of the two sexes was similar with a few exceptions. Female and male brown bear individuals selected habitats at intermediate elevations of 1,235.81 $\mathrm{m}$ (CI 1,228.98, 1,242.28) and 1,310.04 m (CI 1,300.17, 1,319.75), respectively. Mean selected distances to roads was $734.15 \mathrm{~m}$ (CI 723.06, 744.98) for females and $826.29 \mathrm{~m}$ (CI 814.44, 838.68) for males, but there was no significant avoidance of close proximity to main roads. In contrast, for both sexes there was a negative relationship between presence and the quadratic effect of distance to roads, indicating that bears selected for intermediate distances from roads. Females and males were more likely to occur at areas with moderate steepness (mean slope females: 31.15 degrees (CI 30.89, 31.45); mean slope males: 31.27 degrees (CI 30.93, 31.59). Compared to coniferous forest, female and 
male brown bear presence was positively associated with deciduous and mixed forest, and negatively associated with urban areas, orchards, rock and water bodies. Female presence also was negatively related to cultivated land and pastures (Table 2.1).

\section{Suitability of actual vs. random settlement areas}

For each individual, we created a suitability map and compared mean suitability values between the settlement areas and alternative areas available in the study area. We found that the suitability of actual settlement ranges was higher than in alternative settlement areas for both, females (mean suitability: 0.520; mean expected suitability: $0.450 \mathrm{p}<0.01$; paired Wilcoxon test) and males (mean suitability: 0.463; mean expected suitability: 0.391; p < 0.001; Fig. 2.3A). Settlement areas of females were slightly but not significantly more suitable than those of males ( $\mathrm{p}=0.3$; unpaired Wilcoxon test).

\section{Habitat similarity}

We compared environmental distances between mother-offspring pairings to mother-random pairings in order to test whether brown bear offspring settled in more familiar habitat. Across both sexes, the environmental distances between the natal and the settlement sites were smaller among actual range pairs (mother vs. offspring range) than among alternative pairings (mother vs. alternative range) $(\mathrm{n}=37$, mean Euclidean distance $(\mathrm{ED})=0.074$, mean expected $\mathrm{ED}=0.142, \mathrm{p}<0.001)$, i.e., natal and actual settlement areas were more similar to each other than natal and alternative settlement areas. The environmental distance was also smaller than expected for female and male offspring separately including all environmental variables (Fig. 2.3B; Table 2.2). These patterns were not influenced by spatial autocorrelation, because environmental distances were uncorrelated with dispersal distances overall ( $\mathrm{r}$ $=0.13)$, and for both, females $(\mathrm{r}=0.21)$ and males $(\mathrm{r}=0.15)$. Settlement areas of males were slightly but not significantly more similar to natal areas than those of females ( $\mathrm{p}=0.44$; unpaired Wilcoxon test; Fig. 2.3B).

When assessing similarity of each environmental variable separately, female settlement areas were more similar to their natal area than alternative settlement areas for the variables mean slope, distance to roads (quadratic relationship), elevation and overall landcover composition (Table 2.2; Table A2.2). Specifically, mean proportions of urban areas, cultivated land, orchards, and rock were more similar between female natal and settlement areas than 
expected. Male offspring settlement areas were more similar in mean slope and elevation, and in mean proportions of urban areas and cultivated land (Table 2.2; Table A2.2). Individual variation within females and males was small, as indicated by small confidence intervals (Fig. 2.3B).
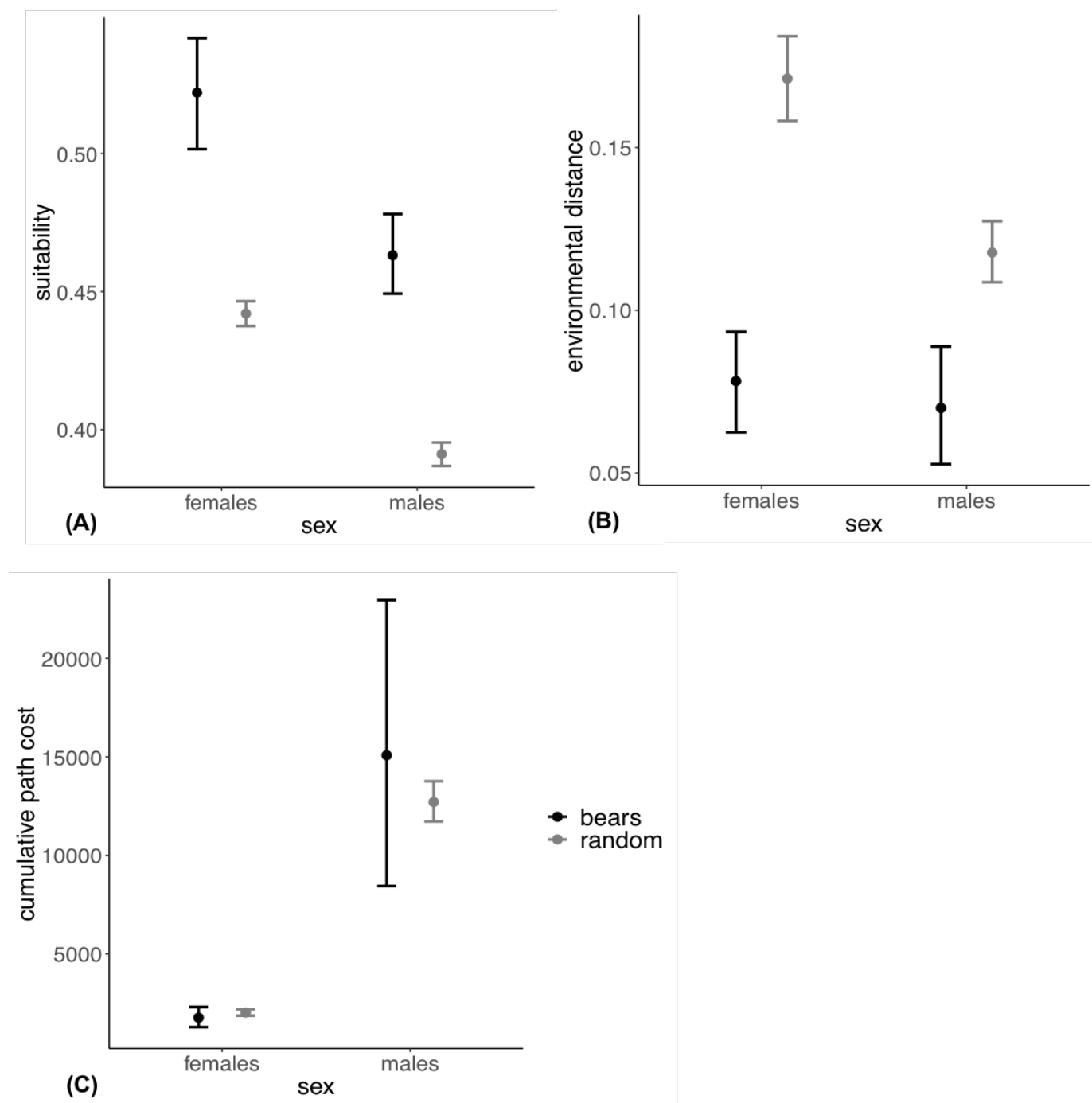

Figure 2.3: Habitat impacts on selection of settlement areas after dispersal in female and male brown bears in Trentino and adjacent Alpine regions according to habitat suitability (A), habitat similarity (B) and landscape reachability (C). Black bars indicate observed patterns, while grey bar indicate patterns expected if the environment does not impact dispersal patterns. Error bars show $95 \%$ confidence intervals. (A) Suitability of female and male settlement sites (MCP50) compared to alternative settlement areas within the region. (B) Environmental distance between natal areas and offspring settlement areas (MCP50) compared to pairings of natal areas and alternative settlement areas within the study area. (C) Cumulative path costs between natal and settlement site compared to path costs between natal and random sites. Habitat selection during movement was estimated using step selection functions (SSF) and the top 5\% of brown bear step length from GPS data. 
Table 2.1: Habitat selection coefficients of the resource selection function (RSF; fixed effects) and step selection function (SSF) for each sex, describing brown bear habitat selection within home ranges and during movement, respectively. SSF was based on the top $5 \%$ of brown bear step length using GPS data, assuming that longer steps reflect "dispersal-like" movements (dispersal movements, exploratory or inter-patch movements). All female and male brown bear locations (i.e., GPS, VHF, data from genetic monitoring) were used for RSF. Due to convergence errors, we were unable to fit the models for two habitat classes (urban areas and water) in each sex for SSF. Significant effects are highlighted in bold.

\begin{tabular}{|c|c|c|c|c|c|c|c|c|c|c|c|c|}
\hline \multirow[b]{3}{*}{ Covariates } & \multicolumn{6}{|c|}{ RSF } & \multicolumn{6}{|c|}{ SSF } \\
\hline & \multicolumn{3}{|c|}{ females } & \multicolumn{3}{|c|}{ males } & \multicolumn{3}{|c|}{ females } & \multicolumn{3}{|c|}{ males } \\
\hline & $\beta$ & $\mathrm{SE}$ & $\mathrm{p}$ & $\beta$ & $\mathrm{SE}$ & $\mathrm{p}$ & $\beta$ & $\mathrm{SE}$ & $\mathrm{p}$ & $\beta$ & $\mathrm{SE}$ & $\mathrm{p}$ \\
\hline Intercept & -0.108 & 0.137 & 0.432 & 0.121 & 0.105 & 0.25 & & & & & & \\
\hline Slope & 0.012 & 0.0043 & $<0.001$ & 0.013 & 0.003 & $<0.001$ & -0.007 & 0.006 & 0.269 & -0.029 & 0.01 & $<0.01$ \\
\hline Roads & -0.075 & 0.126 & 0.553 & 0.27 & 0.144 & 0.06 & 0.066 & 0.178 & 0.71 & 0.289 & 0.21 & 0.169 \\
\hline Roads $^{2}$ a & -0.5 & 0.17 & $<0.01$ & -0.442 & 0.069 & $<0.001$ & 0.078 & 0.061 & 0.203 & 0.007 & 0.06 & 0.902 \\
\hline Elevation & -0.544 & 0.161 & $<0.001$ & -0.642 & 0.146 & $<0.001$ & -0.415 & 0.146 & $<0.01$ & 0.624 & 0.214 & $<0.01$ \\
\hline Elevation $^{2}$ a & -0.607 & 0.079 & $<0.001$ & -0.643 & 0.065 & $<0.001$ & -0.403 & 0.126 & $<0.01$ & -0.244 & 0.165 & 0.138 \\
\hline Northness & -0.134 & 0.105 & 0.202 & -0.192 & 0.093 & $<0.05$ & -0.553 & 0.141 & $<0.001$ & -0.217 & 0.173 & 0.211 \\
\hline Eastness & 0.263 & 0.114 & $<0.05$ & 0.273 & 0.088 & $<0.01$ & -0.063 & 0.119 & 0.6 & 0.125 & 0.142 & 0.38 \\
\hline Urban & -1.387 & 0.167 & $<0.001$ & -1.751 & 0.24 & $<0.001$ & -1.248 & 1.061 & 0.24 & & & \\
\hline Cultivated & -0.162 & 0.057 & $<0.01$ & -0.113 & 0.077 & 0.143 & 0.463 & 0.342 & 0.175 & 0.751 & 0.441 & 0.088 \\
\hline Orchards & -0.481 & 0.149 & $<0.01$ & -0.508 & 0.151 & $<0.001$ & & & & 0.552 & 0.904 & 0.542 \\
\hline Pastures & -0.509 & 0.1 & $<0.001$ & 0.132 & 0.095 & 0.165 & 1.204 & 0.449 & $<0.01$ & -0.019 & 0.545 & 0.972 \\
\hline Deciduous & 0.11 & 0.049 & $<0.05$ & 0.553 & 0.059 & $<0.001$ & 0.642 & 0.331 & 0.051 & 0.585 & 0.41 & 0.154 \\
\hline Mixed & 0.096 & 0.036 & $<0.01$ & 0.501 & 0.045 & $<0.001$ & 0.494 & 0.27 & 0.068 & 0.352 & 0.329 & 0.285 \\
\hline Shrub & -0.073 & 0.043 & 0.09 & 0.052 & 0.049 & 0.289 & 0.716 & 0.345 & $<0.01$ & -0.007 & 0.409 & 0.987 \\
\hline Rock & -0.928 & 0.086 & $<0.001$ & -0.434 & 0.084 & $<0.001$ & -1.262 & 0.973 & 0.195 & -0.827 & 0.759 & 0.276 \\
\hline Water & -1.135 & 0.264 & $<0.001$ & -2.109 & 0.533 & $<0.001$ & & & & & & \\
\hline
\end{tabular}

a quadratic term that allows non-linear selection of roads and elevation 


\section{Habitat reachability}

The mean step length of the steps used in our analysis was 2,279.5 $\pm 792.0 \mathrm{~m}$ for females $(\mathrm{n}=9)$ and $3,636.0 \pm 1067.2 \mathrm{~m}$ for males $(\mathrm{n}=5)$. We took the top five percent of each individual female and male step lengths, respectively, resulting in 357 steps for females and 226 steps for males. The small sample size caused model convergence failures due to underrepresented landcover classes. For each sex, we excluded two landcover classes that were not used during movement and that also had a very low availability in the landscape. For both sexes we excluded water bodies, and orchards and urban areas for females and males, respectively (Table 2.1, right panel).

Overall and in comparison to RSF, the habitat covariates had a weaker effect in the SSF, with only four and two variables being significant for females and males, respectively. Female brown bears preferred to move through habitat at intermediate elevations of 1,028.3 m (CI 965.6, 1092.7) and a mean distance to roads of $505.8 \mathrm{~m}$ (CI 419.3, 594.0). Males selected habitat at on average $1,269.4 \mathrm{~m}$ (CI 1,171.7, 1,371.6) altitude and 671.3m (CI 539.2, 822.4) distance to roads. For females, there was a positive effect of pastures and shrub, but males did not exhibit strong preference or avoidance for any landcover class during movement (Table 2.1). In contrast, there was a significant negative effect of slope on male but not female brown bear movements, with males selecting flatter habitat (mean: 19.7 degrees (CI 17.7, 21.8)).

\section{Reachability of actual vs. random settlement areas}

After converting RSF and SSF models into resistance surfaces, we calculated least cost paths (LCPs) between the natal and the actual settlement areas and compared them to paths between natal and alternative settlement areas (Fig. 2.2). Cumulated costs of LCPs were smaller for females than for males (Fig. 2.3C). With increasing rescaling parameter $(c)$, cumulated costs of LCPs became smaller for both sexes and both selection functions (Table A2.3, supplemental material). However, across rescaling parameters, LCPs between natal and settlement sites were not significantly different from LCPs between natal and alternative sites, neither for translated suitability maps generated from SSF nor RSF. Across selection functions, cumulative costs estimated on resistance surfaces derived from SSF were lower than those derived from RSF for females, whereas the opposite was observed for males (except for the largest 
scaling parameter $\mathrm{c}=16$ ) (Table A2.3, supplemental material).

Table 2.2: Observed and expected environmental distances (ED) between natal and settlement areas for female and male brown bear offspring, for all (multivariate) and single (univariate) environmental variables $(\mathrm{EV})$. The ED range from 0 (similar) to 1 (dissimilar). Significant differences $(\mathrm{p}<0.05)$ between mother-offspring $(E D$ o $=$ observed $)$ and mother-random comparisons $(E D \mathrm{r}=$ expected $)$ are highlighted in bold (paired Wilcoxon test). Description of used environmental variables is provided in Table A2.1.

\begin{tabular}{|c|c|c|c|c|c|c|}
\hline \multirow[b]{2}{*}{ EV } & \multicolumn{3}{|c|}{ Females } & \multicolumn{3}{|c|}{ Males } \\
\hline & $\mathrm{ED}_{o}$ & $\mathrm{ED}_{r}$ & $\mathrm{p}$ & $\mathrm{ED}_{o}$ & $\mathrm{ED}_{r}$ & $\mathrm{p}$ \\
\hline All variables & 0.08 & 0.17 & $<0.001$ & 0.07 & 0.12 & 0.001 \\
\hline Slope & 0.07 & 0.17 & $<0.001$ & 0.06 & 0.11 & 0.001 \\
\hline Road & 0.14 & 0.18 & 0.083 & 0.14 & 0.15 & 0.216 \\
\hline $\operatorname{Road}^{2}$ a & 0.1 & 0.13 & 0.065 & 0.09 & 0.12 & 0.114 \\
\hline Elevation & 0.13 & 0.2 & 0.009 & 0.12 & 0.19 & 0.021 \\
\hline Elevation $^{2}$ a & 0.09 & 0.18 & $<0.001$ & 0.12 & 0.18 & 0.021 \\
\hline Eastness & 0.22 & 0.2 & 0.98 & 0.17 & 0.17 & 0.84 \\
\hline Northness & 0.17 & 0.19 & 0.348 & 0.19 & 0.17 & 0.216 \\
\hline Landcover & 0.28 & 0.37 & $<0.001$ & 0.25 & 0.29 & 0.123 \\
\hline Urban & 0.05 & 0.11 & 0.003 & 0.03 & 0.09 & $<0.001$ \\
\hline Cultivated & 0.08 & 0.14 & 0.004 & 0.06 & 0.12 & $<0.001$ \\
\hline Orchards & 0 & 0.06 & 0.014 & 0.08 & 0.06 & 0.07 \\
\hline Pastures & 0.14 & 0.16 & 0.05 & 0.24 & 0.29 & 0.114 \\
\hline Deciduous & 0.17 & 0.19 & 0.375 & 0.17 & 0.14 & 0.596 \\
\hline Conifer & 0.18 & 0.21 & 0.298 & 0.17 & 0.19 & 0.841 \\
\hline Mixed & 0.2 & 0.24 & 0.144 & 0.18 & 0.21 & 0.245 \\
\hline Shrub & 0.25 & 0.26 & 0.348 & 0.21 & 0.17 & 0.43 \\
\hline Rock & 0.09 & 0.17 & 0.001 & 0.15 & 0.15 & 0.245 \\
\hline Water & 0.15 & 0.17 & 0.159 & 0.2 & 0.2 & 0.841 \\
\hline
\end{tabular}

${ }^{\text {a }}$ quadratic term that allows non-linear selection of roads and elevation

\section{Discussion}

Our results demonstrate that dispersal is influenced by different environmental factors. Using a dataset for brown bears in the Central-European Alps, first, we found that individual bears in the study region settled in areas that are more suitable than alternative available areas. Second, dispersing brown bears also seemed to select settlement areas that are similar to the area they were born in, 
giving support for NHPI in brown bears. Third, we found that settlement sites were not chosen based on their reachability and that habitat selection during movement was different and preferences for certain habitat characteristics were less pronounced compared to habitat selection within home ranges. In sum, these findings suggest that the distribution of brown bears in the Alps could be explained by environmental factors important for the settlement stage of dispersal, whereas the reachability of new habitat does not seem to be a determinant of where the new site is placed in the landscape. We conclude that the consideration of behavioral responses to local and in-between environmental factors experienced during the three stages of dispersal is essential for interpreting and predicting landscape effects on (resulting) dispersal pattern.

\section{The importance of local environmental factors for dispersal}

\section{The importance of habitat suitability}

Since the suitability of selected home ranges was significantly higher than the suitability of alternative ranges, we concluded that habitat suitability was one important criterion for brown bear settlement.

We found that females and males avoided higher and lower altitudes, which could be related to low availability of food resources and less shelter on mountain tops that are key elements for a large wide-ranging, elusive mammal hiding from humans like a brown bear (e.g., Naves et al., 2003; Bojarska and Selva, 2012). Lower altitudes, on the other hand, are associated with urban areas (e.g., Güthlin et al., 2011; Peters et al., 2015), which are avoided by brown bears in general (e.g., Naves et al., 2003, Preatoni et al., 2005).

Males appeared to be more tolerant towards certain landcover types, i.e. cultivated land and pastures, while female tend to avoid them. This could reflect a general sexual difference in habitat selectivity, where females with cubs select areas with a high degree of security (Dahle and Swenson, 2003b; Steyaert et al. 2013), and thus avoid open terrains facilitating detectability by predators, such as raptors and humans. Humans are the main predator of brown bears, being involved in $45 \%$ of brown bear deaths in the Trentino region between 2003 and 2017 (Groff et al., 2018). Cultivated land and pasture are usually associated with a higher probability of human encounters due to cultivation and grazing livestock (e.g., Pop et al., 2012, Tenan et al., 2016), making them least preferable for brown bears, especially for females with cubs.

The avoidance of open terrain in females could also be caused by females with cubs avoiding encounters with males. Male infanticide in mam- 
mals with polygamous mating systems and long periods of maternal care is common (e.g., Van Schaik, 2000, Palombit, 2015), including brown bears (e.g., Bellemain et al., 2006; Steyaert et al., 2013), and also brown bears in Trentino (Davoli et al. , 2018). In the presence of male infanticide, female brown bears can develop several avoidance strategies, such as obscuring information on paternity (Hrdy, 1979) or changing their spatial and temporal behavior (Dahle and Swenson, 2003b; Rode et al., 2006). For brown bears in Trentino, besides pasture also shrub was positively related to male presence whereas these two habitat classes were negatively associated with female presence, although the effect of shrub was not significant in both sexes.

Finally, the avoidance of open terrain in areas with bare rock and at higher altitudes could also be related to the presence of raptors that prefer to breed in cliffs (e.g., Tapia et al., 2007; López-López et al., 2007), which increases the risk of aggressive encounters or predation for brown bear cubs. Eagles have been observed to attack young bears in Scandinavia (Sørensen et al. 2008) and also in Trentino at least one cub was predated by a golden eagle (Preatoni et al., 2005).

We believe that the combination of less shelter and the higher probability for male and human encounters could have reinforced the avoidance behavior of females for open terrain, thus leading to different suitability for females versus males. These results point to the importance of considering sexual differences, when evaluating suitable habitat for a certain species, especially in sexually dimorphic species.

In contrast to the previous study of Peters et al. (2015), we did not find a preference for orchards, which could be caused by differences in the size and nature of the data set of brown bear locations, and a larger study area and a longer observation period in our study. The resource selection functions (RSF) of Peters and colleagues were based on GPS data of a limited number of individuals collared for management reasons (i.e. bold individuals, habituated to humans and attracted by anthropogenic resources). For our study, the pool of individuals was larger and more representatives of the population, containing a higher number of non-management bears. In contrast to Peters et al. (2015), we also included individuals that were located outside Trentino, changing the overall composition and availability of certain habitat types due to a larger study area (Fig. 2.1). The proportion of orchards in Trentino was around $2 \%$, whereas in the whole Alp region this landcover class was relatively rare $(0.3 \%)$. Finally, the difference in the preference for orchards 
might also reflect a change in behavior over time. Orchards can be an attractive supplementary feeding site, but also a resource associated with predation risk, i.e. humans (Penteriani et al., 2018). Behavioral plasticity allows brown bears to react to negative experiences by changing to an alternative behavior (e.g., Kaczensky et al., 2006; Martin et al., 2010. Thus, negative experiences with humans within orchards could have led to a shift from preference to avoidance. Alternatively, brown bears have also shown to develop different space use and movement personalities (Hertel et al., 2019). In Trentino, several bold bears were classified as conflict bears (following the Interregional Action Plan for the Conservation of the Brown Bear in the Central-European Alps) due to repeated usage of human resources or offensive behavior in response to close encounters with humans and were removed from the population (Groff et al. 2018). Thus, the disappearance of preferences towards human resources such as orchards could also be the result of anthropogenic selection against these personalities.

\section{The importance of habitat similarity}

Besides suitability, our analysis indicated that habitat similarity was an important determinant of young female and male brown bear settlement. The finding that settlement areas of males, which generally dispersed further than females, were slightly more similar to natal areas than those of females, gives support for the hypothesis on natal habitat preference induction (NHPI, Davis and Stamps, 2004) in this reintroduced population. NHPI has been observed in several species, such as birds (Piper et al., 2013), small mammals (e.g., Mabry and Stamps, 2008, Merrick and Koprowski, 2016) and also in large mammals with prolonged natal periods (Larue et al., 2018), which is the period between birth and independence from the mother. Within this period, context-dependent and individual-specific reactions of the mother to various habitat characteristics, for example during feeding or hunting, can imprint and improve the offspring's decision-making during settlement (Danchin et al., 2004; Hoppitt et al., 2008). Some empirical studies showed that cub behaviors in bears were influenced by their mother's behavior and the habitats in which she reared her young (Mazur and Seher, 2008; Hopkins, 2013), suggesting that habitat selection in bears rather is learned instead of inherited (Nielsen et al., 2013, Morehouse et al., 2016). When considering environmental factors separately (univariate ED), we found that female settlement areas contained similar low proportions of cultivated land and bare rock than the ranges of their mothers, 
which also underlined the finding of the habitat suitability model (see above) where females selected areas based on their degree of security for themselves and their cubs.

In sum, we conclude that habitat similarity is shaping brown bear settlement, because NHPI induces dispersing individuals to cue for similar natal habitat that supported them to dispersal age.

\section{The importance of in-between environmental factors for dispersal}

\section{The importance of habitat reachability}

During long distance movements, only few habitat variables exhibited significant effects. Female movement was negatively affected by both, low and high elevations, and positively affected by pastures. For males, only slope had a negative effect, whereas lower altitudes had a positive effect on movement. For the remaining variables, no effect was observed indicating that brown bears neither preferred nor avoided these habitat attributes during movement.

Habitat preferences during movement (SSF) differed from those within home ranges of female and male brown bears (RSF). For most variables, effects of habitat attributes in the RSF were not observed in the SSF. For example, deciduous and mixed forests were both preferred according to the RSF but were not preferred during movement. The negative effect of large distances to roads, higher elevation and rocks in the RSF demonstrated that remote areas in steep, rugged terrain were generally avoided when establishing home ranges. In contrast, there was not such an effect in the SSF, suggesting that these areas were not a restriction to movement. For two covariates we found a reversal in habitat selection between RSF and SSF. Within home ranges, females avoided pastures and males preferred steeper areas, whereas during movement pastures were preferred by females and flat areas by males. In addition, shrub positively affected habitat selection during movement in females, and negatively during within-home range residency, although the latter was not significant.

When comparing least cost paths (LCPs) between natal-offspring and natal-random pairings, we found no difference, neither for females nor for males, and neither for resistance maps derived from RSF nor SSF. This suggests that the habitat in the Alps per se has low resistance for brown bear dispersal and offers several opportunities to reach new habitats. Although the cumulative costs were corrected for path lengths, costs were generally higher for males than for females. This could indicate that males, i.e. the dispersing sex with larger dispersal distances (Støen et al., 2006, Zedrosser et al., 2007), 
are willing to cross areas that are less suitable in order to reach new habitats. Since males have larger body sizes (e.g., Swenson et al., 2007), the fitness constraints to traverse less optimal habitat might be lower for males than for females. Males likely also experience larger landscape heterogeneity than females that have lower dispersal distances, thus increasing the probability to encounter and cross less optimal habitat.

Our results demonstrated that the relative influence of different environmental variables differ between long-distance movements and within-range behavior. Specifically, brown bears in the study area seemed to be less influenced by the environment during movement, which was also observed in other European regions, where brown bears were found partly dispersing hundreds of kilometers through human-dominated landscapes (Bartoń et al., 2019). However, the non-significance of habitat reachability in our study should not imply that brown bear movement is never affected by the landscape. Evaluating landscape resistance for a different brown bear population in a different study area or at larger spatial scales, e.g. across Europe, could also reveal negative effects of landscape resistance on brown bear movements. Similarly, movement can also be constrained by linear features acting as barriers to dispersal, such as the Brenner highway in the Adige valley (Peters et al. 2015), which needs further consideration in future studies (LCIE, 2018).

\section{Dispersal and habitat selection of Trentino brown bears}

We found that brown bears in Trentino exhibit different habitat preferences during movement and settlement. For settlement, suitability was an important criterion, because established home ranges overall were more suitable than other alternative ranges within the bear distribution range. Although many preferences for settlement areas were similar, females differed from males in their avoidance behavior for certain landscape characteristics associated with human activity. Thus, females were more restricted by environmental factors, which might make them more habitat-specific than males when establishing own ranges. Both sexes showed signals of NHPI and selected habitat that was similar to their natal range. For movement, both sexes generally were less habitat-specific compared to resource use within home ranges. Elevation was a primary determinant of movement. Mountainous habitat at high elevation seemed to be a natural restriction to female movements, but not to males. Both sexes avoided areas at lower altitudes, probably because of large amounts of human infrastructures (i.e., settlements and roads) that are centered within 
valleys (Peters et al., 2015).

Based on these findings, we conclude that the placement of home ranges for settlement in dispersing brown bears in the Central Alps is influenced primarily by the similarity and suitability of the habitat, rather than by the reachability of these locations. Thus, local habitat suitability and similarity are likely important determinants for the expansion of the reintroduced population and for the establishment of a stable brown bear population in the Alps. Besides the protection of suitable habitat, natal habitat preference induction should also be considered in conservation management, especially when the settlement of females outside the Trentino range is favored.

\section{Limitations}

Dispersal is a complex, multi-causal process Matthysen, 2012; Baguette et al. 2013). Besides the physical environment that is examined here, the three dispersal stages of emigration, movement and settlement also are influenced by social aspects, such as kinship and competition (Clobert et al., 2009). Risk of inbreeding and competition over resources and mates can decrease fitness and are reasons to emigrate from the natal site, to adjust paths during movement, and to select new habitat (Greenwood, 1980, Pusey, 1987, Dobson, 1982). On the other hand, social affiliation between individuals, such as matrilineal assemblages, can be reasons for philopatry (e.g., Zedrosser et al., 2007). Although these factors affect all three dispersal stages, they have an essential effect on the onset of dispersal, i.e., whether dispersal occurs at all. We did not include the stage of departure (or emigration) in our analysis, thus, we cannot conclude why brown bears dispersed from their natal site. Determining the reason of dispersal, such as intra-specific competition, might be more challenging than studying the resulting pattern such as the current distribution of individuals. However, measuring population density relative to the habitat carrying capacity, could provide information on the degree of competition. Since effects of population densities on the dispersal stages can be complex and opposing (i.e., negative- or positive-dependent), we cannot conclude on effects of population density on brown bear dispersal in Trentino. We acknowledge that the incorporation of information on densities and other factors driving emigration would have further complemented the attempt to understand the dispersal process in brown bears. It could also further contribute to our understanding why the brown bear population in Trentino is demographically isolated from the Dinaric population. Thus, we would recommend to account for the effect of 
population density in future studies.

For the analysis of NHPI and habitat similarity, we acknowledge that the limited population expansion from Trentino (Groff et al., 2018) and low dispersal distances of several individuals, especially philopatric females, rise concern for spatial autocorrelation, causing higher similarity values between natal-settlement pairings for individuals closer to the mother's home range. However, the non-correlation of environmental and dispersal distances indicated that the preference for similarity was independent of geographical distance, supporting the prediction that habitat similarity is shaping brown bear settlement.

\section{Conclusions}

Our study demonstrates that dispersal pattern, such as the distribution of a species, is influenced by different environmental factors acting on dispersal. The consideration of different habitat characteristics relevant for different dispersal stages separately allows us to account for the individual dispersal behavior, which is crucial for predicting how populations or communities respond to environmental changes. We believe that an integration of individual behavior into examinations of environmental influences on dispersal, such as the framework presented here, together with technological advances in animal tracking and remote sensing open up opportunities to determine the principles on how animals use the landscape and respond to environmental change. This knowledge could provide us with a more detailed understanding of the dispersal process and resulting dispersal pattern, which might enhance the effectiveness of conservation actions for species in human-dominated landscapes. 


\section{References}

Adriaensen, F., Chardon, J. P., De Blust, G., Swinnen, E., Villalba, S., Gulinck, H., and Matthysen, E. (2003). The application of 'least-cost' modelling as a functional landscape model. Landscape and Urban Planning, 64(4):233-247.

Baguette, M., Blanchet, S., Legrand, D., Stevens, V. M., and Turlure, C. (2013). Individual dispersal, landscape connectivity and ecological networks. Biological Reviews, 88(2):310326 .

Baguette, M., Van Dyck, H., and Dyck, H. (2007). Landscape connectivity and animal behavior: functional grain as a key determinant for dispersal. Landscape Ecology, 22(8):1117-1129.

Bartoń, K. A., Zwijacz-Kozica, T., Zięba, F., Sergiel, A., and Selva, N. (2019). Bears without borders: Long-distance movement in human-dominated landscapes. Global Ecology and Conservation, 17:1-8.

Bellemain, E., Swenson, J. E., and Taberlet, P. (2006). Mating strategies in relation to sexually selected infanticide in a non-social carnivore: The brown bear. Ethology, 112(3):238246.

Benoit, L., Hewison, A. M., Coulon, A., Debeffe, L., Grémillet, D., Ducros, D., Cargnelutti, B., Chaval, Y., and Morellet, N. (2019). Accelerating across the landscape: the energetic costs of natal dispersal in a large herbivore. Journal of Animal Ecology, (August):1-13.

Bischof, R., Steyaert, S. M., and Kindberg, J. (2017). Caught in the mesh: roads and their network-scale impediment to animal movement. Ecography, 40(12):1369-1380.

Bivand, R. (2018). rgrass7: Interface Between GRASS 7 Geographical Information System and $\mathrm{R}$.

Boitani, L., Alvarez, F., Anders, O., Andren, H., Avanzinelli, E., and et al. (2015). Key actions for Large Carnivore populations in Europe. Institute of Applied Ecology (Rome, Italy). Report to DG Environment; European Commission, Bruxelles.

Bojarska, K. and Selva, N. (2012). Spatial patterns in brown bear Ursus arctos diet: The role of geographical and environmental factors. Mammal Review, 42(2):120-143.

Bolker, B. M., Brooks, M. E., Clark, C. J., Geange, S. W., Poulsen, J. R., Stevens, M. H. H., and White, J. S. S. (2009). Generalized linear mixed models: a practical guide for ecology and evolution. Trends in Ecology and Evolution, 24(3):127-135.

Bonte, D., Lukáč, M., and Lens, L. (2008). Starvation affects pre-dispersal behaviour of Erigone spiders. Basic and Applied Ecology, 9(3):308-315.

Bonte, D., Van Dyck, H., Bullock, J. M., Coulon, A., Delgado, M., and et al. (2012). Costs of dispersal. Biological Reviews of the Cambridge Philosophical Society, 87(2):290-312.

Bowler, D. E. and Benton, T. G. (2005). Causes and consequences of animal dispersal strategies: relating individual behaviour to spatial dynamics. Biological Reviews of the Cambridge Philosophical Society, 80(2):205-225. 
Boyce, M. S., Vernier, P. R., Nielsen, S. E., and Schmiegelow, F. K. A. (2002). Evaluating resource selection functions. Ecological Modelling, 157(2-3):281-300.

Brown, J. and Kodric-Brown, A. (1977). Turnover Rates in Insular Biogeography: Effect of Immigration on Extinction. Ecology, 58(2):445-449.

Burnham, K. and Anderson, D. (2002). Model Selection and Multimodel Inference: A Practical Information-Theoretic Approach. Springer, 2nd edition.

Burt, W. H. (1943). Territoriality and Home Range Concepts as Applied to Mammals. Journal of Mammalogy, 24(3):346-352.

Clobert, J., Le Galliard, J.-F., Cote, J., Meylan, S., and Massot, M. (2009). Informed dispersal, heterogeneity in animal dispersal syndromes and the dynamics of spatially structured populations. Ecology Letters, 12(3):197-209.

Cote, J., Bestion, E., Jacob, S., Travis, J., Legrand, D., and Baguette, M. (2017). Evolution of dispersal strategies and dispersal syndromes in fragmented landscapes. Ecography, $40(1): 56-73$.

Cushman, S. A. and Lewis, J. S. (2010). Movement behavior explains genetic differentiation in American black bears. Landscape Ecology, 25(10):1613-1625.

Dahle, B. and Swenson, J. E. (2003a). Home ranges in adult Scandinavian brown bears (Ursus arctos): Effect of mass, sex, reproductive category, population density and habitat type. Journal of Zoology, 260(4):329-335.

Dahle, B. and Swenson, J. E. (2003b). Seasonal range size in relation to reproductive strategies in brown bears Ursus arctos. Journal of Animal Ecology, 72(4):660-667.

Danchin, É., Giraldeau, L. A., Valone, T. J., and Wagner, R. H. (2004). Public information: From nosy neighbors to cultural evolution. Science, 305(5683):487-491.

Davis, J. M. and Stamps, J. A. (2004). The effect of natal experience on habitat preferences. Trends in Ecology and Evolution, 19(8):411-416.

Davoli, F., Cozzo, M., Angeli, F., Groff, C., and Randi, E. (2018). Infanticide in brown bear: A case-study in the Italian Alps - Genetic identification of perpetrator and implications in small populations. Nature Conservation, 25:55-75.

De Barba, M., Groff, C., and Genovesi, P. (2013). Reintroduction of the brown bear (Ursus arctos) in the central Alps, Trentino, Italy. In Soorae, P. S., editor, Reintroduction Perspectives: 2013. Further case studies from around the globe, pages 125-130. IUCN/ SSC Re-introduction Specialist Group and Abu Dhabi, UAE: Environment Agency-Abu Dhabi, Gland, Switzerland.

De Barba, M., Waits, L. P., Garton, E. O., Genovesi, P., Randi, E., Mustoni, A., and Groff, C. (2010). The power of genetic monitoring for studying demography, ecology and genetics of a reintroduced brown bear population. Molecular Ecology, 19(18):3938-3951.

Dobson, F. S. (1982). Competition for mates and predominant juvenile male dispersal in mammals. Animal Behaviour, 30:1183-1192. 
Doligez, B. and Pärt, T. (2008). Estimating fitness consequences of dispersal: a road to 'know-where'? Non-random dispersal and the underestimation of dispersers' fitness. Journal of Animal Ecology, 77(6):1199-1211.

Dormann, C. F., Elith, J., Bacher, S., Buchmann, C., Carl, G., and et al. (2013). Collinearity: A review of methods to deal with it and a simulation study evaluating their performance. Ecography, 36(1):027-046.

Etherington, T. R. and Holland, E. P. (2013). Least-cost path length versus accumulatedcost as connectivity measures. Landscape Ecology, (28):1223-1229.

Fretwell, S. and Lucas, H. (1969). On territorial behavior and other factors influencing habitat distribution in birds. Acta Biotheoretica, 19:16-36.

Gandon, S. (1999). Kin competition, the cost of inbreeding and the evolution of dispersal. Journal of Theoretical Biology, 200(4):345-364.

Gastón, A., Blázquez-Cabrera, S., Garrote, G., Mateo-Sánchez, M. C., Beier, P., Simón, M. A., and Saura, S. (2016). Response to agriculture by a woodland species depends on cover type and behavioural state: insights from resident and dispersing Iberian lynx. Journal of Applied Ecology, 53(3):814-824.

GRASS Development Team (2017). Geographic Resources Analysis Support System (GRASS GIS) Software, Version 7.2.

Graves, T., Chandler, R. B., Royle, J. A., Beier, P., and Kendall, K. C. (2014). Estimating landscape resistance to dispersal. Landscape Ecology, 29(7):1201-1211.

Green, J. P. and Hatchwell, B. J. (2018). Inclusive fitness consequences of dispersal decisions in a cooperatively breeding bird, the long-tailed tit (Aegithalos caudatus). Proceedings of the National Academy of Sciences of the United States of America, 115(47):12011-12016.

Greenwood, P. (1980). Mating systems, philopatry and dispersal in birds and mammals. Animal Behaviour, 28:1140-1162.

Groff, C., Angeli, F., Asson, D., Bragalanti, N., Pedrotti, L., Rizzoli, R., and Zanghellini, P. (2018). Large Carnivores Report, Autonomous Province of Trento's Forestry and Wildlife Department.

Güthlin, D., Knauer, F., Kneib, T., Küchenhoff, H., Kaczensky, P., Rauer, G., Jonozovič, M., Mustoni, A., and Jerina, K. (2011). Estimating habitat suitability and potential population size for brown bears in the Eastern Alps. Biological Conservation, 144(5):17331741.

Hamilton, W. and May, R. (1977). Dispersal in stable habitats. Nature, 269:578-581.

Hanski, I. A. and Gilpin, M. E. (1997). Metapopulation Biology: Ecology, Genetics, and Evolution. Academic Press, San Diego, California.

Hertel, A. G., Leclerc, M., Warren, D., Pelletier, F., Zedrosser, A., and Mueller, T. (2019). Don't poke the bear: using tracking data to quantify behavioural syndromes in elusive wildlife. Animal Behaviour, 147:91-104. 
Hopkins, J. B. (2013). Use of genetics to investigate socially learned foraging behavior in free-ranging black bears. Journal of Mammalogy, 94(6):1214-1222.

Hoppitt, W. J., Brown, G. R., Kendal, R., Rendell, L., Thornton, A., Webster, M. M., and Laland, K. N. (2008). Lessons from animal teaching. Trends in Ecology and Evolution, $23(9): 486-493$.

Howard, W. E. (1960). Innate and Environmental Dispersal of Individual Vertebrates. American Midland Naturalist, 63(1):152-161.

Hrdy, S. B. (1979). Infanticide among animals: a review, classification, and examination of the implications for the reproductive strategies of females. Ethology and Sociobiology, $1: 13-40$.

Johnson, C. J., Seip, D. R., and Boyce, M. S. (2004). A quantitative approach to conservation planning: Using resource selection functions to map the distribution of mountain caribou at multiple spatial scales. Journal of Applied Ecology, 41(2):238-251.

Kaczensky, P., Huber, D., Knauer, F., Roth, H., Wagner, A., and Kusak, J. (2006). Activity patterns of brown bears (Ursus arctos) in Slovenia and Croatia. Journal of Zoology, $269(4): 474-485$.

Kaufmann, J. H. (1962). Ecology and social behavior of the coati, Nasua narica on Barro Colorado Island, Panama. University of California Press.

Keeley, A. T. H., Beier, P., and Gagnon, J. W. (2016). Estimating landscape resistance from habitat suitability: effects of data source and nonlinearities. Landscape Ecology, 31(9):2151-2162.

Kirkpatrick, Mark \& Barton, N. H. (1997). Evolution of a Species' Range. The American Naturalist, 150(1):1-23.

Larue, B., Côté, S. D., St-Laurent, M. H., Dussault, C., and Leblond, M. (2018). Natal habitat preference induction in large mammals - Like mother, like child? Ecology and Evolution, 8(24):12629-12640.

LCIE (2018). Assessment of the Brown Bear Project in Trentino (Italy). Large Carnivore Initiative for Europe.

Leclerc, M., Vander Wal, E., Zedrosser, A., Swenson, J. E., Kindberg, J., and Pelletier, F. (2016). Quantifying consistent individual differences in habitat selection. Oecologia, 180(3):697-705.

López-López, P., García-Ripollés, C., Soutullo, Á., Cadahía, L., and Urios, V. (2007). Identifying potentially suitable nesting habitat for golden eagles applied to 'important bird areas' design. Animal Conservation, 10(2):208-218.

Mabry, K. and Stamps, J. (2008). Dispersing brush mice prefer habitat like home. Proceedings of the Royal Society B: Biological Sciences, 275:543-548.

Manly, B. F. J., McDonald, L. L., Thomas, D. L., McDonald, T. L., and Erickson, W. P. (2002). Resource Selection by Animals: Statistical Design and Analysis for Field Studies. Kluwer Academic Publishers, Dordrecht, 2nd edition. 
Martin, J., Basille, M., van Moorter, B., Kindberg, J., Allainé, D., and Swenson, J. E. (2010). Coping with human disturbance: Spatial and temporal tactics of the brown bear (Ursus arctos). Canadian Journal of Zoology, 88(9):875-883.

Mateo-Sánchez, M. C., Balkenhol, N., Cushman, S., Pérez, T., Domínguez, A., and Saura, S. (2015). Estimating effective landscape distances and movement corridors: Comparison of habitat and genetic data. Ecosphere, 6(4):1-16.

Mathieu, J., Barot, S., Blouin, M., Caro, G., Decaëns, T., and et al. (2010). Habitat quality, conspecific density, and habitat pre-use affect the dispersal behaviour of two earthworm species, Aporrectodea icterica and Dendrobaena veneta, in a mesocosm experiment. Soil Biology and Biochemistry, 42(2):203-209.

Matthysen, E. (2012). Multicausality of dispersal: a review. In Clobert, J., Baguette, M., Benton, T., and Bullock, J., editors, Dispersal Ecology and Evolution, pages 3-18. Oxford University Press, Oxford.

Mazur, R. and Seher, V. (2008). Socially learned foraging behaviour in wild black bears, Ursus americanus. Animal Behaviour, 75(4):1503-1508.

Merrick, M. J. and Koprowski, J. L. (2016). Evidence of natal habitat preference induction within one habitat type. Proceedings of the Royal Society B: Biological Sciences, 283(1842):20162106.

Morehouse, A. T., Graves, T. A., Mikle, N., and Boyce, M. S. (2016). Nature vs. nurture: Evidence for social learning of conflict behaviour in grizzly bears. PLoS ONE, 11(11):1-15.

Muff, S., Signer, J., and Fieberg, J. (2020). Accounting for individual-specific variation in habitat-selection studies: Efficient estimation of mixed-effects models using Bayesian or frequentist computation. Journal of Animal Ecology, 89(1):80-92.

Mustoni, A., Carlini, E., Chiarenzi, B., Chiozzini, S., Lattuada, E., Dupré, E., and et al. (2003). Planning the Brown Bear Ursus arctos reintroduction in the Adamello Brenta Natural Park. A tool to establish a metapopulation in the Central-Eastern Alps. Hystrix, the Italian Journal of Mammalogy, 14(1-2):3-27.

Nathan, R., Getz, W., Revilla, E., Holyoak, M., Kadmon, R., Saltz, D., and Smouse, P. (2008). A movement ecology paradigm for unifying organismal movement research. Proceedings of the National Academy of Sciences of the United States of America, 105(49):19052-19059.

Naves, J., Wiegand, T., Revilla, E., and Delibes, M. (2003). Endangered Species Constrained by Natural and Human Factors: The Case of Brown Bears in Northern Spain. Conservation Biology, 17(5):1276-1289.

Nielsen, S. E., Shafer, A. B., Boyce, M. S., and Stenhouse, G. B. (2013). Does Learning or Instinct Shape Habitat Selection? PLoS ONE, 8(1):1-5.

Palombit, R. A. (2015). Infanticide as sexual conflict: Coevolution of male strategies and female counterstrategies. Cold Spring Harbor Perspectives in Biology, 7(6):1-31.

Penteriani, V., Delgado, M. D. M., Krofel, M., Jerina, K., Ordiz, A., Dalerum, F., ZarzoArias, A., and Bombieri, G. (2018). Evolutionary and ecological traps for brown bears Ursus arctos in human-modified landscapes. Mammal Review, 48(3):180-193. 
Peters, W., Hebblewhite, M., Cavedon, M., Pedrotti, L., Mustoni, A., Zibordi, F., Groff, C., and et al. (2015). Resource selection and connectivity reveal conservation challenges for reintroduced brown bears in the Italian Alps. Biological Conservation, 186:123-133.

Piper, W. H., Palmer, M. W., Banfield, N., and Meyer, M. W. (2013). Can settlement in natal-like habitat explain maladaptive habitat selection? Proceedings of the Royal Society B: Biological Sciences, 280(1765):20130979.

Pop, I. M., Sallay, A., Bereczky, L., and Chiriac, S. (2012). Land use and Behavioral Patterns of Brown Bears in the South-Eastern Romanian Carpathian Mountains: A Case Study of Relocated and Rehabilitated Individuals. Procedia Environmental Sciences, 14:111-122.

Preatoni, D., Mustoni, A., Martinoli, A., Carlini, E., Chiarenzi, B., Chiozzini, S., Van Dongen, S., Wauters, L. A., and Tosi, G. (2005). Conservation of brown bear in the Alps: Space use and settlement behavior of reintroduced bears. Acta Oecologica, 28(3):189-197.

Proctor, M. F., Paetkau, D., McLellan, B. N., Stenhouse, G. B., and et al. (2012). Population fragmentation and inter-ecosystem movements of grizzly bears in Western Canada and the Northern United States. Wildlife Monographs, 180:1-46.

Pusey, A. E. (1987). Sex-biased dispersal and inbreeding avoidance in birds and mammals. Trends in Ecology and Evolution, 2(10):295-299.

QGIS Development Team (2009). QGIS Geographic Information System.

R Development Core Team (2019). R: A Language and Environment for Statistical Computing.

Reding, D. M., Cushman, S. A., Gosselink, T. E., and Clark, W. R. (2013). Linking movement behavior and fine-scale genetic structure to model landscape connectivity for bobcats (Lynx rufus). Landscape Ecology, 28(3):471-486.

Rode, K. D., Farley, S. D., and Robbins, C. T. (2006). Sexual Dimorphism , Reproductive Strategy, and Human Activities Determine Resource Use by Brown Bears. Ecology, 87(10):2636-2646.

Ronce, O. (2007). How Does It Feel to Be Like a Rolling Stone? Ten Questions About Dispersal Evolution. Annual Review of Ecology, Evolution, and Systematics, 38(1):231253.

Selonen, V. and Hanski, I. K. (2012). Dispersing Siberian flying squirrels (Pteromys volans) locate preferred habitats in fragmented landscapes. Canadian Journal of Zoology, 90(7):885-892.

Shigesada, N. and Kawasaki, K. (2002). Invasion and the range expansion of species: effects of long-distance dispersal. In Bullock, J., Kenward, R., and Hails, R., editors, Dispersal Ecology, chapter 17, pages 350-373. Blackwell Science.

Signer, J., Fieberg, J., and Avgar, T. (2019). Animal movement tools (amt): R package for managing tracking data and conducting habitat selection analyses. Ecology and Evolution, $9(2): 880-890$.

Slatkin, M. (1987). Gene flow and the geographic structure of natural populations. Science, 236:787-792. 
Sørensen, O. J., Totsås, M., Solstad, T., and Rigg, R. (2008). Predation by a Golden Eagle on a Brown Bear Cub. Ursus, 19(2):190-193.

Squires, J. R., DeCesare, N. J., Olson, L. E., Kolbe, J. A., Hebblewhite, M., and Parks, S. A. (2013). Combining resource selection and movement behavior to predict corridors for Canada lynx at their southern range periphery. Biological Conservation, 157:187-195.

Stamps, J., Luttbeg, B., Krishnan, V. V., Stamps, J., Luttbeg, B., and Krishnan, V. V. (2009). Effects of survival on the attractiveness of cues to natal dispersers. The American Naturalist, 173(1):41-6.

Stamps, J. A. and Davis, J. M. (2006). Adaptive effects of natal experience on habitat selection by dispersers. Animal Behaviour, 72(6):1279-1289.

Steyaert, S. M., Reusch, C., Brunberg, S., Swenson, J. E., Hackländer, K., and Zedrosser, A. (2013). Infanticide as a male reproductive strategy has a nutritive risk effect in brown bears. Biology Letters, 9(5):20130624.

Støen, O.-G. (2005). Natal dispersal and social organization in brown bears. PhD thesis.

Støen, O.-G., Zedrosser, A., Saebø, S., Swenson, J. E., and Zedrosser, O.-g. S. Æ. A. (2006). Inversely density-dependent natal dispersal in brown bears Ursus arctos. Oecologia, 148(2):356-64.

Swenson, J. E., Adamič, M., Huber, D., and Stokke, S. (2007). Brown bear body mass and growth in northern and southern Europe. Oecologia, 153(1):37-47.

Tapia, L., Domínguez, J., and Lado, L. R. (2007). Modelling habitat use and distribution of golden eagles Aquila chrysaetos in a low-density area of the Iberian Peninsula. Biodiversity and Conservation, 16:3559-3574.

Templeton, A. R., Shaw, K., Routman, E., and Davis, S. K. (1990). The Genetic Consequences of Habitat Fragmentation. Annals of the Missouri Botanical Garden, 77(1):13-27.

Tenan, S., Iemma, A., Bragalanti, N., Pedrini, P., De Barba, M., Randi, E., Groff, C., and Genovart, M. (2016). Evaluating mortality rates with a novel integrated framework for nonmonogamous species. Conservation Biology, 30(6):1307-1319.

Thurfjell, H., Ciuti, S., and Boyce, M. S. (2014). Applications of step-selection functions in ecology and conservation. Movement Ecology, 2(1):1-12.

Tosi, G., Chirichella, R., Zibordi, F., Mustoni, A., Giovannini, R., Groff, C., Zanin, M., and Apollonio, M. (2015). Brown bear reintroduction in the Southern Alps: To what extent are expectations being met? Journal for Nature Conservation, 26:9-19.

Trainor, A. M., Walters, J. R., Morris, W. F., Sexton, J., and Moody, A. (2013). Empirical estimation of dispersal resistance surfaces: A case study with red-cockaded woodpeckers. Landscape Ecology, 28(4):755-767.

Tucker, M. A., Böhning-Gaese, K., Fagan, W. F., Fryxell, J. M., Van Moorter, B., and et al. (2018). Moving in the Anthropocene: Global reductions in terrestrial mammalian movements. Science, 359(6374):466-469. 
Tuomainen, U. and Candolin, U. (2011). Behavioural responses to human-induced environmental change. Biological reviews of the Cambridge Philosophical Society, 86(3):640-57.

Van Schaik, C. (2000). Vulnerability to infanticide by males: patterns among mammals. In Van Schaik, C. and Janson, C., editors, Infanticide by Males and Its Implications, pages 61-72. Cambridge University Press, Cambridge, Cambridge, UK.

VanDerWal, J., Shoo, L. P., Johnson, C. N., and Williams, S. E. (2009). Abundance and the environmental niche: Environmental suitability estimated from niche models predicts the upper limit of local abundance. American Naturalist, 174(2):282-291.

Vasudev, D., Fletcher, R. J., Goswami, V. R., and Krishnadas, M. (2015). From dispersal constraints to landscape connectivity: Lessons from species distribution modeling. Ecography, 38(10):967-978.

Wiens, J. A. (2001). The landscape context of dispersal. In Clobert, J., Danchin, E., Dhondt, A., and Nichols, J., editors, Dispersal, pages 96-109. Oxford University Press, New York.

Zedrosser, A., Steyaert, S. M., Gossow, H., and Swenson, J. E. (2011). Brown bear conservation and the ghost of persecution past. Biological Conservation, 144(9):2163-2170.

Zedrosser, A., Støen, O. G., Sæbø, S., and Swenson, J. E. (2007). Should I stay or should I go? Natal dispersal in the brown bear. Animal Behaviour, 74(3):369-376.

Zeller, K. A., McGarigal, K., Beier, P., Cushman, S. A., Vickers, T. W., and Boyce, W. M. (2014). Sensitivity of landscape resistance estimates based on point selection functions to scale and behavioral state: Pumas as a case study. Landscape Ecology, 29(3):541-557.

Zeller, K. A., McGarigal, K., Cushman, S. A., Beier, P., Vickers, T. W., and Boyce, W. M. (2017). Sensitivity of resource selection and connectivity models to landscape definition. Landscape Ecology, 32(4):835-855.

Zeller, K. A., McGarigal, K., and Whiteley, A. R. (2012). Estimating landscape resistance to movement: a review. Landscape Ecology, 27(6):777-797. 


\section{Supporting information}

Appendix A2.1: Supplemental material.

Table A2.1 Landscape variables used in the analysis of the importance of habitat suitability, habitat similarity, and habitat reachability for brown bear settlement in the Central Alps. Also given are data sources and resolution of GIS layers.

Table A2.2: Observed and expected environmental distances (ED) and 95\% confidence intervals (CI) between natal and settlement areas (MCP50) for female (a) and male (b) brown bear offspring, for all and single environmental variables $(\mathrm{EV})$. The ED range from 0 (similar) to 1 (dissimilar). Significant differences between mother-offspring $\left(\mathrm{ED}_{\mathrm{o}}\right)$ and mother-random comparisons $\left(\mathrm{ED}_{\mathrm{r}}\right)$ are highlighted in bold (paired Wilcoxon test). Also shown are the mean environmental characteristics of offspring (value $\mathrm{o}_{\mathrm{o}}$ ), random ( value $_{\mathrm{r}}$ ) and mother $\left(\right.$ value $_{\mathrm{m}}$ ) home ranges. Units were as follows: degree for slope, meters for roads and elevation, and percentages for landcover types.

Table A2.3: Observed and expected least cost paths (LCP) and 95\% confidence intervals (CI) between natal and (alternative) settlement sites for female (a) and male (b) brown bear offspring. LCPs were estimated on resistance surfaces derived from resource selection functions (RSF, left panel) or step selection functions (SSF, right panel). Habitat suitability was translated into resistance using different transformations that are either linear (scaling parameter $\mathrm{c}=0.25)$ or negative exponential $(\mathrm{c}=4,8,16)$. 


\section{Appendix A2.1: Supplemental material}

Table A2.1: Landscape variables used in the analysis of the importance of habitat suitability, habitat similarity, and habitat reachability for brown bear settlement in the Central Alps. Also given are data sources and resolution of GIS layers.

\begin{tabular}{|c|c|c|}
\hline Covariate & $\begin{array}{l}\text { Proportion } \\
\text { in study } \\
\text { area (\%) }\end{array}$ & Description \\
\hline \multicolumn{3}{|c|}{ Land cover ${ }^{1)}$} \\
\hline Urban & 5 & $\begin{array}{l}\text { Continuous urban fabric, Discontinuous urban fabric, Industrial or } \\
\text { commercial units, Road and rail networks and associated land, Port } \\
\text { areas, Airports, Mineral extraction sites, Dump sites, Construction } \\
\text { sites, Green urban areas, Sport and leisure facilities }\end{array}$ \\
\hline Cultivated & 18 & $\begin{array}{l}\text { Non-irrigated arable land, Permanent irrigated land, Olive groves, } \\
\text { Annual crops associated with permanent crops, Complex cultivation } \\
\text { patterns, Land principally occupied by agriculture, with significant } \\
\text { areas of natural vegetation, Agro-forestry areas }\end{array}$ \\
\hline Orchards & 0.3 & Fruit trees and berry plantations, Fruit trees and berry plantations \\
\hline Pastures & 9 & Pastures \\
\hline Deciduous & 9 & Broad-leaved forest \\
\hline Conifer & 22 & Coniferous forest \\
\hline Mixed & 13 & Mixed forest \\
\hline Shrub & 12 & $\begin{array}{l}\text { Transitional woodland-shrub, Sclerophyllous vegetation, Moors and } \\
\text { heathland, Natural grasslands, }\end{array}$ \\
\hline Rock & 10 & Glaciers and perpetual snow, Bare rocks \\
\hline Water & 1 & Water courses, Water bodies \\
\hline None & 0.7 & No data \\
\hline \multicolumn{3}{|l|}{ Roads $s^{2)}$} \\
\hline \multirow[t]{2}{*}{ Road } & & $\begin{array}{l}\text { Distance to highways, trunks (important roads, typically divided), } \\
\text { national and regional roads in meter }\end{array}$ \\
\hline & & Distances were also squared to allow for non-linear selection (Road2) \\
\hline
\end{tabular}

$D E M^{3)}$

Elevation Elevation in meters

Elevation was also squared to allow for non-linear selection (Elevation2)

Slope $\quad$ Slope $(0-90)$

Northness Cosine function of aspect (in radians), between -1 (directly south) and 1 (directly north)

Eastness $\quad$ Sine function of aspect (in radians), between -1 (directly west) and 1 (directly east)

\footnotetext{
1) Corine Land Cover 2012 (100m resolution, https://land.copernicus.eu/pan-european/corineland-cover/clc-2012?tab=mapview)

2) OpenStreetMap (http://download.geofabrik.de/europe.html)

3) Digital Elevation Model (10m resolution, https://earthexplorer.usgs.gov)
} 
Table A2.2: Observed and expected environmental distances (ED) and 95\% confidence intervals (CI) between natal and settlement areas (MCP50) for female (a) and male (b) brown bear offspring, for all and single environmental variables (EV). The ED range from 0 (similar) to 1 (dissimilar). Significant differences between mother-offspring $\left(\mathrm{ED}_{\mathrm{o}}\right)$ and mother-random comparisons $\left(\mathrm{ED}_{\mathrm{r}}\right)$ are highlighted in bold $($ paired Wilcoxon test). Also shown are the mean environmental characteristics of offspring ( value $_{\mathrm{o}}$ ), random (value ${ }_{\mathrm{r}}$ ) and mother (value $\mathrm{m}$ ) home ranges. Units were as follows: degree for slope, meters for roads and elevation, and percentages for landcover types.

\begin{tabular}{|c|c|c|c|c|c|c|c|c|c|c|c|c|c|c|}
\hline \multirow[b]{2}{*}{$\mathrm{EV}$} & \multicolumn{3}{|c|}{ offspring } & \multicolumn{3}{|c|}{ random } & \multirow{2}{*}{$\begin{array}{l}\mathrm{ED}_{r}> \\
E D_{o} ? \\
\mathrm{p}\end{array}$} & \multicolumn{3}{|c|}{ offspring } & \multicolumn{3}{|c|}{ random } & \multirow{2}{*}{$\begin{array}{c}\text { mother } \\
\text { value }_{m}\end{array}$} \\
\hline & $\mathrm{ED}_{o}$ & $\mathrm{CI}_{L}$ & $\mathrm{CI}_{U}$ & $\mathrm{ED}_{r}$ & $\mathrm{CI}_{L}$ & $\mathrm{CI}_{U}$ & & value $_{o}$ & $\mathrm{CI}_{L}$ & $\mathrm{CI}_{U}$ & value $_{r}$ & $\mathrm{CI}_{L}$ & $\mathrm{CI}_{U}$ & \\
\hline \multicolumn{15}{|l|}{ a) Females } \\
\hline All variables & 0.08 & 0.06 & 0.09 & 0.17 & 0.15 & 0.19 & $<0,001$ & & & & & & & \\
\hline Slope & 0.07 & 0.05 & 0.09 & 0.17 & 0.14 & 0.19 & $<\mathbf{0 , 0 0 1}$ & 27.6 & 25 & 30.4 & 30.3 & 28.3 & 32.5 & 27.2 \\
\hline Road & 0.14 & 0.1 & 0.19 & 0.18 & 0.15 & 0.21 & 0.083 & 685.2 & 500 & 881.9 & 933.2 & 773.3 & 1082.5 & 753.5 \\
\hline $\operatorname{Road}^{2}$ a & 0.1 & 0.07 & 0.14 & 0.13 & 0.11 & 0.16 & 0.065 & 882181.2 & 516408.9 & 1290213 & 2100459.6 & 1616735.8 & 2646104.2 & 1228762.3 \\
\hline Elevation & 0.13 & 0.09 & 0.18 & 0.2 & 0.16 & 0.24 & 0.009 & 1218.9 & 1068.9 & 1361.6 & 1160.3 & 1027.7 & 1290.1 & 1229.3 \\
\hline Elevation $^{2}$ a & 0.09 & 0.07 & 0.12 & 0.18 & 0.15 & 0.21 & $<0,001$ & 1730010.2 & 1399672.5 & 2030865.5 & 1833925 & 1499577.5 & 2170238.3 & 1801842.2 \\
\hline Eastness & 0.22 & 0.14 & 0.3 & 0.2 & 0.16 & 0.24 & 0.98 & 0.1 & -0.1 & 0.3 & 0 & 0 & 0 & 0.2 \\
\hline Northness & 0.17 & 0.09 & 0.26 & 0.19 & 0.15 & 0.23 & 0.35 & 0 & -0.2 & 0.1 & 0 & -0.1 & 0 & -0.1 \\
\hline Landcover & 0.28 & 0.23 & 0.33 & 0.37 & 0.32 & 0.42 & $<0,001$ & & & & & & & \\
\hline Urban & 0.05 & 0.03 & 0.08 & 0.11 & 0.09 & 0.14 & 0.003 & 0.3 & 0.1 & 0.5 & 3.4 & 2.2 & 4.9 & 1 \\
\hline Cultivated & 0.08 & 0.05 & 0.11 & 0.14 & 0.1 & 0.2 & 0.004 & 6.3 & 3.3 & 9.4 & 9 & 6.6 & 11.3 & 6.5 \\
\hline Orchards & 0 & 0 & 0.01 & 0.06 & 0.03 & 0.11 & 0.014 & 0 & 0 & 0 & 3.2 & 1.3 & 5.3 & 0.2 \\
\hline Pastures & 0.14 & 0.04 & 0.28 & 0.16 & 0.09 & 0.24 & 0.05 & 1.2 & 0.2 & 2.6 & 1.3 & 1 & 1.7 & 2.2 \\
\hline Deciduous & 0.17 & 0.1 & 0.25 & 0.19 & 0.13 & 0.26 & 0.375 & 7.8 & 4.8 & 11 & 8.2 & 6.9 & 9.7 & 9.3 \\
\hline Conifer & 0.18 & 0.11 & 0.26 & 0.21 & 0.18 & 0.25 & 0.3 & 27.5 & 18.6 & 37.1 & 23.2 & 19.9 & 27 & 27.8 \\
\hline Mixed & 0.2 & 0.11 & 0.28 & 0.24 & 0.22 & 0.27 & 0.14 & 35 & 26.6 & 44 & 22.3 & 18.8 & 26.1 & 28.4 \\
\hline Shrub & 0.25 & 0.15 & 0.37 & 0.26 & 0.18 & 0.35 & 0.348 & 19.3 & 13 & 25.5 & 15.3 & 12.9 & 17.7 & 18.9 \\
\hline
\end{tabular}




\begin{tabular}{|c|c|c|c|c|c|c|c|c|c|c|c|c|c|c|}
\hline $\mathrm{EV}$ & $\mathrm{ED}_{o}$ & $\mathrm{CI}_{L}$ & $\mathrm{CI}_{U}$ & $\mathrm{ED}_{r}$ & $\mathrm{CI}_{L}$ & $\mathrm{CI}_{U}$ & $\mathrm{p}$ & value $_{o}$ & $\mathrm{CI}_{L}$ & $\mathrm{CI}_{U}$ & value $_{r}$ & $\mathrm{CI}_{L}$ & $\mathrm{CI}_{U}$ & value $_{m}$ \\
\hline Rock & 0.09 & 0.06 & 0.13 & 0.17 & 0.14 & 0.2 & 0.001 & 2.3 & 1.1 & 3.6 & 13.4 & 10.1 & 16.9 & 5.7 \\
\hline Water & 0.15 & 0.07 & 0.24 & 0.17 & 0.1 & 0.25 & 0.159 & 0.3 & 0 & 0.8 & 0.7 & 0.3 & 1.1 & 0 \\
\hline \multicolumn{15}{|l|}{ b) Males } \\
\hline All variables & 0.07 & 0.05 & 0.09 & 0.12 & 0.1 & 0.13 & 0.001 & & & & & & & \\
\hline Slope & 0.06 & 0.04 & 0.08 & 0.11 & 0.09 & 0.13 & 0.001 & 26.6 & 25.2 & 28.1 & 24.6 & 23.8 & 25.5 & 27.2 \\
\hline Road & 0.14 & 0.09 & 0.19 & 0.15 & 0.13 & 0.18 & 0.216 & 932.8 & 713 & 1153.5 & 828.7 & 737.6 & 924.4 & 753.5 \\
\hline $\operatorname{Road}^{2}$ a & 0.09 & 0.05 & 0.14 & 0.12 & 0.1 & 0.14 & 0.114 & 1849135.4 & 1212002.3 & 2640721 & 1765066.5 & 1456894.6 & 2075809.3 & 1228762.3 \\
\hline Elevation & 0.12 & 0.08 & 0.16 & 0.19 & 0.17 & 0.2 & 0.021 & 1153.5 & 1027.4 & 1313.9 & 1223.2 & 1159.5 & 1282.2 & 1229.3 \\
\hline Elevation $^{2}$ a & 0.12 & 0.07 & 0.18 & 0.18 & 0.16 & 0.2 & 0.021 & 1788898.7 & 1413229.8 & 2256754.3 & 2059147.1 & 1858743.3 & 2246211.6 & 1801842.2 \\
\hline Eastness & 0.17 & 0.1 & 0.26 & 0.17 & 0.1 & 0.24 & 0.841 & 0.1 & 0 & 0.1 & 0 & 0 & 0 & 0.2 \\
\hline Northness & 0.19 & 0.14 & 0.24 & 0.17 & 0.13 & 0.2 & 0.216 & 0 & -0.1 & 0 & 0 & 0 & 0 & -0.1 \\
\hline Landcover & 0.25 & 0.21 & 0.3 & 0.29 & 0.26 & 0.32 & 0.123 & & & & & & & \\
\hline Urban & 0.03 & 0.02 & 0.05 & 0.09 & 0.07 & 0.11 & $<0.001$ & 1.6 & 1.2 & 2 & 4.1 & 3.7 & 4.6 & 1 \\
\hline Cultivated & 0.06 & 0.04 & 0.08 & 0.12 & 0.11 & 0.13 & $<0.001$ & 5.6 & 3.8 & 7.8 & 12.6 & 11.4 & 13.9 & 6.5 \\
\hline Orchards & 0.08 & 0.01 & 0.18 & 0.06 & 0.05 & 0.08 & 0.07 & 1.8 & 0.5 & 3.4 & 3.1 & 2.2 & 4.1 & 0.2 \\
\hline Pastures & 0.24 & 0.15 & 0.32 & 0.3 & 0.21 & 0.37 & 0.114 & 2.7 & 1.5 & 4.4 & 2.4 & 2.1 & 2.7 & 2.2 \\
\hline Deciduous & 0.17 & 0.11 & 0.24 & 0.14 & 0.11 & 0.16 & 0.596 & 13 & 8.5 & 18 & 8.9 & 7.7 & 10.1 & 9.3 \\
\hline Conifer & 0.17 & 0.12 & 0.22 & 0.19 & 0.14 & 0.25 & 0.841 & 21.9 & 16.6 & 28.3 & 23.2 & 21.4 & 25.3 & 27.8 \\
\hline Mixed & 0.18 & 0.13 & 0.24 & 0.21 & 0.18 & 0.23 & 0.245 & 24.2 & 18.7 & 29.3 & 17.8 & 15.7 & 19.6 & 28.4 \\
\hline Shrub & 0.21 & 0.16 & 0.27 & 0.17 & 0.14 & 0.21 & 0.43 & 18.5 & 14.4 & 23.6 & 14.4 & 13.3 & 15.6 & 18.9 \\
\hline Rock & 0.15 & 0.08 & 0.24 & 0.15 & 0.13 & 0.18 & 0.245 & 10.1 & 5.2 & 15.3 & 12.8 & 10.6 & 15.2 & 5.7 \\
\hline Water & 0.2 & 0.12 & 0.3 & 0.2 & 0.12 & 0.28 & 0.84 & 0.6 & 0.3 & 1 & 0.6 & 0.4 & 0.9 & 0 \\
\hline
\end{tabular}

${ }^{a}$ quadratic term that allows non-linear selection of roads and elevation 
Table A2.3: Observed and expected least cost paths (LCP) and 95\% confidence intervals (CI) between natal and (alternative) settlement sites for female (a) and male (b) brown bear offspring. LCPs were estimated on resistance surfaces derived from resource selection functions (RSF, left panel) or step selection functions (SSF, right panel). Habitat suitability was translated into resistance using different transformations that are either linear (scaling parameter $\mathrm{c}=0.25$ ) or negative exponential (c $=4,8,16)$.

\begin{tabular}{lllllllll}
\hline & & \multicolumn{3}{c}{$\mathrm{RSF}$} & & \multicolumn{3}{c}{$\mathrm{SSF}$} \\
\cline { 8 - 9 } \cline { 7 - 8 } & $\mathrm{c}$ & $\mathrm{LCP}$ & $\mathrm{CI}_{L}$ & $\mathrm{CI}_{U}$ & & $\mathrm{LCP}$ & $\mathrm{CI}_{L}$ & $\mathrm{CI}_{U}$ \\
\hline a) Females & & & & & & & \\
Offspring & 0.25 & 2023.8 & 1492.9 & 2586.8 & & 1765.3 & 1284.4 & 2286.6 \\
& 4 & 507.4 & 367.7 & 652.2 & & 397 & 289.9 & 510.4 \\
& 8 & 137.9 & 101.7 & 175.6 & & 94.7 & 68.5 & 119.7 \\
& 16 & 62.1 & 43.7 & 79.4 & & 46.1 & 33.2 & 59 \\
Random & 0.25 & 2166.6 & 1992.7 & 2340.6 & & 2025.3 & 1870.4 & 2182.6 \\
& 4 & 609.7 & 552.8 & 670.6 & & 525.5 & 478.9 & 575.7 \\
& 8 & 175.3 & 157 & 194.1 & & 135.2 & 123 & 148 \\
& 16 & 77.8 & 67.1 & 89.6 & & 60.2 & 54.6 & 66.4 \\
b) Males & & & & & & & \\
& & & & & & & & \\
& 0.25 & 11523.3 & 6733.9 & 17916.1 & & 15079.5 & 8665.8 & 23928 \\
& 4 & 2576.8 & 1436.1 & 3877.6 & & 4508.3 & 2521.4 & 6955.5 \\
& 8 & 713.7 & 413.3 & 1066.2 & & 1182.2 & 589.5 & 1905.4 \\
& 16 & 369.8 & 210.6 & 581.9 & & 347.7 & 186.6 & 579.5 \\
Random & 0.25 & 9672.7 & 8873.2 & 10438.9 & & 12710.2 & 11694.4 & 13796.8 \\
& 4 & 2431.9 & 2231.7 & 2666.2 & & 4057.2 & 3718 & 4371.7 \\
& 8 & 696.4 & 634.4 & 757.9 & & 1041.6 & 958.5 & 1124.1 \\
& 16 & 334.5 & 304.5 & 367.5 & & 314.6 & 290.8 & 340.1 \\
& & & & & & & \\
\hline
\end{tabular}


CHAPTER 3

\title{
A plea for simultaneously considering matrix quality and local environmental conditions when analyzing landscape impacts on effective dispersal
}

This chapter is published as:

Pflüger, F.J and Balkenhol, N. (2014). A plea for simultaneously considering matrix quality and local environmental conditions when analysing landscape impacts on effective dispersal. Molecular Ecology, 23(9): 2146-2156.

\begin{abstract}
Landscape genetics has tremendous potential for enhancing our understanding about landscape effects on effective dispersal and resulting genetic structures. However, the vast majority of landscape genetic studies focuses on effects of the landscape among sampling locations on dispersal (i.e., matrix quality), while effects of local environmental conditions are rather neglected. Such local environmental conditions include patch size, habitat type, or resource availability and are commonly used in (meta-) population ecology and population genetics. In our opinion, landscape genetic studies would greatly benefit from simultaneously incorporating both matrix quality and local environmental conditions when assessing landscape effects on effective dispersal. To illustrate this point, we first outline the various ways in which environmental heterogeneity can influence different stages of the dispersal process. We then propose a three-step approach for assessing local and matrix effects on effective dispersal, and re-
\end{abstract}


view how both types of effects can be considered in landscape genetic analyses. Using simulated data, we show that it is possible to correctly disentangle the relative importance of matrix quality versus local environmental conditions for effective dispersal. We argue that differentiating local and matrix effects in such a way is crucial for predicting future species distribution and persistence, and for optimal conservation decisions that are based on landscape genetics. In sum, we think it is timely to move beyond purely statistical, pattern-oriented analyses in landscape genetics, and towards process-oriented approaches that consider the full range of possible landscape effects on dispersal behavior and resulting gene flow.

Keywords: behavioural mechanisms, carrying capacity, effective distance, habitat (dis-)similarity, landscape connectivity, metapopulation connectivity index

\section{Introduction}

Landscape genetics aims to provide information about the interaction between landscape features and microevolutionary processes, such as gene flow, genetic drift, and selection (Manel et al., 2003; Storfer et al., 2007). The majority of current landscape genetics studies focuses on assessing 'functional connectivity', or the degree to which landscapes between habitats or populations facilitate or impede dispersal movements and gene flow of study organisms (Holderegger and Wagner, 2008). Dispersal is one of the key mechanisms linking microevolutionary processes to landscape patterns, and since genetic data

reflect only those dispersal movements that result in successful breeding (Broquet and Petit, 2009), landscape genetics is particularly well-suited for assessing landscape influences on effective dispersal. Understanding these landscape impacts on effective dispersal is crucial for many research questions in ecology, evolution, and conservation, because dispersal affects the demography of connected populations, their evolution, or both (Lowe and Allendorf, 2010). Consequently, a growing number of published studies use genetic approaches to infer landscape impacts on effective dispersal, and results from such studies are increasingly used to guide practical management and conservation (Epps et al., 2007; Beier et al., 2008; Cushman et al., 2008).

While landscape genetics clearly has tremendous potential for enhancing our understanding of effective dispersal in heterogeneous environments, we are worried that too few current landscape genetic studies fully 
consider the multiple ways in which environmental heterogeneity influences dispersal behavior and resulting gene flow patterns. Specifically, environmental heterogeneity can be defined as the spatially and temporally varying abundance and quality of constraining biotic and abiotic factors (e.g., habitats or resources; Wiens, 2000). From a landscape ecological standpoint, such environmental heterogeneity exists at or around sampling locations ('local environmental conditions'), but also among locations ('matrix quality'). For example, local environmental conditions include patch size, habitat type, or availability of resources within a certain area. On the other hand, matrix quality among locations depends on the properties and spatial arrangement of non-habitat elements or on the number of landscape features that presumably constrain dispersal movements among habitats (e.g., putative barriers, such as roads or rivers).

The vast majority of current landscape genetic studies emphasize the effects of matrix quality on dispersal and resulting genetic structures (Storfer et al., 2010). For this, researchers usually estimate effective distances that account for hypothesized impacts of varying matrix quality on successful dispersal among sampling units (i.e., individuals or populations). Effective distances are then statistically compared to genetic measures of connectivity, such as genetic distances, indices of genetic differentiation, genetically-estimated emi- and immigration rates, or direct identification of migrants via assignment methods. By comparing these genetic data to effective distances, researchers can then test their hypotheses about the effects of matrix quality on effective dispersal. Much effort is put into identifying the best model of matrix quality for such analyses, and many landscape genetic studies have demonstrated an influence of matrix quality on effective dispersal and spatial genetic structure (Coulon et al., 2004; Broquet et al., 2006; Wang, 2013).

Unfortunately, the potential influences of local environmental conditions on dispersal and genetic structures have received less consideration in landscape genetics. In contrast, research in (meta-) population ecology and genetics focuses more on the effects of local environmental conditions on population dynamics and connectivity, but these studies often neglect the potential influences of matrix quality on dispersal-mediated connectivity (Geffen et al. 2004: Busch et al. 2009, Roy et al., 2012). It seems that there is a substantially underdeveloped link between 'classic' population genetics, which focuses on effect of the local factors, and landscape genetics, which mostly focuses on effects found among locations. In our opinion, this severely limits our ability to 
fully elucidate the effects of environmental heterogeneity on effective dispersal using genetic approaches. However, understanding the influences of environmental heterogeneity on effective dispersal is vital for accurate inferences about eco-evolutionary population dynamics(Vuilleumier et al., 2010, Hanski, 2012).

Here, we make a plea for a more rigorous and simultaneous consideration of both matrix quality and local environmental conditions when analyzing landscape effects on dispersal. To motivate our plea, we first briefly review the different stages of the dispersal process, including emigration, transience and immigration. We then outline how each stage can be influenced by environmental heterogeneity and highlight that focusing either on local environmental conditions or matrix quality is unlikely to truly enhance our understanding of effective dispersal in heterogeneous environments. We then present selected studies that have used various analytical approaches to simultaneously consider both types of effects. We propose a three-step approach for combining local factors and matrix quality, and use simulated data to demonstrate the applicability of meta-population connectivity indices for evaluating the relative importance of local conditions versus matrix quality for effective dispersal. Finally we emphasize the importance of considering different environmental effects on dispersal for research on source-sink dynamics and corridor design.

\section{Rethinking environmental effects on dispersal}

Dispersal is a life-history process that is shaped by its fitness cost and benefits due to spatio-temporally varying environments, kin competition and inbreeding avoidance (Hamilton and May, 1977; Gandon, 1999, Matthysen, 2012). Moreover, dispersal is also a multi-stage process consisting of the stages of emigration, transience and immigration (Baguette et al., 2007; Clobert et al., 2009). In the first 'departure' or 'emigration' stage, individuals leave their current location to avoid local fitness costs or to obtain fitness benefits elsewhere, for example by seeking areas with reduced competition for resources or between kin. Second, during the 'transfer' or 'transience' stage, a moving animal has to decide where to move (e.g., direction and distances) and how to move there (e.g., navigation and movement path selection; (Nathan et al., 2008). In this stage, costs such as mortality risk or energetic expenses are linked to the movement itself, e.g. as a function of distance (Bonte et al., 2012). Finally, in the third 'immigration' or 'settlement' stage, an individual either stays at the new location or moves on, which will again depend on the fitness prospects under the current local conditions. Importantly, these three different stages of 
dispersal are influenced by environmental heterogeneity in different ways, as we will show in the following sections.

\section{Environmental influences on emigration}

The quality of a habitat and the local availability of resources are important factors triggering emigration, because dispersing animals are generally more likely to leave habitats of lower quality or with limited resources (Bonte et al., 2008; Mathieu et al., 2010). More specifically, effects of local habitat quality and resource abundance interact with population density, which in turn can influence dispersal through either increased or decreased competition. Such density-dependent dispersal behavior is well-documented in the ecological literature and common across vertebrate species (reviewed in Matthysen, 2005). Generally, individuals show a greater tendency to emigrate out of areas with high local densities, in order to avoid fitness costs associated with intra-specific competition (Travis et al., 1999, Clutton-Brock et al., 2002). For example, higher densities in black bears (Ursus americanus) force males to leave their current habitat in order to reduce mate competition, leading to increased emigration rates (Costello et al., 2008). Thus, higher rates of dispersal can be expected to occur from high density areas to low density areas (Fig. 3.1A). Such density-dependent emigration behavior is shaped by the ratio of local population size $(N)$ to local carrying capacity $(K)$, with $K$ reflecting 'the number of animals that a habitat can maintain' (Dasmann, 1964). As $N$ reaches or exceeds $K$, an increasing number of individuals can be expected to emigrate out of a local population, because fitness costs via competition are increasing. Importantly, carrying capacity is largely determined by local environmental conditions, because these conditions determine the abundance and distribution of resources, such as food, cover, nesting sites etc. Thus, local environmental conditions can be expected to strongly affect emigration behavior via density-dependence.

\section{Environmental influences on transience}

The composition and configuration of the landscape matrix can influence individual movement decisions and impact the immediate and future fitness of dispersing individuals (Fig. 3.1B; Wiens, 2001). For example, individuals adjust their actual movement paths according to physical landscape features such as linear landscape elements and barriers, such as roads or habitat boundaries (Doncaster et al., 2001, Hein et al., 2003), or according to other environmental 
cues that either attract or repel individuals (e.g., perceived predation risk or competition; Russell et al., 2007; Clobert et al., 2009). Furthermore, the environment that dispersing individuals experience during transience will directly impacts their survival. For example, effective dispersal in amphibians can be substantially reduced across dry, open areas, because these species are highly susceptible to mortality through desiccation while dispersing (e.g., Spear et al. 2012 ). Hence, the transience phase is essentially influenced by a heterogeneous cost-benefit landscape that depends on behavioral, morphological, and physiological constraints (i.e., phenotypic plasticity). The response of animals to this cost-fitness balance will determine individual dispersal success and gene flow.

\section{Environmental influences on immigration}

The decision to immigrate into a certain area is affected by habitat preferences of dispersing individuals. Under natal habitat preference induction (NHPI), these habitat preferences are influenced by experiences that individuals made as juveniles (Davis and Stamps, 2004) assuming that individuals have higher fitness performance in habitats that are familiar to them (Stamps, 2001). Specifically, the resources that animals were exposed to in their natal habitat (i.e., the habitat in which they were born and raised) provide individuals with environmental cues that influence their future decisions to move into and settle in a certain location. For example, dispersing Siberian flying squirrels (Pteromys volans) and brush mice (Peromyscus boylii) actively choose between different habitats types and prefer to settle in habitats that are compositionally and structurally similar to their natal habitat (Selonen et al., 2007; Mabry and Stamps, 2008). Thus, dispersal rates under NHPI depend on the degree of compositional and structural similarity between natal and alternative environmental conditions (Davis and Stamps, 2004), with higher environmental similarity promoting dispersal, and lower similarity constraining it (Fig. 3.1C). In addition to such habitat-dependent settlement behavior, local population densities can also affect immigration, because dispersing individuals often prefer to immigrate into areas with lower population size relative to carrying capacity, as such areas promise the lowest fitness costs due to intra-specific competition. For example, root voles (Microtus oeconomus) immigrating into lower density patches have higher immigration success in terms of survival, rate of sexual maturation and body growth (Gundersen et al., 2002).

In sum, the three stages of dispersal are all influenced by environmen- 

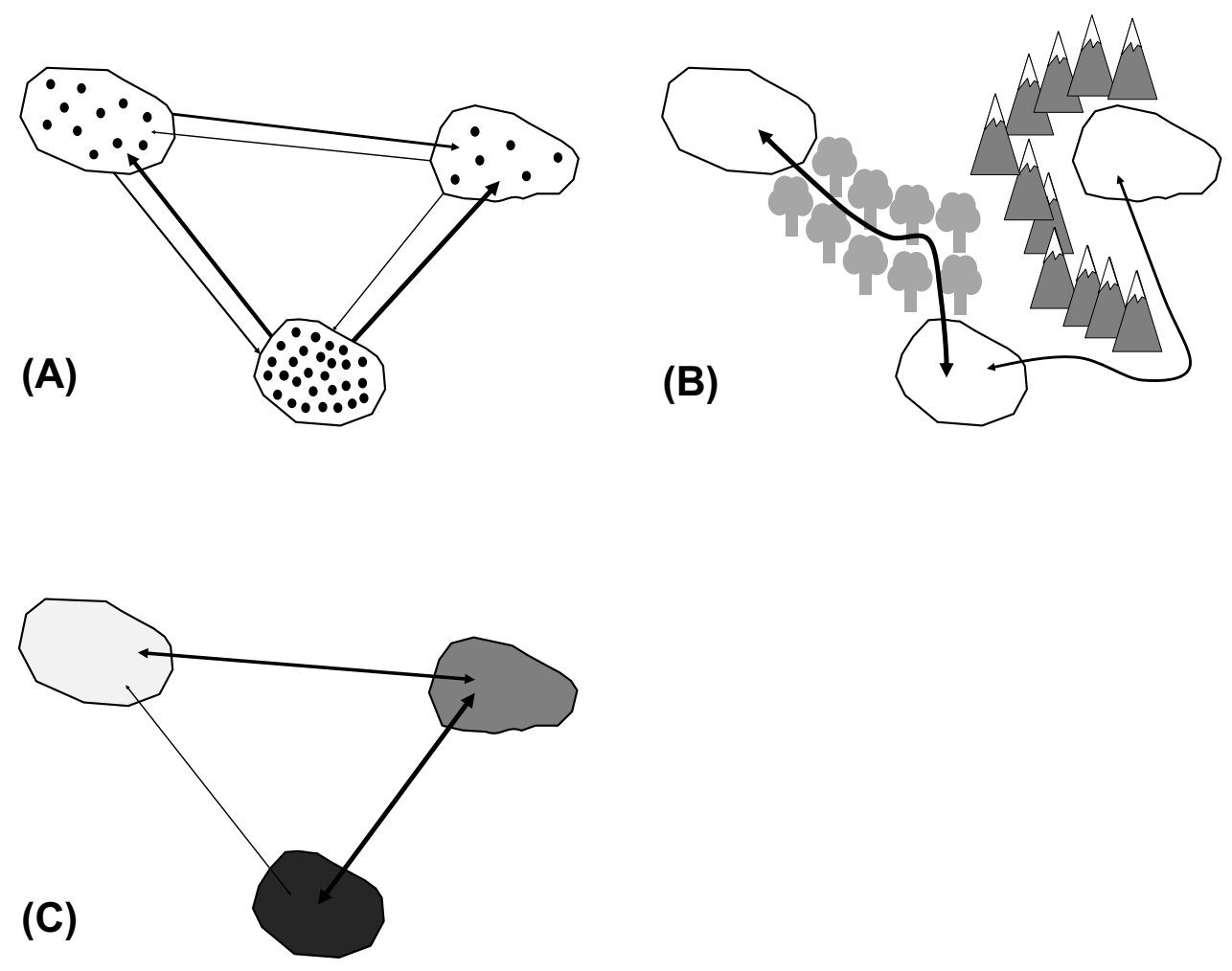

Figure 3.1: Possible effects of environmental heterogeneity on dispersal behaviour and resulting levels of effective dispersal. In each panel, polygons represent habitat patches, while arrows represent dispersal, with thicker arrows indicating higher expected levels of effective dispersal. (A) Local population densities are dependent on local carrying capacities and represented by the number of black dots. Under positive density-dependence, individuals preferably disperse from high-density populations to low-density populations. (B) Dispersing individuals adjust their movements according to matrix quality among populations. Thus, higher levels effective dispersal can be expected where dispersal is facilitated (e.g. by a corridor), while lower levels can be expected when landscape features hinder dispersal (e.g. mountain range). (C) Grey shading of patches represents local environmental conditions, with a different shade for each type of environmental conditions. Under natal habitat preference induction (NHPI), higher levels of effective dispersal can be expected among more similar patches, because individuals prefer to disperse into areas similar to their natal habitat. Note that matrix quality affects the transience stage of dispersal only in scenario $\mathrm{B}$, while local environmental conditions affect emigration and immigration behaviour in scenarios $\mathrm{A}$ and $\mathrm{C}$.

tal heterogeneity, and these environmental effects occur either locally (emiand immigration stage) or among locations (transience). Thus, the effective distance approach currently emphasized in landscape genetics considers only the effects of matrix quality on the transience stage of dispersal, while metapopulation genetic studies largely focus on the effects of local environmental conditions on emi- and immigration. In the next section, we illustrate how we can simultaneously consider both local environmental conditions and matrix 
effects when analyzing landscape effects on all stages of realized dispersal.

\section{Simultaneous consideration of landscape resistance and local envi- ronmental conditions}

We propose a simple, three-step procedure to simultaneously account for local environmental conditions and matrix effects. The procedure can be used with typically available data sets encompassing spatial-genetic and landscape data, and can be applied to population- and individual-level analyses.

\section{Step 1: Quantify matrix quality among sampling locations}

This is the step commonly conducted in landscape genetics, and it usually involves the estimation of effective distances among sampled individuals or populations. For this, researchers create 'resistance surfaces' from digital GISlayers representing vegetation type, elevation, water or anthropogenic factors (Sawyer et al., 2011). The resistance surfaces represent the willingness or ability of the study organism to move through a particular environment (Zeller et al., 2012), and assume that landscapes units (usually grid cells on a raster map) differ in permeability for the dispersing animal (Ricketts, 2001; Wiegand et al., 1999). Effective distances are then estimated from these resistance surfaces, for example using least-cost or circuit-theoretic algorithms Adriaensen et al., 2003, McRae, 2006). By correlating various effective distances against genetic estimates of connectivity, researchers can then identify the landscape resistance model that statistically best fits the empirical genetic data (Shirk et al., 2010). A review of resistance modeling approaches is beyond our scope, but can be found in Spear et al. (2010). Alternatively, matrix characteristics can be quantified within transects or along straight lines among sampling locations (Van Strien et al., 2012), or by assessing whether sampling locations are separated by putative barriers (Etherington, 2011).

Step 2: Quantify local environmental conditions and convert them into meaningful variables

In addition to matrix quality among locations, we need to quantify relevant environmental variables at, around, or within sampling locations (Wagner and Fortin, 2013). For population-level analyses, this is relatively straightforward, as estimates of local environmental conditions (e.g., habitat suitability, resource availability) can be obtained within the patch or area occupied by each 
population. However, local environmental conditions can also be considered in individual-based landscape genetic studies, which focus on genetic structures within populations. Such analyses are particularly meaningful in gradient landscapes, where subpopulations or discrete habitat patches cannot be delineated (Cushman et al., 2006). In such studies, local environmental heterogeneity can be measured within ecological neighborhoods that reflect home ranges or assumed perceptual ranges (Fig. 3.2).

When no meaningful ecological neighborhood can be delineated a priori, several different radii can simply be used to quantitatively find the optimal scale that best captures effects of the local environment on genetic structure. Furthermore, ecological neighborhoods can be adjusted based on known connectivity barriers in the landscape, such as impermeable rivers or roads. As shown in Figure 3.2, quantifying environmental conditions within ecological neighborhoods is possible even if individuals are only represented by a single spatial location, as is commonly the case in current landscape genetic studies. Clearly, such analyses will require very fine-scale environmental data to be meaningful, and we are aware that acquiring such data through field mapping or high-resolution remote sensing remains financially and logistically challenging. However, we are convinced that improved technology in conjunction with an increased interest in fine-scale environmental data will soon alleviate this current challenge, at least for some studies.

After quantifying local environmental conditions, we need to convert these data into variables that reflect our hypotheses about how local environmental conditions affect dispersal behavior and individual fitness (i.e., survival and reproduction). For example, to test for density dependence, data on local resource availability can be converted into estimates of area-weighted habitat quality. A positive correlation between local habitat quality and geneticallyestimated emigration rates would indicate that individuals preferably disperse out of locations with high potential densities.

Similarly, to test for NHPI, environmental (dis-) similarities can be calculated that compare environmental conditions found locally Legendre and Legendre, 2012). Under NHPI, a significantly negative relationship can be expected between genetic distances and environmental similarities (i.e., individuals inhabiting similar environments should also be genetically more similar). 


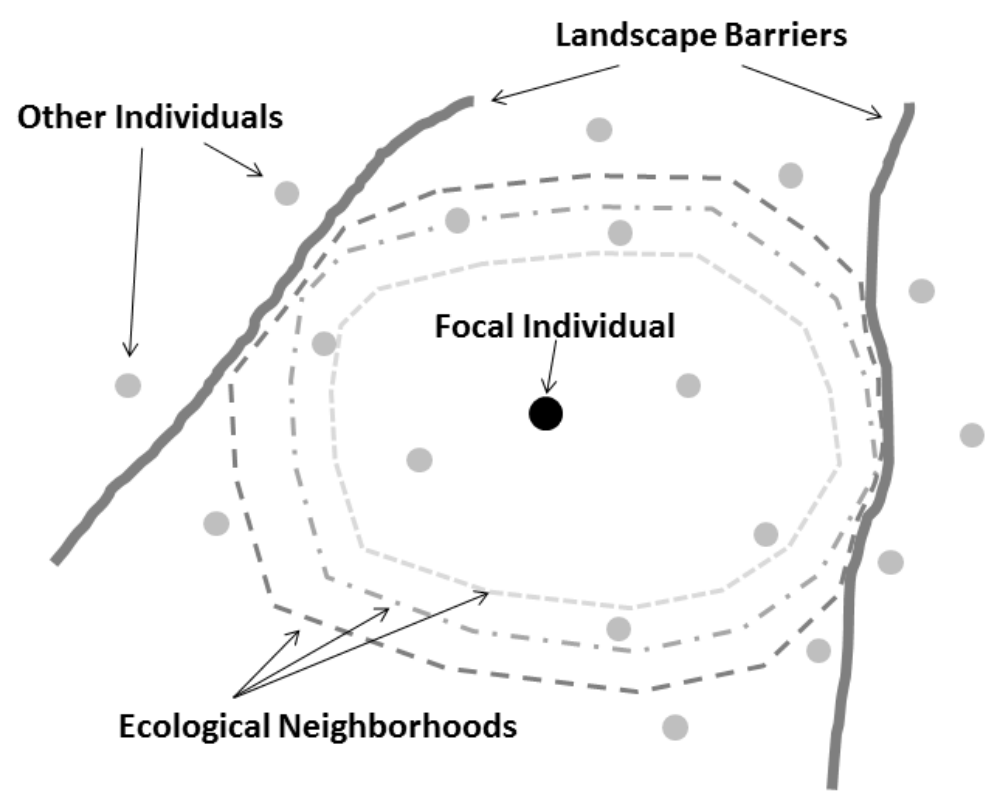

Figure 3.2: Quantifying local environmental conditions in individual-based studies. The black dot is the sampling location of a single individual for which genetic data are available. The three dashed lines represent ecological neighbourhoods of varying size and could be based on average home ranges sizes, perceptual ranges, etc. Environmental heterogeneity is quantified within these neighbourhoods. The grey dots resemble sampling locations of other individuals and could be used to estimate density within the local neighbourhood. Note that assumed or known landscape barriers to dispersal (thick grey lines) can be used to adjust the boundaries of the neighbourhoods.

\section{Step 3: Combine landscape resistances and local environmental variables}

Once data on local environmental conditions and matrix quality are available, they have to be combined for meaningful analyses. There are several different options available for this, as illustrated by a few studies that have already simultaneously considered both local environmental conditions and matrix quality (Table 3.1). For example, Murphy et al. (2010) used network-based gravity models to simultaneously assess the effects of matrix quality (i.e. permeability of meadows and forests, topographic morphology, temperature-moisture regime) and local environmental variables (within-patch quality; i.e. site productivity, predator presence) on functional connectivity in Columbia spotted frogs (Rana luteiventris). In the context of effective dispersal, gravity models include local factors that influence emi- and immigration (i.e., site-specific attraction/ productivity) and factors that influence successful movement among locations (i.e., spatial and effective distances). Using the gravity model approach, Murphy et al. (2010) were able to identify source-sink dynamics among the studies ponds, and showed that gene flow was best explained by models 
that included both matrix and pond-specific variables.

Using a different analytical approach, Wang et al. (2013) quantified the relative contribution of ecological and geographic isolation to genetic differentiation among 17 Anolis lizard species. For this, geographic isolation was measured via effective distances calculated from a resistance model, while isolation-by-environment (IBE) was measured via environmental dissimilarities that reflect differences in local environmental conditions among sampling locations. Both effective distances and environmental dissimilarities were then used in structural equation models, which highlighted that genetic differentiation in all species was affected by both matrix quality and local environmental conditions, and not just by either one of these factors.

Wang (2013) investigated a similar research question and used multiple regression of distance matrices to assess the effects of isolation-by-distance (IBD) and IBE (again expressed in terms of environmental dissimilarities) on genetic differentiation in four frog species (see Table 3.1). He found that IBD explained observed patterns of genetic differentiation in all study species, but that IBE also had a significant influence on genetic differentiation in two of the four species.

In a study of woodland caribou (Rangifer tarandus), Weckworth et al. (2013) included effective distances based on resistance models and also local effective population sizes $\left(N_{\mathrm{e}}\right)$ as variables that could explain genetic structure. Results showed that population genetic structure was best explained by $N_{\mathrm{e}}$ and a resistance model based on preferred habitat availability. Importantly, Weckworth et al. (2013) concluded that a lack of effective migrants among some studied populations might be due to a synergistic relationship between declining population size and density-dependent dispersal behavior.

Even though these studies did not focus on effective dispersal per se, they all demonstrate that it is possible to simultaneously include matrix quality and local environmental conditions in landscape genetic research. Moreover, all of the mentioned studies showed that both types of effects are important for explaining gene flow and spatial genetic structure in various species. Thus, the analytical frameworks used by these studies could also provide a first step towards gaining a more comprehensive understanding of effective dispersal in heterogeneous environments. To further illustrate this, we next use simulated data to show how another analytical option based on metapopulation connectivity indices can help to assess the relative importance of local environmental 
conditions versus matrix quality for effective dispersal.

Table 3.1: Overview of studies that incorporated both local variables and matrix quality to assess environmental influences on dispersal and genetic structure.

\begin{tabular}{|c|c|c|c|c|}
\hline Author(s) & Species & $\begin{array}{l}\text { Statistical } \\
\text { approach }\end{array}$ & Local variables & Matrix variables \\
\hline $\begin{array}{l}\text { Murphy et } \\
\text { al. } 2010\end{array}$ & $\begin{array}{l}\text { Columbia } \\
\text { spotted frog } \\
\text { (Rana } \\
\text { luteiventris) }\end{array}$ & $\begin{array}{l}\text { Network-based } \\
\text { gravity models }\end{array}$ & $\begin{array}{l}\text { Patch quality } \\
\text { (site } \\
\text { productivity, } \\
\text { predator } \\
\text { presence) }\end{array}$ & $\begin{array}{l}\text { Effective distances } \\
\text { accounting for varying } \\
\text { permeability of } \\
\text { meadows and forests, } \\
\text { topographic } \\
\text { morphology, } \\
\text { temperature-moisture } \\
\text { regime }\end{array}$ \\
\hline $\begin{array}{l}\text { Wang et } \\
\text { al. } 2013\end{array}$ & $\begin{array}{l}\text { Anolis lizards } \\
\text { (17 species) }\end{array}$ & $\begin{array}{l}\text { Structural } \\
\text { equation model } \\
\text { (SEM) }\end{array}$ & $\begin{array}{l}\text { Climate, } \\
\text { vegetation, } \\
\text { elevation } \\
\text { (environmental } \\
\text { dissimilarity) }\end{array}$ & $\begin{array}{l}\text { Effective distances } \\
\text { estimated from a } \\
\text { niche suitability } \\
\text { model }\end{array}$ \\
\hline $\begin{array}{l}\text { Wang } \\
2013\end{array}$ & $\begin{array}{l}\text { Red-eyed tree } \\
\text { frog (Agalychnis } \\
\text { callidryas), } \\
\text { hourglass } \\
\text { treefrog } \\
\text { (Dendropsophus } \\
\text { ebraccatus), } \\
\text { strawberry } \\
\text { poison frog } \\
\text { (Dendrobates } \\
\text { pumilio), } \\
\text { Yosemite toad } \\
\text { (Bufo canorus) }\end{array}$ & $\begin{array}{l}\text { Multiple } \\
\text { regression on } \\
\text { distance } \\
\text { matrices }\end{array}$ & $\begin{array}{l}19 \text { bioclimatic } \\
\text { variables, } 4 \\
\text { vegetation } \\
\text { variables (leaf } \\
\text { area, } \\
\text { vegetation, tree } \\
\& \text { herbaceous } \\
\text { density) (= } \\
\text { environmental } \\
\text { distances) }\end{array}$ & $\begin{array}{l}\text { Effective distances } \\
\text { accounting for } \\
\text { topography and } \\
\text { species-specific } \\
\text { habitat resistance }\end{array}$ \\
\hline $\begin{array}{l}\text { Weckworth } \\
\text { et al. } 2013\end{array}$ & $\begin{array}{l}\text { Woodland } \\
\text { caribou (Rangifer } \\
\text { tarandus) }\end{array}$ & $\begin{array}{l}\text { Simple \& } \\
\text { partial Mantel } \\
\text { tests }\end{array}$ & $\begin{array}{l}\text { Effective } \\
\text { population size }\end{array}$ & $\begin{array}{l}\text { Effective distance } \\
\text { based on a habitat } \\
\text { suitability model that } \\
\text { included multiple } \\
\text { topographic, climatic } \\
\text { and vegetative factors, } \\
\text { as well as predation } \\
\text { and anthropogenic } \\
\text { footprints }\end{array}$ \\
\hline
\end{tabular}

\section{Evaluating the relative importance of local environmental conditions and matrix quality}

We believe that metapopulation connectivity indices are particularly interesting for combining local and between-location environmental data in landscape genetics (e.g., Keyghobadi et al., 2005). These indices include local patch characteristics as well as inter-patch data (i.e., geographic distances) to describe the effective isolation of populations (Hanski, 1994), and could ultimately link landscape genetic patterns to metapopulation dynamics and persistence. For example, an extended metapopulation connectivity index suggested by (Moila- 
nen and Nieminen, 2002) can be calculated as:

$$
S_{i}=A_{i} * \sum\left[\exp \left(-k d_{i j}\right) * A_{j}\right]
$$

where $S_{\mathrm{i}}$ is the connectivity of patch $i, A_{\mathrm{i}}$ is a characteristic of patch $i$ (usually its size), $A_{\mathrm{j}}$ is the same characteristic for another patch $j, d_{\mathrm{ij}}$ is the distance between the two patches, summation is across all patches $j$, with $j \neq i$, and $k$ is a scaling parameter related to the average dispersal distance of the study species. Rather than using patch size, $A$ could be replaced by area-weighted habitat quality, carrying capacity, or any other estimate related to environmental effects on density-dependent dispersal behavior. Similarly, instead of using straight-line inter-patch distances, $d_{\mathrm{ij}}$ can be replaced by effective distances obtained from resistance models, to reflect environmental effects on dispersal movements during transience (Moilanen and Hanski, 1998). Furthermore, an additional distance reflecting environmental (dis-) similarity can be incorporated into connectivity indices to account for possible effects of NHPI. Thus, different indices can be used to reflect varying hypotheses about how environmental heterogeneity at or among populations influences individual dispersal behavior and resulting genetic structures. By making connectivity indices a function of different combinations of local and among-location estimates of environmental heterogeneity, the relative importance of the different factors can be evaluated, for example within an information-theoretic model selection framework. This makes it possible to use a coherent statistical framework for assessing the relative importance of multiple effects of environmental heterogeneity on dispersal and resulting population connectivity (e.g., landscape resistance, density-dependence, and NHPI; Table 3.2). This approach treats genetic connectivity as the dependent variable rather than an explanatory variable, as is commonly done in metapopulation studies (Goodwin, 2003). Thus, the approach we suggest emphasizes the environmental causes of successful dispersal, rather than the effects that assumed connectivity has on population dynamics (e.g., patch occupancy, re-colonization).

\section{An illustration using simulated data}

To illustrate the multi-model analytical approach involving different metapopulation connectivity indices, we performed individual-based simulations in QuantiNemo Neuenschwander et al., 2008, details on the simulations can be found in the Appendix A3.1). QuantiNemo simulates gene flow among popu- 
Table 3.2: Multi-model analytical framework for assessing environmental effects on effective dispersal through the use of different connectivity indices. The dependent data are (genetic) estimates of effective dispersal among sampling locations, for example genetic distances or migration rates. Note that 'habitat quality' can also refer to estimates of carrying capacity or local densities. " $f$ " reads "function of".

\begin{tabular}{lll}
\hline Dependent data & Connectivity index & Modelled effects \\
\hline Effective dispersal $=$ & $f$ (effective distance) & Landscape resistance \\
Effective dispersal $=$ & $f$ (habitat quality) & Density dependence \\
Effective dispersal $=$ & $f$ (habitat similarity) & $\begin{array}{l}\text { Natal habitat preference } \\
\text { induction (NHPI) }\end{array}$ \\
Effective dispersal $=$ & $f$ (effective distance, habitat & $\begin{array}{l}\text { Landscape resistance }+ \\
\text { quality) }\end{array}$ \\
Effective dispersal $=$ & $\begin{array}{c}\text { Density dependence } \\
\text { (effective distance, habitat } \\
\text { similarity) }\end{array}$ & Landscape resistance + NHPI \\
Effective dispersal $=$ & $\begin{array}{c}\text { (effective distance, habitat } \\
\text { quality, habitat similarity) }\end{array}$ & $\begin{array}{l}\text { Landscape resistance }+ \\
\text { Density dependence }+ \text { NHPI }\end{array}$ \\
\hline
\end{tabular}

lations as a function of user-defined population sizes and inter-population emiand immigration rates. We created these migration rates in three ways, reflecting different scenarios of environmental impacts on effective dispersal. In the first scenario, migration rates were only influenced by density-dependent dispersal behavior. For this, we modeled migration rates through a logistic function that leads to positive density-dependence. Using this function, populations with a higher $N / K$ ratio (i.e., higher local population densities) will experience greater emigration, and lower immigration rates. For this scenario, we varied local carrying capacities from 50 to 160 individuals, with an initial local population size of 100 individuals in each population (see supplement for details). This reflects a situation where effective dispersal is affected by local environmental conditions, but not by matrix quality among locations.

In the second scenario, we simulated migration rates as a function of effective distances among populations, again containing 100 individuals, but did not vary local carrying capacities (i.e., same local density in all populations). This scenario reflects a situation where effective dispersal is affected by matrix quality among locations, but not by local environmental conditions.

Finally, in the third scenario, we simulated migration rates as a function of both density-dependent dispersal and effective distances, which reflects a scenario where both matrix quality and local environmental conditions affect dispersal.

In all scenarios, we simulated genetic data at 15 neutral genetic markers (i.e., microsatellites) for 12 populations and 20 generations. Resulting ge- 
netic data sets were used to calculate pairwise $F_{\mathrm{ST}}$ values (Wright 1965) as a measure of inter-population dispersal, and the average of these $F_{\mathrm{ST}}$ values was calculated for each population. This results in a unique, population-specific $F_{\mathrm{ST}}$ value for each population that reflects the genetic differentiation of a subpopulation to all other subpopulations (see also Gaggiotti and Foll, 2010). The population-specific $F_{\mathrm{ST}}$ values obtained for each scenario were then modeled as function of three different metapopulation connectivity indices $S$ for each subpopulation $i$ :

$$
\begin{gathered}
S_{i}=C_{i} \\
S_{i}=\sum\left[\exp \left(-k d_{i j}\right)\right] \\
S_{i}=C_{i} * \sum\left[\exp \left(-k d_{i j}\right)\right]
\end{gathered}
$$

where $C_{\mathrm{i}}$ is the local carrying capacity of focal population $i, d_{\mathrm{ij}}$ is the effective distance between focal population $i$ and population $j$, summation is across all subpopulations $(j \neq i)$, and $k$ is a scaling parameter related to average dispersal distance (see Appendix A3.1 for details). The first index reflects the hypothesis that effective dispersal and resulting genetic differentiation are determined by local carrying capacity only, while the second index corresponds to the hypothesis that genetic connectivity is solely dependent on matrix quality among populations. Finally, the third index assumes that carrying capacity and matrix quality interact in shaping genetic structures of the metapopulation.

Note that the population-specific $F_{\mathrm{ST}}$ values, as well as the connectivity indices, combine pairwise data into unique values for each subpopulation, so that there is no issue of non-independent data usually encountered with pairwise data. This also means that we can use simple linear regression and an information-theoretic approach (i.e., AIC values) to identify the best model for each scenario. As shown in Table 3.3, this analytical framework is able to correctly identify the connectivity index that best reflects the simulated environmental effects on dispersal in all three scenarios. Thus, we would have correctly concluded that effective dispersal is only influenced by densitydependence in scenario 1 , only by matrix resistance in scenario 2 , and by both factors in scenario 3.

In sum, using metapopulation indices in the suggested way is a promis- 
ing approach for identifying the relative importance of local environmental conditions versus matrix quality in landscape genetic studies.

Table 3.3: Modelling results for the three simulated scenarios. Population-specific $F_{\mathrm{ST}}$ values obtained for each scenario were modelled as function of the three different connectivity indices listed in column 1 . For each model, adjusted R-square $\left(A d j . R^{2}\right)$, AIC adjusted for small sample sizes $(A I C c)$, as well as $\triangle A I C c$ values are shown. The best model for each scenario is highlighted in bold.

\begin{tabular}{|c|c|c|c|c|c|c|c|c|c|}
\hline \multirow[b]{3}{*}{$\begin{array}{l}\text { Connectivity index } \\
\text { (=explanatory } \\
\text { variable) }\end{array}$} & \multicolumn{9}{|c|}{ Scenario } \\
\hline & \multicolumn{3}{|c|}{ Carrying capacity only } & \multicolumn{3}{|c|}{ Effective distance only } & \multicolumn{3}{|c|}{$\begin{array}{l}\text { Carrying capacity \& } \\
\text { effective distance }\end{array}$} \\
\hline & Adj. $R^{2}$ & $A I C c$ & $\triangle A I C c$ & $\operatorname{Adj} . R^{2}$ & $A I C c$ & $\triangle A I C c$ & Adj. $R^{2}$ & $A I C c$ & $\triangle A I C c$ \\
\hline$C_{\mathrm{i}}$ & 0.54 & -69.9 & 0.00 & -0.04 & -79.03 & 10.75 & 0.24 & -78.54 & 0.27 \\
\hline$\sum\left[\exp \left(-k d_{i j}\right)\right]$ & 0.1 & -61.82 & 8.09 & 0.58 & -89.78 & 0.00 & 0.23 & -78.38 & 0.43 \\
\hline$C_{\mathrm{i}} * \sum\left[\exp \left(-k d_{i j}\right)\right]$ & 0.35 & -65.68 & 4.23 & 0.1 & -80.77 & 9.01 & 0.26 & -78.8 & 0.00 \\
\hline
\end{tabular}

\section{Relevance of simultaneous analyses for landscape genetic inferences}

The simultaneous analyses illustrated above are not only interesting from a methodological standpoint, but can greatly improve the reliability and meaningfulness of landscape genetic inferences. Since landscape genetics currently focuses largely on effects of matrix quality, we next provide two examples of research where a simultaneous consideration of local environmental effects and their interplay with behavioral mechanisms, such as density-dependent dispersal and natal habitat preference induction (NHPI), is particularly important.

\section{Effects of density-dependent dispersal on source-sink and range dynamics}

Neglecting local environmental influences on density-dependent dispersal makes it challenging to understand the emergence of certain ecological and genetic patterns, including source-sink and range dynamics landscape genetics. For example, Andreasen et al. (2012) used genetic data to show that dispersal in cougars (Puma concolor) was strongly asymmetrical across the Great Basin in the western United States, and that directional migration was due to spatially heterogeneous hunting pressures. Specifically, individual cougars preferably emigrate out of areas with low hunting pressure ('sources') and immigrate into 
areas with high hunting pressure ('sinks'), because intense hunting keeps local population density below carrying capacity (Cooley et al., 2009, Robinson et al., 2008). As pointed out by Holderegger and Gugerli (2012), landscape features among cougar populations also impact cougar gene flow (Ernest et al. 2003; Loxterman, 2011) and could have been included in the analyses of Andreasen et al. (2012). Nevertheless, the study by Andreasen et al. (2012) illustrates that it is important to consider dispersal responses to local environmental conditions (e.g., varying local densities caused by heterogeneous hunting pressures) to understand landscape effects on source-sink dynamics in cougars and many other wildlife species.

Similarly, density-dependent dispersal in response to local environmental conditions impacts the speed of species range shifts and future distributions under climate change (Altwegg et al., 2013). While several recent studies have highlighted the need to incorporate dispersal limitations into species distribution models (Engler et al., 2012, Sinclair et al., 2010), density-dependent dispersal behavior is usually not included in current modeling approaches. By including both matrix effects and local conditions, landscape genetics could substantially contribute to such modeling approaches.

In sum, differences in local carrying capacities and related densities will readily cause asymmetrical and directional dispersal patterns, and substantially affect genetic population structures. Clearly, we need to account for density-dependent dispersal behavior if we want to use landscape genetics to foster our understanding of genetic and demographic source-sink dynamics, and to improve predictive models of future species ranges under climate change (Scoble and Lowe, 2010).

\section{Effects of NHPI on corridor functionality}

Not considering local environmental effects on NHPI could also jeopardize the functionality of conservation corridors, which are an important means to restore or maintain functional landscape connectivity. Finding optimal routes for such corridors is often based on resistance surface modeling (Beier et al. 2008, Cushman et al., 2008; Epps et al., 2007). However, corridors that are designed too similar to the natal habitat could fail to increase connectivity. For example, Horskins et al. (2006) showed that genetic exchange among populations of two rodent species connected by corridors was as reduced as among populations that were completely isolated by non-habitat. The corridors did not increase connectivity as intended, because they provided additional breeding 
habitat that individuals chose to move and settle into, rather than to disperse through.

On the other hand, when habitat patches connected through corridors are environmentally too dissimilar, individuals born in a certain area might not immigrate and settle into another area, even if they are able to reach all areas via the corridor (Alagador et al., 2012). Likewise, if individuals do disperse to these dissimilar habitats, they might not be able to survive there, hence reducing gene flow as well. Thus, if we intend to use landscape genetics to design effective corridors (Cushman et al., 2008; Epps et al., 2007) we need to start to consider local environmental effects on NHPI-based dispersal behavior, in addition to landscape resistances.

\section{Conclusions and suggestions for future research}

Undoubtedly, landscape genetics holds exceptional potential for understanding environmental effects on dispersal-mediated connectivity within and among populations, and for predicting its ecological and evolutionary consequences. However, to fully realize this tremendous potential, we need to move beyond analyses that consider either matrix quality or local environmental conditions, and towards studies that focus on multiple possible links between environmental heterogeneity and effective dispersal.

Importantly, we are not claiming that landscape genetic studies never consider local environmental factors. Indeed, many published papers have evaluated the effects of local environmental conditions on genetic patterns and underlying dispersal (see Keyghobadi, 2007). However, we are stating that a simultaneous consideration of these local factors and matrix quality is lacking, and that this comprehensive approach will greatly improve the meaningfulness of our analyses. More generally, we argue that landscape genetics needs to move from the current, often purely statistical and pattern-focused analyses to approaches that place greater emphasis on ecological theory and underlying behavioral mechanisms. Thus, the first step of any landscape genetic study should be to derive testable hypotheses on how environmental heterogeneity could impact individual behavior at the three stages of dispersal, and what consequences behavioral decisions will have for individual survival and fitness.

Clearly, it will be challenging to identify the exact behavioral mechanisms driving dispersal and realized gene flow in empirical data sets. For example, it is relatively easy to show a significant correlation between genetic structures and environmental conditions, but much more difficult to con- 
firm the exact mechanism underlying the observed patterns, such as densitydependent dispersal or natal habitat preference induction (NHPI). However, we stress that demonstrating statistical relationships between environmental and genetic patterns should not be the end of our scientific inquiries. Instead, a major focus of future studies should lie on disentangling different potential mechanisms through effective study design and creative data analysis.

To advance towards this type of 'behavioral landscape genetics', we need to establish much stronger ties between the field and other research avenues that focus on individual animal behavior. For instance, movement ecology (Nathan et al., 2008) focuses on the causes and consequences of organismal movement, and utilizes modern technologies (e.g., GPS-telemetry, acceleration-based activity sensors) to acquire unprecedented amounts of detailed information on individual movement behavior in response to environmental heterogeneity. Landscape geneticists are starting to apply the technological tools used in movement ecology, but have thus far only used them to derive or validate landscape resistance surfaces (Cushman and Lewis, 2010, Shafer et al., 2012). Ideally, movement ecology and landscape genetics will be combined in the future to assess genotypic influences on dispersal behavior (McDevitt et al., 2012), and quantify how movement decisions in response to environmental conditions impact individual survival and reproductive success.

We believe that such studies will greatly facilitate our ability to link effective dispersal and gene flow with individual movement decisions, by refocusing landscape genetic research towards the environmental effects on fitnessdependent and fitness-impacting dispersal behavior. Ultimately, understanding the exact environmental causes of dispersal and gene flow will be crucial for accurately predicting persistence of different species under current and future environmental conditions, and for deciding on optimal conservation strategies. We hope that the ideas presented here will constitute a first step towards more process-focused analyses of environmental effects on effective dispersal. 


\section{References}

Adriaensen, F., Chardon, J. P., De Blust, G., Swinnen, E., Villalba, S., Gulinck, H., and Matthysen, E. (2003). The application of 'least-cost' modelling as a functional landscape model. Landscape and Urban Planning, 64(4):233-247.

Alagador, D., Triviño, M., Cerdeira, J. O., Brás, R., Cabeza, M., and Araújo, M. B. (2012). Linking like with like: optimising connectivity between environmentally-similar habitats. Landscape Ecology, 27(2):291-301.

Altwegg, R., Collingham, Y. C., Erni, B., and Huntley, B. (2013). Density-dependent dispersal and the speed of range expansions. Diversity and Distributions, 19(1):60-68.

Andreasen, A. M., Stewart, K. M., Longland, W. S., Jon, P., Beckmann, J. P., and Forister, M. L. (2012). Identification of source-sink dynamics in mountain lions of the Great Basin. Molecular Ecology, 21(23):5689-5701.

Baguette, M., Van Dyck, H., and Dyck, H. (2007). Landscape connectivity and animal behavior: functional grain as a key determinant for dispersal. Landscape Ecology, 22(8):1117-1129.

Beier, P., Majka, D. R., and Spencer, W. D. (2008). Forks in the road: choices in procedures for designing wildland linkages. Conservation Biology, 22(4):836-51.

Bonte, D., Lukáč, M., and Lens, L. (2008). Starvation affects pre-dispersal behaviour of Erigone spiders. Basic and Applied Ecology, 9(3):308-315.

Bonte, D., Van Dyck, H., Bullock, J. M., Coulon, A., Delgado, M., and et al. (2012). Costs of dispersal. Biological Reviews of the Cambridge Philosophical Society, 87(2):290-312.

Broquet, T. and Petit, E. J. (2009). Molecular Estimation of Dispersal for Ecology and Population Genetics. Annual Review of Ecology, Evolution, and Systematics, 40(1):193216.

Broquet, T., Ray, N., Petit, E., Fryxell, J. M., and Burel, F. (2006). Genetic isolation by distance and landscape connectivity in the American marten (Martes americana). Landscape Ecology, 21(6):877-889.

Busch, J. D., Waser, P. M., and Dewoody, J. A. (2009). The influence of density and sex on patterns of fine-scale genetic structure. Evolution, 63(9):2302-2314.

Clobert, J., Le Galliard, J.-F., Cote, J., Meylan, S., and Massot, M. (2009). Informed dispersal, heterogeneity in animal dispersal syndromes and the dynamics of spatially structured populations. Ecology Letters, 12(3):197-209.

Clutton-Brock, T. H., Coulson, T. N., Milner-Gulland, E. J., Thomson, D., Armstrong, H. M., Zehr, J., Heaney, M., Sapiro, V., and Lo, S. (2002). Sex differences in emigration and mortality affect optimal management of deer populations. Nature, 415(6872):633-637.

Cooley, H. S. H., Wielgus, R. B. R., Koehler, G. G. M., Robinson, H. S., and Maletzke, B. B. T. (2009). Does Hunting Regulate Cougar Populations? A Test of the Compensatory Mortality Hypothesis. Ecology, 90(10):2913-2921. 
Costello, C. M., Creel, S. R., Kalinowski, S. T., Vu, N. V., and Quigley, H. B. (2008). Sexbiased natal dispersal and inbreeding avoidance in American black bears as revealed by spatial genetic analyses. Molecular Ecology, 17(21):4713-4723.

Coulon, A., Cosson, J. F., Angibault, J. M., Cargnelutti, B., Galan, M., Morellet, N., Petit, E., Aulagnier, S., and Hewison, a. J. M. (2004). Landscape connectivity influences gene flow in a roe deer population inhabiting a fragmented landscape: an individual-based approach. Molecular Ecology, 13(9):2841-2850.

Cushman, S. A. and Lewis, J. S. (2010). Movement behavior explains genetic differentiation in American black bears. Landscape Ecology, 25(10):1613-1625.

Cushman, S. a., McKelvey, K. S., Hayden, J., and Schwartz, M. K. (2006). Gene flow in complex landscapes: testing multiple hypotheses with causal modeling. The American Naturalist, 168(4):486-499.

Cushman, S. a., McKelvey, K. S., and Schwartz, M. K. (2008). Use of empirically derived source-destination models to map regional conservation corridors. Conservation Biology, 23(2):368-376.

Dasmann, R. F. (1964). Wildlife biology. John Wiley, New York.

Davis, J. M. and Stamps, J. A. (2004). The effect of natal experience on habitat preferences. Trends in Ecology and Evolution, 19(8):411-416.

Doncaster, C., Rondinini, C., and Johnson, P. (2001). Field test for environmental correlates of dispersal in hedgehogs Erinaceus europaeus. Journal of Animal Ecology, 70(1):33-46.

Engler, R., Hordijk, W., and Guisan, A. (2012). The MIGCLIM R package - seamless integration of dispersal constraints into projections of species distribution models. Ecography, (35):001-007.

Epps, C. W., Wehausen, J. D., Bleich, V. C., Torres, S. G., and Brashares, J. S. (2007). Optimizing dispersal and corridor models using landscape genetics. Journal of Applied Ecology, 44(4):714-724.

Ernest, H., Boyce, W., Bleich, V., May, B., Stiver, S., and Torres, S. (2003). Genetic structure of mountain lion (Puma concolor) populations in California. Conservation Genetics, 4:353-366.

Etherington, T. R. (2011). Python based GIS tools for landscape genetics: visualising genetic relatedness and measuring landscape connectivity. Methods in Ecology and Evolution, $2(1): 52-55$.

Gaggiotti, O. E. and Foll, M. (2010). Quantifying population structure using the F-model. Molecular Ecology Resources, 10(5):821-830.

Gandon, S. (1999). Kin competition, the cost of inbreeding and the evolution of dispersal. Journal of Theoretical Biology, 200(4):345-364.

Geffen, E., Anderson, M. J., and Wayne, R. K. (2004). Climate and habitat barriers to dispersal in the highly mobile grey wolf. Molecular Ecology, 13(8):2481-2490. 
Goodwin, B. J. (2003). Is landscape connectivity a dependent or independent variable? Landscape Ecology, 18(7):687-699.

Gundersen, G., Andreassen, H. P., Ims, R. a., and Letters, E. (2002). Individual and population level determinants of immigration success on local habitat patches: an experimental approach. Ecology Letters, 5(2):294-301.

Hamilton, W. and May, R. (1977). Dispersal in stable habitats. Nature, 269:578-581.

Hanski, I. (1994). A practical model of metapopulation dynamics. Journal of Animal Ecology, 63(1):151-162.

Hanski, I. (2012). Eco-evolutionary dynamics in a changing world. Annals of the New York Academy of Sciences, 1249(1):1-17.

Hein, S., Gombert, J., Hovestadt, T., and Poethke, H.-J. (2003). Movement patterns of the bush cricket Platycleis albopunctata in different types of habitat: matrix is not always matrix. Ecological Entomology, 28:432-438.

Holderegger, R. and Gugerli, F. (2012). Where do you come from, where do you go? Directional migration rates in landscape genetics. Molecular Ecology, 21(23):5640-6542.

Holderegger, R. and Wagner, H. H. (2008). Landscape Genetics. BioScience, 58(3):199-208.

Horskins, K., Mather, P. B., and Wilson, J. C. (2006). Corridors and connectivity: when use and function do not equate. Landscape Ecology, 21(5):641-655.

Keyghobadi, N. (2007). The genetic implications of habitat fragmentation for animals. Canadian Journal of Zoology, 85(10):1049-1064.

Keyghobadi, N., Roland, J., Matter, S. F., and Strobeck, C. (2005). Among- and withinpatch components of genetic diversity respond at different rates to habitat fragmentation: an empirical demonstration. Proceedings of the Royal Society B: Biological Sciences, 272(1562):553-60.

Legendre, P. and Legendre, L. (2012). Numerical Ecology. Elsevier, Amsterdam.

Lowe, W. H. and Allendorf, F. W. (2010). What can genetics tell us about population connectivity? Molecular Ecology, 19(15):3038-3051.

Loxterman, J. L. (2011). Fine scale population genetic structure of pumas in the Intermountain West. Conservation Genetics, 12(4):1049-1059.

Mabry, K. and Stamps, J. (2008). Dispersing brush mice prefer habitat like home. Proceedings of the Royal Society B: Biological Sciences, 275:543-548.

Manel, S., Schwartz, M. K., Luikart, G., and Taberlet, P. (2003). Landscape genetics: combining landscape ecology and population genetics. Trends in Ecology and Evolution, 18(4):189-197.

Mathieu, J., Barot, S., Blouin, M., Caro, G., Decaëns, T., and et al. (2010). Habitat quality, conspecific density, and habitat pre-use affect the dispersal behaviour of two earthworm species, Aporrectodea icterica and Dendrobaena veneta, in a mesocosm experiment. Soil Biology and Biochemistry, 42(2):203-209. 
Matthysen, E. (2005). Density-dependent dispersal in birds and mammals. Ecography, 3:403-416.

Matthysen, E. (2012). Multicausality of dispersal: a review. In Clobert, J., Baguette, M., Benton, T., and Bullock, J., editors, Dispersal Ecology and Evolution, pages 3-18. Oxford University Press, Oxford.

McDevitt, A. D., Oliver, M. K., Piertney, S. B., Szafrańska, P. A., Konarzewski, M., and Zub, K. (2012). Individual variation in dispersal associated with phenotype influences fine-scale genetic structure in weasels. Conservation Genetics, 14(2):499-509.

McRae, B. (2006). Isolation by resistance. Evolution, 60(8):1551-1561.

Moilanen, A. and Hanski, I. (1998). Metapopulation dynamics: effects of habitat quality and landscape structure. Ecology, 79(7):2503-2515.

Moilanen, A. and Nieminen, M. (2002). Simple connectivity measures in spatial ecology. Ecology, 83(4):1131-1145.

Murphy, M. a., Dezzani, R., Pilliod, D. S., and Storfer, A. (2010). Landscape genetics of high mountain frog metapopulations. Molecular Ecology, 19(17):3634-3649.

Nathan, R., Getz, W., Revilla, E., Holyoak, M., Kadmon, R., Saltz, D., and Smouse, P. (2008). A movement ecology paradigm for unifying organismal movement research. Proceedings of the National Academy of Sciences of the United States of America, 105(49):19052-19059.

Neuenschwander, S., Hospital, F., Guillaume, F., and Goudet, J. (2008). quantiNemo: an individual-based program to simulate quantitative traits with explicit genetic architecture in a dynamic metapopulation. Bioinformatics, 24(13):1552-1553.

Ricketts, T. H. (2001). The matrix matters: effective isolation in fragmented landscapes. The American Naturalist, 158(1):87-99.

Robinson, H., Wielgus, R., Cooley, H., and Cooley, S. (2008). Sink Populations in Carnivore Management: Cougar Demography and Immigration in a Hunted Population. Ecological Applications, 18(4):1028-1037.

Roy, J., Yannic, G., Côté, S. D., and Bernatchez, L. (2012). Negative density-dependent dispersal in the American black bear (Ursus americanus) revealed by noninvasive sampling and genotyping. Ecology and Evolution, 2(3):525-537.

Russell, R. R. E., Swihart, R. K., and Craig, B. B. A. (2007). The Effects of Matrix Structure on Movement Decisions of Meadow Voles (Microtus pennsylvanicus). Journal of Mammalogy, 88(3):573-579.

Sawyer, S. C., Epps, C. W., and Brashares, J. S. (2011). Placing linkages among fragmented habitats: do least-cost models reflect how animals use landscapes? Journal of Applied Ecology, 48(3):668-678.

Scoble, J. and Lowe, A. J. (2010). A case for incorporating phylogeography and landscape genetics into species distribution modelling approaches to improve climate adaptation and conservation planning. Diversity and Distributions, 16(3):343-353. 
Selonen, V., Hanski, I. K., and Desrochers, A. (2007). Natal habitat-biased dispersal in the Siberian flying squirrel. Proceedings of the Royal Society B: Biological Sciences, 274(1621):2063-2068.

Shafer, A. B., Northrup, J. M., White, K. S., Boyce, M. S., Côté, S. D., and Coltman, D. W. (2012). Habitat selection predicts genetic relatedness in an alpine ungulate. Ecology, 93(6):1317-1329.

Shirk, A. J., Wallin, D. O., Cushman, S. A., Rice, C. G., and Warheit, K. I. (2010). Inferring landscape effects on gene flow: A new model selection framework. Molecular Ecology, 19(17):3603-3619.

Sinclair, S. J., White, M. D., and Newell, G. R. (2010). How useful are species distribution models for managing biodiversity under future climates? Ecology and Society, 15(1):8.

Spear, S. F., Balkenhol, N., Fortin, M.-J., McRae, B. H., and Scribner, K. (2010). Use of resistance surfaces for landscape genetic studies: considerations for parameterization and analysis. Molecular Ecology, 19(17):3576-3591.

Spear, S. F., Crisafulli, C. M., and Storfer, A. (2012). Genetic structure among coastal tailed frog populations at Mount St. Helens is moderated by post-disturbance management. Ecological Applications, 22(3):856-869.

Stamps, J. (2001). Habitat selection by dispersers: integrating proximate and ultimate approaches. In Clobert, J., Danchin, E., Dhondt, A. A., and Nichols, J. D., editors, Dispersal, pages 230-242. Oxford University Press, New York.

Storfer, A., Murphy, M., Evans, J., Goldberg, C., Robinson, S., Spear, S., Dezzani, R., Delmelle, E., Vierling, L., and Waits, L. (2007). Putting the "landscape" in landscape genetics. Heredity, 98(3):128-142.

Storfer, A., Murphy, M. a., Spear, S. F., Holderegger, R., and Waits, L. P. (2010). Landscape genetics: where are we now? Molecular Ecology, 19(17):3496-3514.

Travis, J. M. J., Murrell, D. J., and Dytham, C. (1999). The evolution of density-dependent dispersal. Proceedings of the Royal Society B: Biological Sciences, 266(1431):1837-1842.

Van Strien, M. J., Keller, D., and Holderegger, R. (2012). A new analytical approach to landscape genetic modelling: least-cost transect analysis and linear mixed models. Molecular Ecology, 21(16):4010-4023.

Vuilleumier, S., Goudet, J., and Perrin, N. (2010). Evolution in heterogeneous populations: from migration models to fixation probabilities. Theoretical Population Biology, 78:250258.

Wagner, H. H. and Fortin, M.-J. (2013). A conceptual framework for the spatial analysis of landscape genetic data. Conservation Genetics, 14(2):253-261.

Wang, I. J., Glor, R. E., Losos, J. B., and Letters, E. (2013). Quantifying the roles of ecology and geography in spatial genetic divergence. Ecology Letters, 16(2):175-182.

Wang, I. J. I. (2013). Examing the full effects of landscape heterogeneity on spatial genetic variation: a multiple matrix regression approach for quantifying geographic and ecological isolation. Evolution, 67(12):3403-3411. 
Weckworth, B. V. B., Musiani, M., DeCesare, N. J. N., McDevitt, A. A. D., Hebblewhite, M., and Mariani, S. (2013). Preferred habitat and effective population size drive landscape genetic patterns in an endangered species. Proceeding of the Royal Society London B, 280(1769):20131756.

Wiegand, T., Moloney, K. A., Naves, J., and Knauer, F. (1999). Finding the missing link between landscape structure and population dynamics: A spatially explicit perspective. American Naturalist, 154(6):605-627.

Wiens, J. A. (2000). Ecological heterogeneity: an ontogeny of concepts and approaches. In Hutchings, M., John, E., and Stewart, A., editors, The ecological consequences of environmental heterogeneity, pages 53-69. Blackwell.

Wiens, J. A. (2001). The landscape context of dispersal. In Clobert, J., Danchin, E., Dhondt, A., and Nichols, J., editors, Dispersal, pages 96-109. Oxford University Press, New York.

Zeller, K. A., McGarigal, K., and Whiteley, A. R. (2012). Estimating landscape resistance to movement: a review. Landscape Ecology, 27(6):777-797. 


\section{Supporting information}

Pflüger, F.J and Balkenhol, N. (2014). A plea for simultaneously considering matrix quality and local environmental conditions when analysing landscape impacts on effective dispersal. Molecular Ecology, 23(9): 2146-2156.

Appendix A3.1: Simulation details.

Fig. A3.1 Study area for the simulations. Red dots are the locations of the 12 simulated populations, the blue background shows the resistance surface with darker colours denoting higher costs, and the yellow lines are the least cost paths (i.e., effective distances) among populations. The area is $750 \mathrm{~km}$ and the resistance grid has a resolution of $40 \mathrm{~m}$.

Table A3.1: Settings for population sizes $(N)$ and carrying capacities $(K)$ used in the simulations. Density-dependent dispersal in our simulations is determined by the ratio $\mathrm{D}(=N / K)$.

Table A3.2: Parameter values used for simulating density-dependent dispersal. 


\section{Appendix A3.1: Simulation details}

To illustrate the utility of the proposed analytical framework using metapopulation indices, we simulated genetic data in software QuantiNemo (Neuenschwander et al., 2008). QuantiNemo is an individual-based, genetically explicit stochastic simulation program that simulates gene flow among populations as a function of user-defined population sizes and inter-population emiand immigration rates. We created these migration rates in three ways, reflecting different scenarios of environmental impacts on effective dispersal. Specifically, we simulated neutral microsatellite data for 12 populations connected via migration across a study area shown in Fig. A3.1.

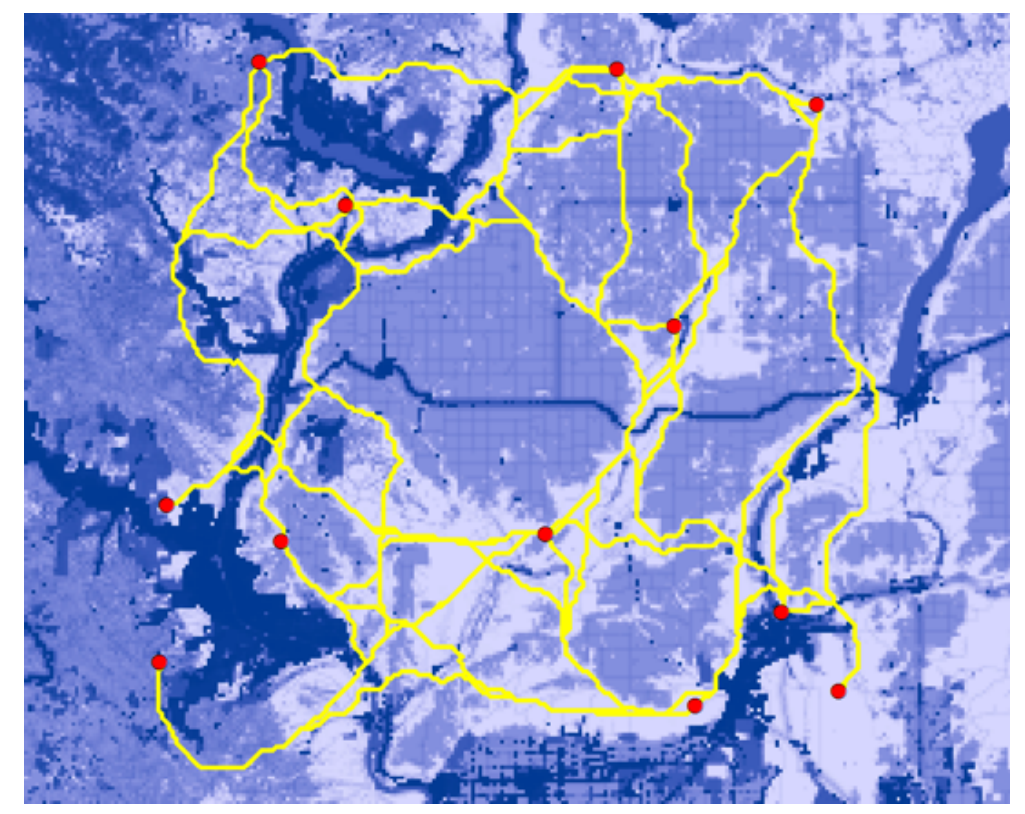

Figure A3.1: Study area for the simulations. Red dots are the locations of the 12 simulated populations, the blue background shows the resistance surface with darker colors denoting higher costs, and the yellow lines are the least-cost paths (i.e., effective distances) among populations. The area is $750 \mathrm{~km}^{2}$ and the resistance grid has a resolution of 40 meters.

In all scenarios, we simulated 15 microsatellite loci with a mutation rate of 0.0001 under the k-allele model of mutation, and ran simulations for 20 generations, with an initial size of 100 individuals per population. The life cycle implemented in the program comprises the following steps in a fixed order: breeding, statistics, outputs, aging, (population size) regulation, dispersal, (population size) regulation, and extinction (for details see the QuantiNemo manual). Migration rates among populations were varied as follows: 
1) In the first scenario, migration rates were only influenced by densitydependent dispersal. For this, we gave different carrying capacities to the populations (Table A3.1), so that their population size $(N=100)$ was either above, at, or below carrying capacity $(K)$.

QuantiNemo then uses a generalized logistic function (Richards, 1959) to simulate density-dependent dispersal:

$$
f=\min +\frac{\max -\min }{\left(1+s *\left[e^{r\left(D_{r M a x}-D\right)}\right]\right)^{1 / s}}
$$

where $f$ is a density-dependent factor that is multiplied with the densityindependent dispersal rate among populations, which we set to be 0.15 . Since QuantiNemo can simulate asymmetrical dispersal rates among populations (i.e., migration from a to b must not equal migration from $\mathrm{b}$ to $\mathrm{a}$ ), this function leads to a dispersal pattern where more individuals emigrate out of populations with high densities, and into populations with low densities. In essence, the factor depends the relationship between population size and carrying capacity $D$, which is defined as $D=N / K$. Parameter $D_{\text {rMax }}$ defines the population density with maximum slope, and $r$ is the population growth rate, which in our simulations was 1 for all populations, because we set the number of offspring to the number of adults, so that populations sizes and the ratio of $N / K$ did not change within populations. The other factors are user-defined scale and shape parameters of the logistic curve, with ( $\mathrm{min}$ ) defining the lower asymptote, $(\max )$ defining the upper asymptote, and s defining the shape of the curve. Parameters values used for the generalized logistic function are shown in Table A3.2.

We rescaled the calculated migration rates to range from 0 to 1 through the formula:

$$
m_{r}=\frac{\left.m_{i}-\operatorname{Min}\left(m_{i \ldots n}\right)\right)}{\operatorname{Max}\left(m_{i \ldots n}\right)-\operatorname{Min}\left(m_{i \ldots n}\right)}
$$

where $m_{\mathrm{r}}$ is the rescaled migration rate, $m_{\mathrm{i}}$ is the unscaled migration rate, and $\operatorname{Min}\left(m_{\mathrm{i} . . . \mathrm{n}}\right)$ and $\operatorname{Max}\left(m_{\mathrm{i} \ldots \mathrm{n}}\right)$ are the minimum and maximum of all calculated migration rates, respectively. Applying this procedure to all scenarios (see below) ensures that the strength of influence on migration is similar for carrying capacity and effective distances, respectively. This first scenario reflects a situation where effective dispersal is affected by local environmental conditions (i.e., local carrying capacities), but not by matrix quality among locations. 
Table A3.1: Settings for population sizes $(N)$ and carrying capacities $(K)$ used in the simulations. Density-dependent dispersal in our simulations is determined by the ratio $D(=N / K)$.

\begin{tabular}{llll}
\hline Population & $N$ & $K$ & $N / K(=D)$ \\
\hline 1 & 100 & 140 & 0.71 \\
2 & 100 & 60 & 1.67 \\
3 & 100 & 160 & 0.63 \\
4 & 100 & 100 & 1.00 \\
5 & 100 & 90 & 1.11 \\
6 & 100 & 130 & 0.77 \\
7 & 100 & 110 & 0.91 \\
8 & 100 & 120 & 0.83 \\
9 & 100 & 80 & 1.25 \\
10 & 100 & 50 & 2.00 \\
11 & 100 & 150 & 0.67 \\
12 & 100 & 70 & 1.43 \\
\hline
\end{tabular}

Table A3.2: Parameter values used for simulating density-dependent dispersal.

\begin{tabular}{ll}
\hline Parameter & Setting \\
\hline$D$ & see Table A3.1 \\
Drmax & 1 \\
$\min$ & 0.5 \\
$\max$ & 1.38 \\
$r$ & 1 \\
$s$ & 2 \\
\hline
\end{tabular}

2) As a second scenario, we modeled migration rates as a function of effective distances among populations, and this time did not vary local carrying capacities (i.e., same local density in all populations). For this, we estimated least-cost paths among the 12 populations using a resistance grid with cost values ranging from 1 to 2,000 (Fig. A3.1). Least-cost paths were calculated using the Landscape Genetic Toolbox by Etherington (2011) in ArcMap 10.1 (ESRI 2012, Redlands, CA, USA). We then used the resulting distances to model migration rates through an exponential dispersal function:

$$
m_{i j}=e^{-k d_{i j}}
$$


where $m_{\mathrm{ij}}$ is the migration rate among two populations, which depends on the effective (i.e., least-cost path) distance among them $\left(d_{\mathrm{ij}}\right)$ and a scaling parameters $k$ that is often calculated as ' 1 / average dispersal distance' in empirical studies (Moilanen and Nieminen, 2002). We set $k=3.9 * 10^{64}$, so that the average migration rates in this scenario were similar to the ones in scenario 1. This $k$ value would reflect an average dispersal distance of $5.3 \mathrm{~km}$ for the simulated species. We again re-scaled migration rates to range from 0 to 1 before using them in the simulations, so that the influence of effective distances on migration was similar to the effect of density-dependence in the first scenario. This second scenario reflects a situation where effective dispersal is affected by matrix quality among locations, but not by local environmental conditions.

3) Finally, in the third scenario, we simulated migration rates as a function of both density-dependent dispersal and effective distances, which reflects a scenario where both matrix quality and local environmental conditions affect dispersal. For this, we simply added inter-population migration rates obtained with the generalized logistic function (scenario 1) to the migration rates obtained from the effective distances (scenario 2), and then again re-scaled the result to range from 0 to 1 .

We then used software FSTAT (Goudet, 1995) to calculate basic population genetic statistics and to estimate $F_{\mathrm{ST}}$-values (Weir and Cockerham, 1984). The simulated scenarios showed similar levels of heterozygosity $\left(H_{\mathrm{O}}=\right.$ $0.853,0.855,0.861$ for scenarios 1,2 and 3 , respectively), and overall genetic differentiation $\left(F_{\mathrm{ST}}=0.047,0.038\right.$, and 0.036 for scenario 1,2 and 3, respectively). We then used linear regression in software R 2.15.2 (R Foundation 2012 ) to model average $F_{\mathrm{ST}}$-values for each subpopulation as a function of three different metapopulation connectivity indices $S$ for each subpopulation $i$ :

$$
\begin{gathered}
S_{i}=C_{i} \\
S_{i}=\sum\left[\exp \left(-k d_{i j}\right)\right] \\
S_{i}=C_{i} * \sum\left[\exp \left(-k d_{i j}\right)\right]
\end{gathered}
$$

where $C_{\mathrm{i}}$ is the local carrying capacity of focal population $i, d_{\mathrm{ij}}$ is the effective distance between focal population $i$ and population $j$, summation is across all subpopulations $1 \ldots 12(j \neq i)$, and $k$ is a scaling parameter related to average dispersal distance (see above).

We used an information-theoretic approach to select the most likely 
models, i.e., lowest AIC values were used to identify the best model for each scenario (see Table 3.3 in chpater 3 ).

\section{References}

Etherington, T. R. (2011). Python based GIS tools for landscape genetics: visualising genetic relatedness and measuring landscape connectivity. Methods in Ecology and Evolution, $2(1): 52-55$.

Goudet, J. (1995). FSTAT (Version 1.2): A Computer Program to Calculate F-Statistics. Journal of Heredity, 86(6):485-486.

Moilanen, A. and Nieminen, M. (2002). Simple connectivity measures in spatial ecology. Ecology, 83(4):1131-1145.

Neuenschwander, S., Hospital, F., Guillaume, F., and Goudet, J. (2008). quantiNemo: an individual-based program to simulate quantitative traits with explicit genetic architecture in a dynamic metapopulation. Bioinformatics, 24(13):1552-1553.

Richards, F. (1959). A flexible growth function for empirical use. Journal of Experimental Botany, 10(29):290-300.

Weir, B. S. and Cockerham, C. C. (1984). Estimating F-Statistics for the Analysis of Population Structure. Evolution, 38(6):1358. 

CHAPTER 4

\title{
Habitat loss causes non-linear genetic erosion in specialist species
}

This chapter is published as:

Pflüger, F.J, Signer, J., and Balkenhol, N. (2019). Habitat loss causes nonlinear genetic erosion in specialist species. Global Ecology and Conservation, $17: \mathrm{e} 00507$.

\begin{abstract}
Habitat loss can lead to non-linear declines in species abundance once the amount of landscape-wide habitat is reduced to a critical value. Previous studies have suggested that such non-linear responses to landscape-wide habitat loss might also exist in genetic variation, and an in-depth understanding of non-linear habitat loss effects on all levels of biodiversity levels is vital to take appropriate conservation actions. Using individual-based simulations we evaluated the existence of generic non-linear responses in three different response variables and across different combinations of traits related to dispersal and population density. We simulated habitat loss scenarios by incrementally reducing the landscape-wide habitat amount within a previously undisturbed landscape and monitored population abundance, genetic diversity and differentiation of populations within constant sampling areas over time. We found aside from population abundance, genetic variation also responded non-linearly to habitat loss across all scenarios. Importantly, the populations that persisted in remaining habitat fragments experienced genetic erosion before a noticeable effect on local abundance occurred. The observed increase in genetic differen-
\end{abstract}


tiation and the decrease in genetic diversity of remaining populations are likely caused by the indirect effects of landscape-wide habitat loss on effective patch isolation. Thus, genetic data might have the potential to detect indirect effects of landscape-wide habitat loss before it directly affects the size of a population. Since indirect effects of habitat loss might go unnoticed when extinction risk is estimated from abundance data alone, we argue that an improved understanding of genetic effects is crucial to anticipate and ultimately prevent the negative effects of habitat loss.

Keywords: biodiversity, extinction threshold, habitat fragmentation, population decline, genetic diversity, genetic structure

\section{Introduction}

Habitat loss and fragmentation are major global threats to species diversity and ecosystem functions (Fahrig, 2003; Haddad et al., 2015; Pardini et al. 2017). Populations affected by habitat loss and fragmentation are often small and isolated, thus showing increased extinction probabilities because they are vulnerable to demographic variability, inbreeding depression, and environmental stochasticity (Frankham, 2005; Shaffer, 1981).

For population density and abundance, previous conceptual, simulation and empirical studies suggest that habitat loss often leads to sharp population declines and hence increased extinction rates when the amount of remaining habitat drops below 10 - 50\% within a landscape Andrén, 1994 , Banks-Leite et al., 2014, Swift et al., 2010). This non-linear response to increasing habitat loss is sometimes called an 'extinction threshold' (Ovaskainen and Hanski, 2003; With and King, 1999), and challenges the prediction about the future persistence of species, as even small additional amounts of habitat loss can cause rapid extinction and potentially irreversible regime shifts (Pardini et al., 2010). Extinction thresholds are often used to develop simple guidelines for how much habitat has to remain for a species to persist in a disturbed landscape.

Despite the appealing nature of a simple habitat extinction threshold, empirical studies have found mixed and species-dependent evidence for the occurrence of such a threshold (Swift et al., 2010). For example, threshold values for species diversity in mammals and birds ranged between 10 and 30\% of native habitat cover (Andrén, 1994), and for Amazonian mammals' and birds' 
species richness between 19 and 43\% (Ochoa-Quintero et al., 2015). Richness in Australian forest-dependent bird species declined dramatically when habitat cover reached a threshold of 10 (Radford et al. 2005). Other studies have even concluded that abundance or species richness did not at all show a threshold response to decreasing habitat (Lindenmayer et al., 2005). Because of this variability, the use of simple general habitat thresholds in practical conservation has been repeatedly criticized (Johnson, 2013, Lindenmayer and Luck, 2005, Hoek et al., 2015), and the general existence of sudden, non-linear responses to decreasing habitat (i.e., thresholds effects) remains highly controversial.

In addition to species-dependence, the existence or magnitude of a non-linear response may also depend on the measured population response. While most studies on habitat thresholds focus on population abundances, densities or species richness as response variables, habitat loss effects on genetic variation are underrepresented. Habitat loss in general can directly lead to a reduction in genetic diversity when it reduces the size of sampled patches, as this leads to a reduction of local population sizes and an associated direct loss of alleles. Landscape-wide habitat loss can also indirectly affect genetic variation, when decreasing habitat amount in the surrounding landscape reduces gene flow among populations, thus increasing their effective isolation Jackson and Fahrig, 2014, 2016). A few empirical studies suggest that genetic variation, similar to the more typical response variables, can sometimes show sudden changes when the amount of landscape-wide habitat drops below a certain threshold (Balkenhol et al. 2013, Lange et al., 2010). However, empirical studies are always limited with respect to the number of landscapes they can consider and the time scale at which analyses are conducted. Thus, the general existence of non-linear genetic responses to landscape-wide habitat loss remains to be tested.

Here, we used simulations to test the hypothesis that genetic variation can respond non-linearly to continuous, landscape-wide habitat loss and compare the responses of genetic diversity and differentiation to that of population abundance. Simulations are by definition only a simplified proxy of reality, however, they allow us to control scenarios of habitat loss in many landscapes and to observe and compare changes in population responses over long time periods. We approximated situations where a study species is constantly monitored over several generations in the same localities (i.e., focal populations), while experiencing increasing habitat loss in the surrounding landscape. Since we used binary landscapes with a hostile matrix, our sce- 
nario corresponds best to specialist species, which are expected to be most sensitive to habitat loss (Bommarco et al., 2010; Keinath et al., 2017; Pardini et al. 2010) and to exhibit threshold levels for abundance (With and Crist, 1995). Specifically, we used individual-based simulations of specialist species with different dispersal capacities inhabiting landscapes with varying amount, fragmentation and carrying capacities of habitat. Using the simulations, we a) compare the relative sensitivity and consistency of responses in population abundance, genetic diversity and genetic differentiation to ongoing habitat loss and b) assess the trajectory of the different metrics after experiencing habitat loss.

\section{Methods}

We simulated individuals living in landscapes that are continuously reduced in habitat amount. Specifically, we used the spatially-explicit, population genetic simulation model SimAdapt developed by Rebaudo et al. (2013) for NetLogo 5.0.3 (Wilenski, 1999), which has been validated in its consistency with classical population genetic models (Rebaudo et al. 2013). The model simulates dispersal, reproduction, birth and death of individuals living in landscapes that vary in the amount and fragmentation of habitat. We made slight changes in the SimAdapt code in order to adjust the model to our study goals, e.g. we replaced random dispersal with correlated random walks (see below). Detailed information on the individual-based simulations is provided as an ODD protocol (Grimm et al. 2006, 2010) in the Appendix A4.1 (see also Table A4.1 and Fig. A4.1).

\section{Simulation experiments}

\section{Trait parameters}

We created habitat specialists and varied parameters related to dispersal and population size. Specifically, we varied dispersal distance (disp.dist, five levels), movement probability (disp.prob, three levels) and carrying capacity of the habitat ( $k$, three levels), resulting in different population densities and dispersal characteristics (Table 4.1). Note that these different parameter combinations (hereafter referred to as 'traits') represent a cross section of possible dispersal capacities and population densities, rather than particular species with specific dispersal behaviors. We simulated this variety of dispersal capacities and population densities to ensure that our results are valid for a 
range of specialist species rather than being limited to a single set of parameter values. Hence, including a combination of different dispersal and density characteristics increases the robustness of our inferences.

\section{Landscape characteristics and habitat loss}

We simulated binary (habitat vs. non-habitat) landscapes using the randomHabitat function of the secr R package (Efford, 2018). Simulated landscapes always had the same extent (50 x 50 cells), but differed in habitat amount and fragmentation (see supplementary material for details on simulated landscape). The spatial configuration of habitat patches was controlled by the spatial autocorrelation parameter $p$, with smaller $p$ values indicating more fragmented habitat Gardner et al., 1987). We varied $p$ across five levels (0.1-0.5 in 0.1 increments, Fig. A4.2) and modelled habitat loss through five scenarios differing in the maximum amount of habitat loss a landscape experienced (rem.Hab, five levels). Within each scenario, habitat amount $(A)$ was reduced in $10 \%$ increments every generation starting from landscapes completely covered with habitat $(A=100 \%)$, down to a rem.Hab value of either $50,40,30,20$ or $10 \%$ of remaining habitat. In order to analyze the development of response variables over time, simulations continued for 20 generations after the maximum value was reached, i.e. after habitat loss had stopped (Fig. A4.3). Overall, the total simulation period comprised 124 to 128 generations, depending on rem.Hab. We replicated each combination of $p$ and $A$ ten times and each species scenario five times in order to account for the stochasticity in our simulations (i.e. random components of genetic and landscape simulations). In total, the combination of all parameters lead to 56,250 individual simulation runs ( 5 levels of $p \times 5$ levels of rem.Hab x 45 trait combinations $\mathrm{x}$ 10 landscape replicates $\mathrm{x} 5$ genetic replicates). Our simulation of habitat loss mimicked a relatively fast reduction in habitat (10\% loss in every time step) down to a final habitat amount value where habitat loss was no longer ongoing, for example due to habitat protection. Since we sampled only populations within a constant focal site (see below and Fig. 4.1), habitat loss in the beginning proceeded in the surrounding landscape and thus, represents indirect effects of habitat loss. In contrast, direct loss of habitat only occurred when the landscape-wide habitat amount reduced the area of focal sites. 
Table 4.1: Landscape and species parameters of the simulation model.

\begin{tabular}{ll}
\hline Parameters & Values / description \\
\hline Landscape parameters & \\
Habitat amount $(A)$ & $10,20,30,40,50,60,70,80,90,100 \%$ \\
Habitat aggregation $(p)$ & $0.1,0.2,0.3,0.4,0.5$ \\
Species parameters & \\
Carrying capacity per cell $(k)$ & $5,10,20$ \\
Initial population size $(N)$ & $\begin{array}{l}\text { Maximal number of individuals depending on } \\
\text { carrying capacity }\end{array}$ \\
Number of offspring & $N_{\mathrm{t}+1}=N_{\mathrm{t}} e^{r\left(N_{\mathrm{t}} / K\right)}$ \\
Dispersal distance $($ disp.dist $)$ & $\begin{array}{l}\text { very low: } 1-2 \text { steps, low: } 2-7 \text { steps, } \\
\text { intermediate: } 3-12 \text { steps, high: } 4-17 \text { steps, } \\
\text { very high: } 5-22 \text { steps }\end{array}$ \\
& $0.05,0.1,0.5$ \\
Dispersal probability $($ disp.prob $)$ & \\
\hline
\end{tabular}

\section{Population genetic simulation}

Every simulation experiment started with a continuous landscape that was homogeneously inhabited by individuals. The total number of individuals depended on the carrying capacity $(k)$ of each cell (Table 4.1). Thirty neutral genetic loci were simulated and alleles at each locus were assigned to individuals randomly. Alleles were chosen from a normal distribution, which corresponded to an expected heterozygosity around $70 \%$ and a number of possible alleles $\mathrm{z}$ around 10 (see SimAdapt documentation of Rebaudo et al., 2013, pp. 12). To reach a stable population before habitat loss started, each scenario was started with a burn-in period of 100 generations running on the continuous landscape (i.e. no habitat loss).

Individual dispersal was modeled as a correlated random walk (CRW) (Kareiva and Shigesada, 1983) where movement direction depends on the direction of the previous step. This approach simulates moving animals that exhibit directional persistence while dispersing, as is commonly the case in reality (Fagan and Calabrese, 2014; Schtickzelle et al., 2007), especially when habitat becomes fragmented (Van Dyck and Baguette, 2005). The dispersal distance was influenced by the landscape, i.e. by different resistance values of habitat $(=1)$ and matrix cells $(=5)$ (see ODD protocol in Appendix A4.1). Since a hostile matrix causes higher mortality rates (Fahrig, 2002), individuals 
that were located in the landscape matrix at the end of the dispersal movements did not reproduce and died. This approach was chosen to create model species that are characterized by limited tolerance towards matrix habitat, i.e., specialist species. Dispersal behavior partly followed an informed dispersal strategy. In the last steps, the individual was given a perceptual range of a two-cell radius. If there was habitat within this radius, the individual moved to this cell instead of passing nearby habitat and terminating movement in the matrix.

Reproduction was sexual with non-overlapping generations, and the number of offspring was determined by a density-dependent logistic growth function (Ricker, 1954). This, together with the probability to disperse (disp. prob) creates density-dependent dispersal, as more individuals are available to emigrate out of high density patches. For each reproduction, two parents were randomly drawn among the different individuals inhabiting a cell, and offspring genotypes were generated from parental genotypes using Mendelian inheritance.

\section{Sampling}

It is usually not feasible to sample all individuals of a species within an entire study landscape, and, thus, empirical studies are often conducted in predefined sampling areas (i.e., remaining habitat patches) within a fragmented landscape. Hence, to track the development of the different population responses as habitat loss increased, we sampled individuals in sampling areas that varied between simulation scenarios, but remained constant over time within each scenario (Fig. 4.1). This sampling approach allowed us to track changes in abundance and genetic variation as landscape-wide habitat loss increased without any bias caused by varying sampling schemes across time. Furthermore, the use of constant sampling areas cross time ensures that focal populations within these sites are affected by both indirect effects of landscapewide loss (i.e., habitat loss increases isolation of focal populations; Fig. 4.1BC), as well as by direct local habitat loss (Fig. 4.1D). Finally, this sampling approach also mimics empirical monitoring schemes, where the same sites are repeatedly sampled over time to detect changes in response variables (see also discussion).

Since the fragmentation parameter $p$ (see above) determines the clustering of habitat, the focal sites differed between simulation experiments but remained constant within one simulation run of habitat loss. Depending on 
the simulation experiment, the number of sampled sites ranged between 5 and 42. Individuals within a site were considered to belong to the same focal population. For all scenarios, we counted the number of individuals in the focal populations (population size $N$ ) and recorded individual genotypes and spatial coordinates of all individuals within focal populations.
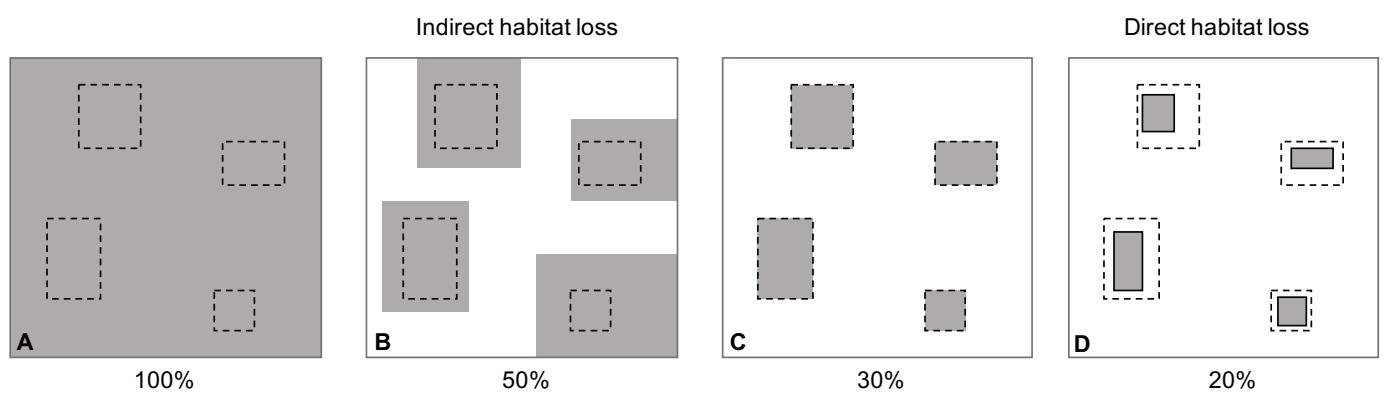

Figure 4.1: Schematic illustration of sampling scheme within one landscape simulation. Pre-defined focal sites (dotted lines) were chosen within a continuous landscape A, where the relative amount of landscape-wide habitat (grey color) was 100\%. During habitat loss (B, C, D), these sampling sites remained constant. Population abundance, genetic diversity and differentiation were estimated for populations inhabiting these sites ("focal populations") to track the dynamics of each of these responses over time as habitat loss continued (10\% reduction every generation). Note that in $\mathbf{B}$ and C, focal populations are affected indirectly by habitat loss via increased population isolation. In $\mathbf{D}$, focal populations are also affected directly by habitat loss.

\section{Quantifying genetic variation}

We used the R package fpga (Signer, 2015)for population genetic analyses. Genetic diversity was calculated as allelic richness $\left(A_{R}\right)$ for each focal population using rarefaction (Kalinowski, 2004), and we averaged $A_{R}$ over all populations to compare genetic diversity among landscapes with different amounts of habitat. We chose Jost' D (Jost, 2008) to measure genetic differentiation, as it correctly accounts for within-population diversity and is hence suitable to compare genetic differentiation among multiple landscapes Balkenhol et al. 2013). To compare genetic differentiation between landscapes, we averaged pair-wise Jost' D for each population compared to all other populations to describe its overall genetic differentiation. 


\section{Statistical analysis}

\section{Critical thresholds in population abundance and genetic variation}

We used piecewise regression models to detect potential non-linear responses of population abundance, genetic diversity and genetic differentiation to decreasing habitat amount using the $\mathrm{R}$ package segmented (Murphy et al., 2010). Basically this approach uses an iterative process where multiple possible values of breakpoints $(\Psi)$ and slopes $(\beta)$ are fitted repeatedly until parameters converge at the maximum likelihood estimate (Muggeo, 2003). Piecewise regression requires a starting estimate for $\Psi$. Initial estimates for breakpoints were based on the examination of scatterplots. We systematically tested for different breakpoints and also tested for multiple thresholds when suggested by exploratory plots. To test whether habitat loss led to linear responses, rather than thresholds, we also calculated linear regressions and compared linear and threshold models based on their Akaike's information criterion $(\Delta \mathrm{AIC}$, Burnham and Anderson, 2002).

\section{Temporal change in population abundance and genetic variation}

In order to investigate the rate of change in population abundance, $A_{R}$ and Jost'D over time within the last 20 generations following habitat loss, we calculated the relative difference between the first generation and each subsequent generation and compared the magnitude of changes between the three response variables. All statistical analyses were performed in $\mathrm{R}$ software ( $\mathrm{R}$ Development Core Team, 2017).

\section{Results}

Across scenarios, Jost'D and $A_{R}$ were strongly negatively correlated $(r=-$ $0.995)$, while abundance was positively correlated with $\mathrm{A}_{\mathrm{R}}(r=0.596)$ and negatively correlated with Jost'D $(r=-0.519)$. Despite these correlations among the three measured population responses, we found differences in their reaction to increasing habitat loss, especially with respect to the location and consistency of non-linear thresholds. Since the general patterns within response variables were very similar across simulation parameters, we first summarize our results across all simulated traits and habitat loss scenarios, before discussing effects of individual simulation parameters. 


\section{Threshold effects of habitat loss}

Overall, there was a clear relationship between the amount of remaining habitat and the three calculated metrics. Specifically, population abundance and genetic diversity declined with increasing habitat loss, while genetic differentiation increased (Fig. 4.2A-C, solid horizontal lines). In all three metrics, these responses were not linear, but instead indicated the existence of critical thresholds of habitat loss with stable values before the threshold and a rapid change in slope at the threshold. Hence, the response variables were best predicted by threshold models compared to linear models (Table 4.2) across the 45 modelled traits. The location of these thresholds differed strongly in population abundance versus genetic variation. Specifically, the detected breakpoints were more consistent across traits for the two genetic metrics (allelic richness and genetic differentiation) than for abundance. For the latter, we found a strong decline at 32.6\% (CI 29.3-35.9\%) of remaining habitat (Fig. 4.2A, vertical lines). At this point, population abundance in the focal sites had on average dropped by about $10.0 \%$ (CI 5.3-16.6\%) compared to its initial value in the continuous landscape (Table A4.2). However, in 18 out of 45 trait combinations, breakpoint models with two breakpoint estimates $\left(\Psi_{1}=30, \Psi_{2}=60\right)$ performed better than models with only one estimate $\left(\Psi_{1}=30\right)$ (Table 4.2$)$. For these traits, piecewise regression modeling indicated a first threshold at on average $59.0 \%$ (CI 54.5-63.4\%) of habitat (Fig. 4.2A). However, in 12 of these 18 traits, population abundance first dropped slightly until on average $48 \%$ habitat remained, but then increased again until the actual threshold at $30 \%$. Thus, this first threshold detected in $27 \%$ of simulations indicates the transition from a negative to a positive change in the slope of population abundance whereas in only $13 \%$ of simulations an actual, slight decrease was detected.

In 662 simulation scenarios (i.e., $1.2 \%$ of simulations), individuals went extinct before simulations were complete. These scenarios were distributed over five parameter settings, but population went extinct more often under low population densities and high dispersal abilities (i.e., high dispersal distance and high dispersal probability). Extinction occurred more often when habitat was reduced heavily to a remaining value of $10 \%(A=10$, extinction probability of $55 \%$ ), but also occurred at other values (i.e., with $A=20,30$, 40 and $50 \%$, where extinction occurred in $28,8,4$, and $1 \%$ of simulations, respectively).

Thresholds detected for genetic variation were more consistent and occurred at lower levels of habitat loss. Specifically, piecewise regression per- 
formed best when selecting two breakpoints $\left(\Psi_{1}=30, \Psi_{2}=60\right)$ in all scenarios for both $A_{R}$ and Jost'D (Table 2.2). $A_{R}$ first significantly decreased at habitat amounts of $59.7 \%$ (CI 58.5-60.9\%) and Jost'D increased at 58.8\% (CI 57.6$60.0 \%$ ) of remaining habitat (Fig. 4.2B, C, solid horizontal lines). At this first threshold, populations lost on average $0.3 \%$ (CI 0.2-0.4\%) of genetic diversity and genetic differentiation increased by $9 \%$ (CI 6.4-11.9\%) (Table A4.2). This change in the two genetic metrics was followed by a second pronounced decrease in $\mathrm{A}_{\mathrm{R}}$ at $22.8 \%$ (CI 22.6-23.0\%) and a strong increase in Jost'D at $22.5 \%$ (CI 22.3-22.8\%) of remaining habitat. At this second threshold, $\mathrm{A}_{\mathrm{R}}$ decreased on average by $1.8 \%$ (CI $1.3-2.2 \%$ ) and Jost'D increased by $67.0 \%$ (CI 44.8-88.9\%) (Table A4.2).

For $A_{R}$ and Jost'D, breakpoint detection was consistent over scenarios as indicated by narrow confidence intervals at the first breakpoint and even more narrow confidence intervals for the second threshold (Fig. 4.2B, C, dotted vertical lines).

\section{Temporal metric behavior after habitat loss stopped}

In the 20 generations after habitat loss had stopped, the effects of habitat loss generally continued over time, i.e., population abundance and genetic diversity continued to decline and genetic differentiation continued to increase. The magnitude of responses varied between habitat loss scenarios. Landscapes that had experienced extensive habitat loss (rem.Hab $=10 \%$ ) exhibited highest changes in population abundance and $A_{R}$ (Fig. 4.3A, B). Jost'D showed similar patterns within the first five generations, but decreased afterwards to lower values compared to scenarios where habitat was reduced to 20 and 30\% (Fig. $4.3 \mathrm{C})$.

Generally, the further habitat loss had proceeded, the larger was the change between generations for $A_{R}$ and Jost'D. Relative changes in genetic diversity and differentiation were still increasing after 20 generations. In contrast, relative changes in population abundance first increased exponentially, but then become asymptotic after about 15 generation post habitat loss.

In comparison to population abundance and allelic richness, the magnitude of change in Jost'D was much more pronounced. Four generations after habitat loss proceeded to 30,20 or $10 \%$, differentiation values had increased by about $50 \%$ compared to the first generation. In contrast, $A_{R}$ and population abundance had changed by $7 \%$ and $13 \%$, respectively, when habitat loss proceeded to a maximum of $10 \%$ remaining habitat (Table A4.3). 

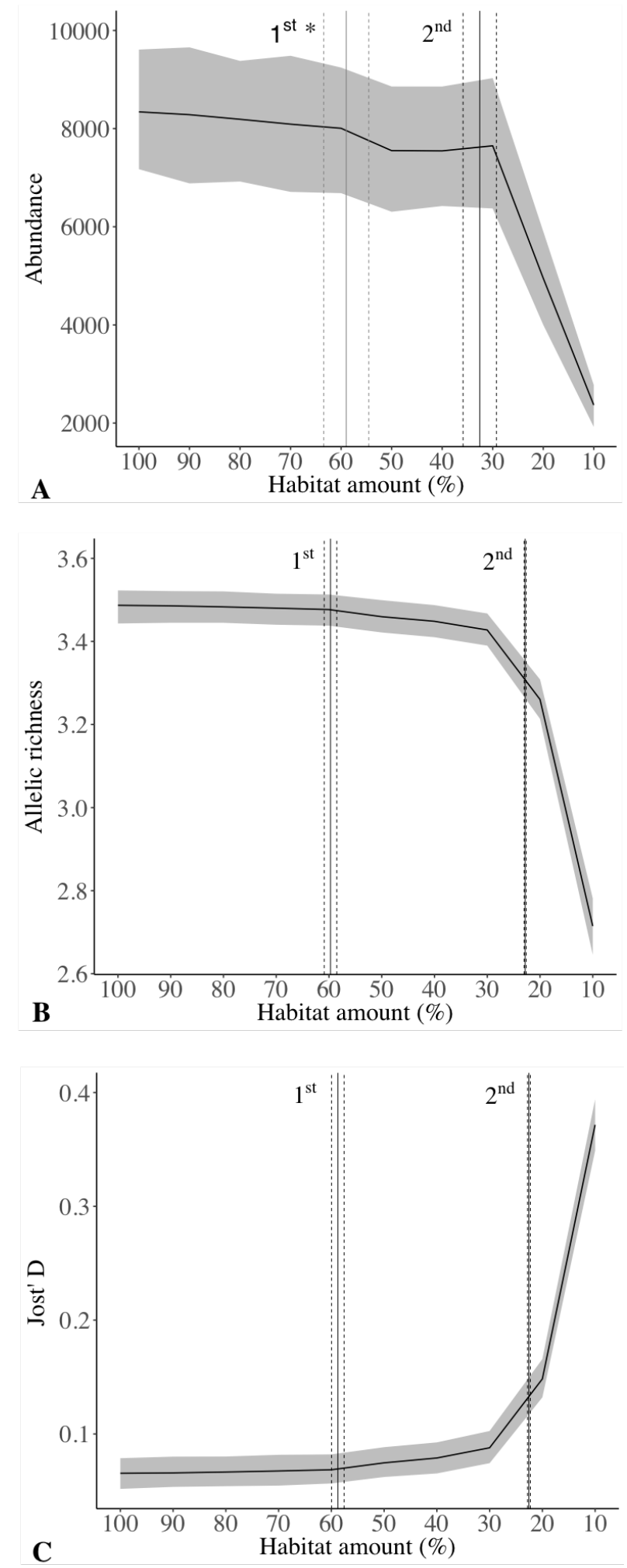

Figure 4.2: Relationship of mean abundance (A), allelic richness (B), and Jost' D (C) values (horizontal solid lines) with habitat loss for all 45 simulated species scenarios with $95 \%$ confidence intervals (grey ribbon). Solid vertical lines indicate first and second breakpoints suggested by piecewise regression and dashed lines indicate their confidence intervals. $\left(^{*}\right)$ A first breakpoint for population abundance was selected in only 18 species. 

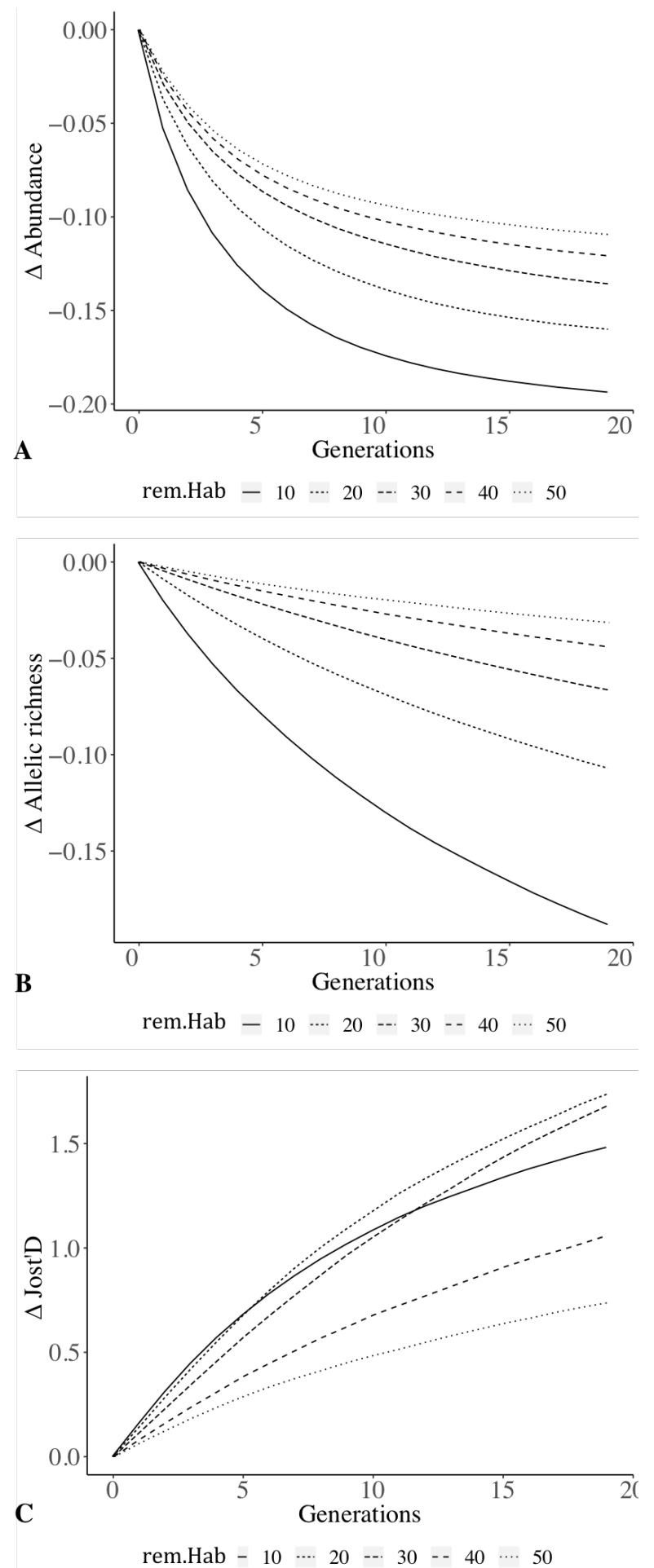

Figure 4.3: Temporal development of mean population abundance (A), allelic richness (B), and Jost' D (C) over the last 20 generations following habitat loss. The relative difference corresponds to the difference between each generation in comparison to the first generation (generation 0) after habitat loss was terminated. Different line types represent the different habitat loss scenarios, where habitat was reduced either to $50,40,30,20$, or $10 \%$ habitat (rem.Hab). 
Table 4.2: $\triangle$ AIC of linear models $(\mathrm{lm})$ and piecewise regression models with either one breakpoint estimate at $30 \%$ habitat $(\Psi: 30)$ or two breakpoint estimates at 60 and 30\% habitat ( $\Psi: 60 \mid 30$ ) for population abundance, allelic richness and Jost'D. When $\triangle \mathrm{AIC}$ was $<4$ the more parsimonious model was selected. NAs indicate that a second breakpoint was not selected by piecewise regression.

\begin{tabular}{|c|c|c|c|c|c|c|c|c|c|}
\hline \multirow[b]{2}{*}{$\operatorname{scn}$} & \multicolumn{3}{|c|}{ Abundance } & \multicolumn{3}{|c|}{ Allelic richness } & \multicolumn{3}{|c|}{ Jost'D } \\
\hline & $\operatorname{lm}$ & $\Psi: 30$ & $\Psi: 60 \mid 30$ & $\operatorname{lm}$ & $\Psi: 30$ & $\Psi: 60 \mid 30$ & $\operatorname{lm}$ & $\Psi: 30$ & $\Psi: 60 \mid 30$ \\
\hline 1 & 108.3 & 6.7 & 0 & 82.5 & 19.9 & 0 & 79.9 & 21.8 & 0 \\
\hline 2 & 77 & 13.9 & 0 & 83.2 & 27.1 & 0 & 79 & 24.4 & 0 \\
\hline 3 & 65.9 & 16.3 & 0 & 90.2 & 29.5 & 0 & 86.2 & 25.7 & 0 \\
\hline 4 & 57.4 & 4.1 & 0 & 97.4 & 28.9 & 0 & 99.9 & 29.1 & 0 \\
\hline 5 & 55.2 & 0 & 3.3 & 99.4 & 23.9 & 0 & 103.1 & 25.8 & 0 \\
\hline 6 & 72.8 & 11.8 & 0 & 75.4 & 22.8 & 0 & 72.1 & 22.9 & 0 \\
\hline 7 & 42.3 & 7.7 & 0 & 78.8 & 25 & 0 & 74.3 & 24.8 & 0 \\
\hline 8 & 14.7 & 0 & NA & 84.7 & 25.5 & 0 & 78.2 & 23.6 & 0 \\
\hline 9 & 8.1 & 0 & 0.1 & 80.4 & 29.2 & 0 & 72.8 & 25.6 & 0 \\
\hline 10 & 5.5 & 0 & NA & 78.4 & 30.9 & 0 & 72.9 & 29.3 & 0 \\
\hline 11 & 119.6 & 0 & NA & 90.8 & 21.5 & 0 & 87.8 & 21.1 & 0 \\
\hline 12 & 72.8 & 0 & NA & 89.4 & 28.2 & 0 & 86.8 & 26.3 & 0 \\
\hline 13 & 59.3 & 0 & NA & 93.5 & 28 & 0 & 93.3 & 26.9 & 0 \\
\hline 14 & 65.7 & 3.5 & 0 & 104.1 & 30.4 & 0 & 104.3 & 28.7 & 0 \\
\hline 15 & 63.9 & 0 & 3.8 & 104.7 & 24.6 & 0 & 102.2 & 18.1 & 0 \\
\hline 16 & 109.4 & 8.4 & 0 & 84.6 & 20.3 & 0 & 81.7 & 21 & 0 \\
\hline 17 & 64.8 & 0 & NA & 88.4 & 28.1 & 0 & 84.1 & 25 & 0 \\
\hline 18 & 60.9 & 9.9 & 0 & 92.6 & 27.8 & 0 & 90.4 & 24.2 & 0 \\
\hline 19 & 54.6 & 0 & 2.1 & 98.6 & 26.1 & 0 & 101.1 & 24.2 & 0 \\
\hline 20 & 56.5 & 0 & NA & 102.8 & 23.1 & 0 & 105.5 & 21 & 0 \\
\hline 21 & 75.4 & 13.6 & 0 & 76.4 & 20.4 & 0 & 74.4 & 21.1 & 0 \\
\hline 22 & 44.3 & 8.3 & 0 & 80.9 & 23.5 & 0 & 78.7 & 23.3 & 0 \\
\hline 23 & 18.5 & 0 & NA & 85.6 & 23.1 & 0 & 82.4 & 21.9 & 0 \\
\hline 24 & 16.3 & 0 & 2.4 & 86.1 & 21.5 & 0 & 84.2 & 21.1 & 0 \\
\hline 25 & 11.6 & 0 & 1.1 & 85.8 & 23.7 & 0 & 85.5 & 24.8 & 0 \\
\hline 26 & 123.3 & 6.2 & 0 & 90.6 & 21 & 0 & 88.5 & 21.2 & 0 \\
\hline 27 & 76.6 & 0 & 0.3 & 91.3 & 26.7 & 0 & 90.8 & 26 & 0 \\
\hline 28 & 63 & 0 & NA & 94 & 25.6 & 0 & 94.5 & 23.4 & 0 \\
\hline 29 & 66.6 & 0 & NA & 103 & 27 & 0 & 105.8 & 24 & 0 \\
\hline 30 & 73.7 & 4.8 & 0 & 102.7 & 18.6 & 0 & 103.9 & 11.3 & 0 \\
\hline 31 & 72 & 0 & NA & 83.8 & 20.6 & 0 & 81.3 & 22.4 & 0 \\
\hline 32 & 66.1 & 8.4 & 0 & 82.4 & 26.5 & 0 & 77.8 & 23.7 & 0 \\
\hline 33 & 44.2 & 0 & NA & 86.9 & 27 & 0 & 82.5 & 21.8 & 0 \\
\hline 34 & 45 & 0 & 3.5 & 96.6 & 28.6 & 0 & 98.7 & 28.5 & 0 \\
\hline 35 & 45 & 0 & 3 & 94.4 & 20.5 & 0 & 99.7 & 21.2 & 0 \\
\hline 36 & 72.9 & 13.7 & 0 & 72.2 & 21.3 & 0 & 69.7 & 22.7 & 0 \\
\hline 37 & 32.9 & 3.8 & 0 & 76 & 24.5 & 0 & 71 & 24.3 & 0 \\
\hline 38 & 3.7 & 0 & 2.7 & 73.5 & 20 & 0 & 77 & 26.7 & 0 \\
\hline 39 & 7.9 & 6.9 & 0 & 65.7 & 28.2 & 0 & 66.8 & 34 & 0 \\
\hline 40 & 10.5 & 11.7 & 0 & 59 & 26 & 0 & 58.3 & 28.4 & 0 \\
\hline 41 & 118.9 & 0 & NA & 94.9 & 24.1 & 0 & 89.2 & 21.7 & 0 \\
\hline 42 & 42.8 & 4.1 & 0 & 80.6 & 25.6 & 0 & 76.4 & 24.2 & 0 \\
\hline 43 & 56.4 & 4.8 & 0 & 93.2 & 26.7 & 0 & 89.4 & 22 & 0 \\
\hline 44 & 51.7 & 0 & 3 & 101.8 & 27.1 & 0 & 99.3 & 21.6 & 0 \\
\hline 45 & 51.7 & 0 & 2.4 & 103.2 & 25.4 & 0 & 101.6 & 19.2 & 0 \\
\hline
\end{tabular}


As stated above, our reason for varying dispersal and density parameters of the simulated species was to ensure that results are robust, and not limited to a specific parameter set. Hence, our simulated data are not suitable to directly quantify the exact influence of different parameter values on obtained results, and a detailed discussion of these effects is out of the scope of this study. Nevertheless, it is informative and important to discuss several obvious patterns in the simulated data.

Overall, a similar trend (i.e., threshold response) could be observed across most simulation parameters for genetic variation and abundance. Simulated species traits mostly affected the initial values of genetic variation (i.e., the values observed at generation 100, after the burn-in without habitat loss). In contrast, the location of the breakpoint, i.e. the value of habitat amount at which the slope rapidly changed, varied across species traits for population abundances.

Initial values of genetic diversity were higher and genetic differentiation weaker for simulated species with higher dispersal distances (simulation parameter disp.dist), and higher probability to disperse (disp.prob). However, with higher dispersal probability, the increase in genetic differentiation and decrease in genetic diversity after the threshold around $60 \%$ was more pronounced. Furthermore, initial values of genetic diversity were higher and genetic differentiation lower in scenarios with higher habitat capacity $(k)$ and lower levels of fragmentation $(p)$.

Relative to carrying capacity $(k)$ settings, initial values for abundance were slightly higher in scenarios with lowest dispersal distances and probability. In these scenarios, individuals were not able to move very far and thus, have a higher probability of remaining in the focal sites. As mentioned above, response curves and thresholds detected for population abundance were not consistent across simulation parameters. In some species scenarios, intermediate dispersal abilities led to a slight increase in population abundance between $50 \%$ and $40 \%$ remaining habitat. In six scenarios, high dispersal ability (i.e., disp.dist $=20$, 25 ; disp.prob $=0.5, k=5,15,20$ ) led to a sharp and pronounced decline in population abundance between 60 and $50 \%$ remaining habitat, but in most scenarios, the first drop in abundance was not observed until $30 \%$ remaining habitat. Finally, the reduction in population abundance after a threshold was generally steeper for scenarios with higher habitat capacity $(k)$. 


\section{Discussion}

Before discussing results and their potential implications in detail, we need to acknowledge several limitations of our simulation approach. Generally, simulations and their underlying models are supposed to simplify complex reality, by representing only those key characteristics or behaviors of a system that are considered most relevant for a specific research question. This means that we need to identify the key variables and processes of interest that should be included in our simulations, and to make simplifying assumptions about which parameters to exclude or hold constant (Grimm and Railsback, 2005). In our simulations, a first simplification was our focus on habitat-specialist species. While other, less specialized species might show different responses to habitat loss, we chose specialists species because they are most sensitive to habitat destruction, making them particularly suitable indicator species for conservation. We also only modeled binary landscapes consisting of habitat and non-habitat, as this is the way that specialist species will most likely perceive landscapes experiencing habitat loss, and because conservation applications of habitat thresholds typically distinguish only between habitat and non-habitat areas. Nevertheless, a heterogeneous landscape matrix with varying resistances to movement will potentially impact when and how populations respond to increasing habitat loss, and we encourage future studies to evaluate how varying matrix qualities alter demographic and genetic responses of populations to landscape-wide habitat loss.

Concerning demography, we only considered a logistic, density dependent model of reproduction (see Table 4.1 and the ODD protocol, Appendix A4.1). Many other options for modeling population dynamics exist, but a logistic, density-dependent growth has been reported in many different terrestrial vertebrate species (Bonenfant et al., 2009; Chavel et al., 2017; Fowler, 1987). Importantly, since population size was determined by densitydependent growth, and because dispersers were chosen as a certain proportion of the total population (determined by the parameter disp.prob), our simulations also include density-dependent dispersal, as more emigrants are sent out from high-density populations. Since we varied initial population size $N_{\mathrm{t}}$ and carrying capacity $k$, our simulations actually lead to a variety of different population trajectories and density-dependent dispersal patterns, thus increasing the robustness of our inferences. Finally, we modelled non-overlapping generations, which is obviously not realistic for most vertebrate species. Overlapping generations can be simulated in only a few simulation tools (Hoban et al., 
2012), and these are typically not individual-based and cannot directly include landscape data in the simulations (Landguth et al., 2015). For example, the software CDMetaPOP (Landguth et al., 2017), can simulate overlapping generations and landscape-dependent dispersal probabilities, but cannot incorporate mortality of individual dispersers in the matrix, which is vital for capturing the effects of habitat loss on population persistence (Fahrig, 2002). Also, CDMetaPop uses age-dependent survival and reproductive rates, which would have required us to make additional assumptions. Moreover, both population abundances and genetic variation were created under the same simulation framework involving non-overlapping generations, so comparing their relative response to increasing landscape-wide habitat loss should still be valid.

Overall, our simulation-based study clearly involves several simplifications that call for a careful interpretation of our results, and for future studies that address some of the limitations of our study. Nevertheless, our results were remarkable clear across a large range of simulation scenarios (i.e., traits and landscapes), and they thus provide a first indication for the general existence of non-linear genetic responses to landscape-wide habitat loss in specialist species.

\section{Non-linear responses}

Both abundance and genetic variation showed non-linear responses to habitat loss. In the early stages of habitat loss, focal populations were stable in size, had high genetic diversity and low genetic structure. However, when a certain value of habitat amount within the surrounding landscape was reached, all metrics responded in a sudden and non-linear way. The value of habitat amount at which the slope rapidly changed differed between abundance and genetic variation, and this difference is most likely due to indirect vs. direct effects of habitat loss.

For genetic differentiation and diversity, and across all modelled parameters, a negative effect of habitat loss could be detected around $60 \%$ remaining habitat. This level of remaining habitat coincides with the level of habitat fragmentation where interpatch distances begin to suddenly increase exponentially, so that habitat patches become effectively isolated (Fig. A4.4, see also Gardener et al. 1987, Fahrig 2003). The growing spatial isolation leads to a severe reduction in successful dispersal, and genetic exchange cannot counterbalance the loss of genetic variation due to genetic drift any more. This indirect effect of habitat loss in the landscape surrounding focal popu- 
lations leads to a strong differentiation among them, as well as to a loss of within-population diversity over few generations.

In contrast, population abundance in focal sites was stable in most scenarios until only $30 \%$ habitat remained and then decreased rapidly to low numbers or even to extinction when habitat loss proceeded. At this high level of landscape-wide habitat loss, the effects are no longer just indirect, but directly affect the sampled focal populations (see Fig. 4.1D). Specifically, any further habitat loss directly reduces the number of individuals within the focal sites, thus substantially decreasing population sizes. This reduction in population size also leads to a large change in allele frequencies, thus increasing genetic differentiation and decreasing genetic diversity in the next generation. Here, genetic variation follows demographic changes with a time-lag, a pattern also found in real systems and other simulation studies (Holzhauer et al., 2006; Landguth et al., 2010; Spear and Storfer, 2008).

In sum, we detected a first non-linear threshold response for genetic variation at around $60 \%$ of remaining habitat. This threshold can be explained by indirect effects of landscape-wide habitat loss on successful dispersal among remaining patches. We next detected a threshold for abundance at ca. $33 \%$ of habitat, which is when direct habitat loss effects become apparent. The resulting decline in local population sizes is followed by another, strong threshold response in genetic variation at $22 \%$ habitat. These results show that population size, genetic diversity and genetic differentiation are not independent, but that their temporal response to ongoing habitat loss differs.

Previous empirical work supports our finding that genetic variation responds more quickly to habitat loss than population abundance or species richness within remaining habitat patches. For example, Pardini et al. (2010) could only detect negative effects of habitat loss on the total number of Amazonian small non-volant mammal species in a landscape with $10 \%$ remaining habitat, while species compositions in study landscapes with 30 and $50 \%$ remaining habitat were still similar to the composition in a continuous landscape. Changes in species composition were caused by the extinction of habitat specialist species in the landscape with only $10 \%$ habitat remaining. In contrast to these results for the species pool, the genetic variation of one of its members, i.e. the habitat specialist Grey Slender Opossum (Marmosops incanus), was already detectable at lower levels of habitat loss (Balkenhol et al., 2013).

Clearly, local population size (i.e., abundance) impacts genetic variation, because the size of a local population governs genetic drift, which is 
counteracted by gene flow. Thus, small populations experience particularly strong drift when they are isolated from other populations, which increases genetic differentiation while reducing genetic diversity. Nevertheless, our results suggest that the response of abundance and of genetic variation to landscapewide habitat loss should be considered separately, as they do not show the same trajectories in our simulations. Indeed, population abundance only explained about $30 \%$ of the genetic metrics (see correlations reported in the results section), indicating that looking at abundance alone will not provide sufficient insight on potential genetic habitat loss effects.

Obviously, landscape-wide habitat loss also directly affects the overall size of the population in the entire landscape. Thus, had we not analyzed data from the focal populations, but instead from the entire study landscapes, we would have a detected a response of abundance to increasing habitat loss at much higher levels of remaining habitat. However, we do not believe that such a complete landscape-wide sampling is realistic in most practical settings. Instead, population responses to increasing habitat loss are usually assessed and monitored in defined focal areas (i.e., remaining habitat patches; Pardini et al., 2010; Ochoa-Quintero et al., 2015) and our goal here was to assess the response of these focal areas to landscape-wide habitat loss over time. Thus, our results suggest that abundance and genetic variation of specialist species in remaining habitat fragments will often show non-linear responses to increasing landscape-wide habitat loss, that thresholds are caused by direct and indirect effects, and that the location of thresholds differs for the three metrics we evaluated.

\section{Consistency of abundance vs. genetic variation}

When dispersal distance and dispersal rate were high (i.e., $50 \%$ of individuals disperse), populations declined earlier than under more sedentary conditions. These negative effects of higher dispersal capabilities on abundance might seem counterintuitive, but Ewers and Didham (2006) showed that the species most sensitive to increasing fragmentation are the ones that either are highly sedentary, or those with high dispersal ability. While the former loose connectivity among subpopulations due to a lack of movement and eventually face inbreeding depression, the latter face high mortality in the matrix. None of our trait combinations led to a completely sedentary behavior (i.e., zero movement out of focal populations), but since we simulated mortality of dispersers located in the matrix after they reached their maximum dispersal distance, 
our simulations likely represent the case where high dispersal is actually more detrimental under increasing habitat loss. Our simulation scenarios with high dispersal abilities of habitat specialists represent rather extreme cases and are possibly not often found in real life, where species might also adapt their dispersal behavior to fragmentation (Schtickzelle et al., 2006; Turlure et al., 2011). Nevertheless, our results are congruent with empirical studies that confirm that longer travels in the matrix increase mortality of dispersers (Bonelli et al., 2013; Mennechez et al., 2003; Waser et al., 1994) while a reduction in dispersal can have a positive effect on the population especially when habitat is highly fragmented (e.g. Schtickzelle et al., 2006). Overall, the response of population abundance appears to be dependent on specific trait characteristics, which agrees with the highly variable results of empirical evaluations of habitat thresholds (e.g. Radford et al., 2005; Ochoa-Quintero et al., 2015).

In contrast, genetic variation showed very consistent responses to habitat loss regardless of simulated traits. However, it is important to highlight that our 45 simulated trait combinations do not resemble completely different species, but were rather supposed to capture variation in dispersal and density characteristics, which are not only species-dependent, but also vary with individual behavior, local habitat qualities, population densities, and degrees of habitat fragmentation (e.g., Schtickzelle et al., 2006; Turlure et al., 2011). Using different combinations of dispersal and density parameters makes our results somewhat robust to variation in these traits, but under very different simulation scenarios, we might have found genetic variation to respond less consistently to landscape-wide habitat loss, even in specialist species. Nevertheless, previous empirical work shows that genetic diversity in a large number of different terrestrial animals is affected by habitat loss, especially when it is very substantial (Lino et al., 2018; Rivera-Ortíz et al., 2015). Thus, even though our results only apply to our specific simulation settings, similar nonlinear genetic responses to habitat loss might exist in a variety of species.

\section{Genetic diversity vs. differentiation}

Allelic richness and Jost'D were highly correlated, but since both indices are commonly reported in empirical studies, both are reported here. While the shape of the response to increasing habitat loss was very similar for both metrics (i.e., thresholds were detected at similar values of remaining habitat), the magnitude of their response differed substantially. Specifically, we found that the distribution of genetic variation (i.e., genetic differentiation) showed a more 
pronounced response to habitat loss than the amount of genetic variation (i.e., genetic diversity), expressed by larger relative changes in Jost'D during habitat loss. These findings are in congruence with previous studies. For example, Keyghobadi et al. (2005) demonstrated that habitat fragmentation impacts genetic diversity and differentiation at different temporal scales. While diversity in the butterfly Parnassius smintheus was best explained by past habitat patterns, genetic differentiation was best explained by recent habitat changes, suggesting that differentiation reacts more quickly to environmental changes. Extending this to multiple landscapes, Balkenhol et al. (2013) found that genetic differentiation of the studied small marsupial was already significantly higher in a landscape with $49 \%$ native forest, compared to a continuous landscape, while significantly lower levels of genetic diversity were only found when comparing the contiguous landscape to a landscape with $31 \%$ forest remaining. These studies and our findings based on multiple simulated species traits strongly suggest that different response trajectories can be expected for population abundance, genetic diversity and genetic differentiation in landscapes experiencing habitat loss.

\section{Legacy effect after stopping habitat loss}

An interesting finding of our simulations is the fact that changes in genetic metrics still continued for up to 20 generations after habitat loss was stopped, while changes in population abundance often reached stable values after five generations following habitat loss (Fig. 4.3A-C). For instance, even when half of the original habitat remained (rem.Hab=50\%), the loss of genetic diversity and increase in genetic differentiation continued over the entire 20 generations post habitat loss. This is again supported by two meta-analyses of empirical studies, which observed stronger habitat loss effects on genetic variation of populations that were longer subjected to these effects (Rivera-Ortíz et al., 2015; Schlaepfer et al., 2018). Our results suggest that just stopping habitat loss might be effective for stabilizing population abundances in the short term, but might not be enough to prevent genetic depletion and associated population declines in the long run (e.g., due to inbreeding depression or insufficient evolutionary capacity of populations). These results seem particularly important in the context of extinction debts, which cause species to go extinct due to events in the past (Kuussaari et al., 2009).

These results are also highly relevant for understanding landscapegenetic relationships in fragmented habitats. Researchers are increasingly 
aware of 'legacy effects' in landscape genetics, which occur when contemporary genetic patterns can be attributed to past landscape characteristics (Cushman et al., 2011; Epps and Keyghobadi, 2015). For example, Landguth et al. (2010) showed that under certain conditions, genetic effects of dispersal barriers can still be detected for more than 100 generations after barrier removal. However, while empirical studies investigating genetic legacy effects consider that the landscape is dynamic (i.e., the past landscape is considered in analyses), these studies still assume that the genetic pattern they measured is stable and representative of current or past landscape influences. Our results suggest that even in now stable landscapes, past habitat loss can still cause diversity to decline and differentiation to increase, which means that truly understanding genetic effects of landscape-wide habitat loss will require temporal monitoring schemes in which landscape-genetic relationships are assessed across multiple generations.

\section{Potential conservation application}

While our results are based on simulations with all their simplifications and limitations (see above), they nevertheless point towards an interesting potential of genetic data in practical conservation. Habitat thresholds, i.e., the maximum value of habitat loss that a species can tolerate before it is threatened by extinction, are often used to define habitat conservation targets (McAlpine et al., 2007; Rompré et al., 2010; van der Hoek et al., 2015). Simple habitat thresholds are appealing, because they do not require actual field data to be collected and because the amount of habitat within a landscape can easily be derived from digital maps or remote sensing data. However, these threshold values can be inaccurate and misleading, and they also do not provide any actual evidence of habitat loss effects, which is often needed to convince stakeholders and policy-makers to invest in conservation actions. On the other hand, sophisticated early-warning indicators of imminent species decline (e.g., Dakos et al., 2012; Scheffer et al., 2009) could theoretically be used as an alternative to simple habitat threshold rules, but they require long-term demographic monitoring data that is difficult and expensive to obtain in most applied settings.

Given the sharp, very consistent and early genetic responses to landscape - wide habitat loss found in our simulation study, we believe that genetic approaches might offer an avenue towards developing useful early-warning indicators for applied conservation management. Specifically, genetic indices 


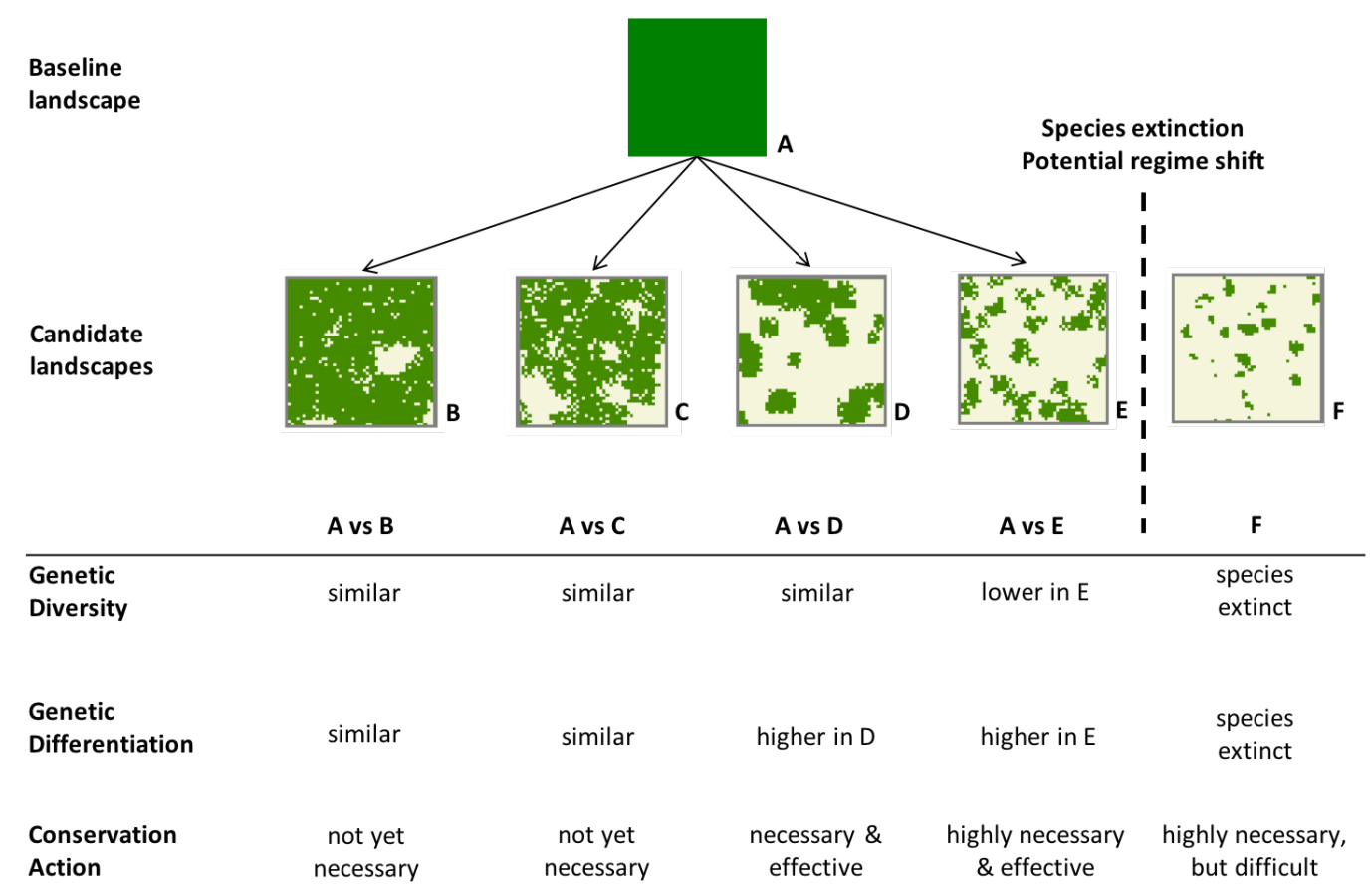

Figure 4.4: Conceptual outline of genetic early warning indicators of landscape-wide habitat loss. Genetic diversity and genetic differentiation in a landscape showing continuous habitat (landscape A) are used as a baseline for comparison with several candidate landscapes where conservation actions are considered. In landscape $\mathbf{B}$ and $\mathbf{C}$, no conservation action is needed, because genetic variation is essentially the same as in the continuous habitat. In landscapes $\mathbf{D}$ and $\mathbf{E}$, conservation action (e.g., habitat restoration) is required and has the potential to be effective, because habitat loss has already impacted genetic variation, but has not yet caused species extinctions. In contrast, effective conservation is very difficult to achieve in landscape $\mathbf{F}$, where habitat loss has already caused species extinctions and a potential regime shift. Shown example landscapes were simulated with a spatial autocorrelation parameter $p$ of 0.3 and habitat amount $A$ of 1 (landscape A), 0.9 (landscape B), 0.7 (landscape C), 0.5 (landscape D), 0.3 (landscape E), 0.1 (landscape F), respectively.

could be used within a monitoring program, where the same landscape is continuously monitored as habitat loss is ongoing. Ideally, genetic data from before habitat loss started, e.g. from museum species, should be available for this temporal approach, as this data serves as a baseline for comparison of different points in time. If genetic differentiation is found to be significantly increased compared to the original, continuous landscape, habitat loss needs to be stopped to prevent species extinctions. If genetic diversity is significantly reduced, such conservation actions are urgently required. In reality, it will often be difficult to apply this temporal monitoring approach, because habitat alterations have already occurred in most unprotected areas across the globe, and because an actual monitoring requires long-term data collection, which is logistically and financially challenging. We therefore suggest that genetic 
early-warning indicators have greatest merit within a spatial framework that compares multiple landscapes at a single point of time to identify those areas that require most urgent conservation attention and where conservation efforts have the greatest potential to be effective (Fig. 4.4). This framework requires a control area (e.g., protected landscape) where genetic metrics of differentiation and diversity are estimated for one or several appropriate indicator (i.e., habitat-specialist) species. Landscapes showing significantly higher levels of genetic differentiation and lower levels of genetic diversity compared to the control area should receive highest priority for conservation, as they are likely close to severe declines in population abundance, resulting in high extinction risk and potentially irreversible regime shifts due to landscape-wide habitat loss (see also Pardini et al., 2010). We encourage future studies to further evaluate the usefulness and reliability of genetic early-warning indicators for detecting negative effects of habitat loss in both simulated and empirical species.

\section{Conclusions}

In sum, sudden non-linear responses to habitat loss and fragmentation can not only be detected in abundance, but also in genetic variation of habitat specialists under a variety of trait characteristics and landscape scenarios. Importantly, even relatively low levels of landscape-wide habitat loss can indirectly impact genetic variation, while abundances of local populations in our simulations were most strongly affected by direct habitat loss. This emphasizes that the current risk of population collapses and extinctions of habitat specialists might be higher than predicted from abundance data alone. Indirect habitat loss, i.e., loss of functional connectivity, is the likely driver for an earlier signal in genetic variation compared to local abundances, which suggests that genetic data may indicate negative habitat loss effects before irreversible tipping points have been reached and species go extinct. Since the loss of genetic variation decreases population viability, we suggest that an improved understanding of non-linear genetic effects is crucial to anticipate and ultimately prevent negative habitat loss effects.

We encourage others to further assess the generality of genetic habitat threshold effects, their relevance for understanding landscape effects on gene flow and population persistence, and their potential use in applied conservation using empirical and simulation studies. 


\section{References}

Andrén, H. (1994). Effects of habitat fragmentation on birds and mammals in landscapes with different proportions of suitable habitat: A review. Oikos, 71(3):355-366.

Balkenhol, N., Pardini, R., Cornelius, C., Fernandes, F., and Sommer, S. (2013). Landscapelevel comparison of genetic diversity and differentiation in a small mammal inhabiting different fragmented landscapes of the Brazilian Atlantic Forest. Conservation Genetics, 14(2):355-367.

Banks-Leite, C., Pardini, R., Tambosi, L. R., Pearse, W. D., Bueno, A. A., Bruscagin, R. T., Condez, T. H., Dixo, M., Igari, A. T., Martensen, A. C., and Metzger, J. P. (2014). Using ecological thresholds to evaluate the costs and benefits of set-asides in a biodiversity hotspot. Science, 345(6200):1041-1045.

Bommarco, R., Biesmeijer, J. C., Meyer, B., Potts, S. G., Pöyry, J., Roberts, S. P., SteffanDewenter, I., and Ockinger, E. (2010). Dispersal capacity and diet breadth modify the response of wild bees to habitat loss. Proceedings of the Royal Society B: Biological Sciences, 277(1690):2075-2082.

Burnham, K. and Anderson, D. (2002). Model Selection and Multimodel Inference: A Practical Information-Theoretic Approach. Springer, 2nd edition.

Efford, M. (2018). secr: Spatially explicit capture-recapture models. R package version 3.1.3. https://CRAN.R-project.org/packagesecr.

Ewers, R. M. and Didham, R. K. (2006). Confounding factors in the detection of species responses to habitat fragmentation. Biological reviews of the Cambridge Philosophical Society, 81(1):117-142.

Fagan, W. F. and Calabrese, J. M. (2014). The correlated random walk and the rise of Movement Ecology. Bulletin of the Ecological Society of America, 95(3):204-206.

Fahrig, L. (2002). Effect of habitat fragmentation on the extinction threshold: a synthesis. Ecological Applications, 12(2):346-353.

Fahrig, L. (2003). Effects of habitat fragmentation on biodiversity. Annual Review of Ecology, Evolution, and Systematics, 34(1):487-515.

Frankham, R. (2005). Genetics and extinction. Biological Conservation, 126(2):131-140.

Gardner, R. H., Milne, B. T., Turner, M. G., and O'Neill, R. V. (1987). Neutral models for the analysis of borad scale landscape pattern. Landscape Ecology, 1(1):19-28.

Grimm, V., Berger, U., Bastiansen, F., Eliassen, S., Ginot, V., and et al. (2006). A standard protocol for describing individual-based and agent-based models. Ecological Modelling, 198(1-2):115-126.

Grimm, V., Berger, U., DeAngelis, D. L., Polhill, J. G., Giske, J., and Railsback, S. F. (2010). The ODD protocol: A review and first update. Ecological Modelling, 221(23):2760-2768.

Haddad, N. M., Brudvig, L. A., Clobert, J., Davies, K. F., Gonzalez, A., and et al. (2015). Habitat fragmentation and its lasting impact on Earth's ecosystems. Science Advances, 1(2):e1500052. 
Hoek, Y. V. D., Zuckerberg, B., Manne, L. L., van der Hoek, Y., Zuckerberg, B., and Manne, L. L. (2015). Application of habitat thresholds in conservation: Considerations, limitations, and future directions. Global Ecology and Conservation, 3:736-743.

Jackson, N. D. and Fahrig, L. (2014). Landscape context affects genetic diversity at a much larger spatial extent than population abundance. Ecology, 95(4):871-881.

Jackson, N. D. and Fahrig, L. (2016). Habitat amount, not habitat configuration, best predicts population genetic structure in fragmented landscapes. Landscape Ecology, 31(5):951-968.

Johnson, C. J. (2013). Identifying ecological thresholds for regulating human activity: Effective conservation or wishful thinking? Biological Conservation, 168:57-65.

Jost, L. (2008). GST and its relatives do not measure differentiation. Molecular Ecology, 17(18):4015-4026.

Kalinowski, S. T. (2004). Counting alleles with rarefaction: Private alleles and hierarchical sampling designs. Conservation Genetics, 5(4):539-543.

Kareiva, P. M. and Shigesada, N. (1983). Analyzing insect movement as a correlated random walk. Oecologia, 56(2-3):234-238.

Keinath, D. A., Doak, D. F., Hodges, K. E., Prugh, L. R., Fagan, W., Sekercioglu, C. H., Buchart, S. H., and Kauffman, M. (2017). A global analysis of traits predicting species sensitivity to habitat fragmentation. Global Ecology and Biogeography, 26(1):115-127.

Lange, R., Durka, W., Holzhauer, S. I., Wolters, V., and Diekötter, T. (2010). Differential threshold effects of habitat fragmentation on gene flow in two widespread species of bush crickets. Molecular Ecology, 19(22):4936-4948.

Lindenmayer, D. B., Fischer, J., and Cunningham, R. B. (2005). Native vegetation cover thresholds associated with species responses. Biological Conservation, 124(3):311-316.

Lindenmayer, D. B. and Luck, G. (2005). Synthesis: Thresholds in conservation and management. Biological Conservation, 124(3):351-354.

Muggeo, V. M. R. (2003). Estimating regression models with unknown break-points. Statistics in Medicine, 22(19):3055-3071.

Murphy, M. a., Dezzani, R., Pilliod, D. S., and Storfer, A. (2010). Landscape genetics of high mountain frog metapopulations. Molecular Ecology, 19(17):3634-3649.

Ochoa-Quintero, J. M., Gardner, T. A., Rosa, I., Frosini de Barros Ferraz, S., and Sutherland, W. J. (2015). Thresholds of species loss in Amazonian deforestation frontier landscapes. Conservation Biology, 29(2):440-451.

Ovaskainen, O. and Hanski, I. (2003). Extinction threshold in metapopulation models. Annual Zool. Fennici, 40:81-97.

Pardini, R., de Bueno, A. A., Gardner, T. A., Prado, P. I., and Metzger, J. P. (2010). Beyond the fragmentation threshold hypothesis: Regime shifts in biodiversity across fragmented landscapes. PLoS ONE, 5(10):e13666. 
Pardini, R., Nichols, E., and Püttker, T. (2017). Biodiversity response to habitat loss and fragmentation. Reference Module in Earth Systems and Environmental Sciences, pages $1-11$.

R Development Core Team (2017). R: A Language and Environment for Statistical Computing.

Radford, J. Q., Bennett, A. F., and Cheers, G. J. (2005). Landscape-level thresholds of habitat cover for woodland-dependent birds. Biological Conservation, 124(3):317-337.

Rebaudo, F., Le Rouzic, A., Dupas, S., Silvain, J. F., Harry, M., and Dangles, O. (2013). SimAdapt: An individual-based genetic model for simulating landscape management impacts on populations. Methods in Ecology and Evolution, 4(6):595-600.

Ricker, W. E. (1954). Stock and Recruitment. Journal of the Fisheries Research Board of Canada, 11(5):559-623.

Schtickzelle, N., Joiris, A., Van Dyck, H., and Baguette, M. (2007). Quantitative analysis of changes in movement behaviour within and outside habitat in a specialist butterfly. BMC Evolutionary Biology, 7:1-15.

Shaffer, M. L. (1981). Minimum population sizes for species conservation. BioScience, 31(2):131-134.

Signer, J. (2015). fpga: fast population genetic analysis. https://github.com/jmsigner/fpga.

Swift, T. L., Hannon, S. J., Swift, T. L., and Hannon, S. J. (2010). Critical thresholds associated with habitat loss: A review of the concepts, evidence, and applications. Biological Reviews, 85(1):35-53.

Van Dyck, H. and Baguette, M. (2005). Dispersal behaviour in fragmented landscapes: Routine or special movements? Basic and Applied Ecology, 6(6):535-545.

Wilenski, U. (1999). NetLogo. http://ccl.northwestern.edu/netlogo/. Center for Connected Learning and Computer-Based Modeling, Northwestern University, Evanston, IL.

With, K. A. and Crist, T. O. (1995). Critical thresholds in species' responses to landscape structure. Ecology, 76(8):2446-2459.

With, K. a. and King, A. W. (1999). Extinction thresholds for species in fractal landscapes. Conservation Biology, 13(2):314-326. 


\section{Supporting information}

Pflüger, F.J, Signer, J., and Balkenhol, N. (2019). Habitat loss causes nonlinear genetic erosion in specialist species. Global Ecology and Conservation, 17:e00507.

Appendix A4.1: ODD protocol and supplemental material.

Fig. A4.1: Initialization, procedures and conditional executions of a simulation run. Submodels are illustrated in rhombus, conditional expressions in circles. $Y$ : yes, $N$ : no, $t$ : time steps (ticks), a_total: habitat amount of the actual landscape file, max.loss: maximum amount of habitat loss a landscape experienced (terminates loading of new landscape files). After reaching rem.Hab, simulation will continue on the same landscape loaded one time step before.

Fig. A4.2: Simulated binary landscapes with varying habitat amount $(A)$ and configuration $(p)$. Black cells represent habitat and white cells represent matrix. This figure shows one replicate of all $\mathrm{p}$ values and five example values of $A$. Landscapes with $A=100,80,60,40$ or $20 \%$ habitat amount are not shown. For each combination, we produced 10 replicates using different random number seed.

Fig. A4.3: Habitat loss scenarios. Habitat was reduced in $10 \%$ increments every generation, until reaching the minimum value either of 50,40,30, 20, or $10 \%$ of remaining habitat. After reaching this minimum value, simulations continued for 20 generations in order to examine changes of response variables over time.

Fig. A4.4: Nearest neighbor distances between habitat patches along the habitat loss gradient for all $p$ values.

Table A4.1: Overview of processes, parameters and values of parameters in the SimAdapt model.

Table A4.2: Mean values for abundance $(a b)$, allelic richness $(A R)$, and Jost'D $(D), 95 \%$ confidence intervals ( $L=$ lower, $U=$ upper), and their relative changes over proceeding habitat loss compared to their initial values (at $100 \%$ habitat amount).

Table A4.3: Mean values for Jost'D $(D)$, allelic richness $(A R)$, and abundance $(a b)$ within the last 20 generations following habitat loss, and their relative changes and 95\% confidence intervals ( $L=$ lower, $U=$ upper) over different habitat loss scenarios compared to the first generation after habitat loss had stopped. 


\section{Appendix A4.1: ODD protocol and supplemental material}

\section{Overview}

The model description follows the ODD (Overview, Design concepts, Details) protocol for describing individual- and agent-based models (Grimm et al. 2006, 2010)). Our model is a modification of the pre-existing, spatially explicit landscape-genetic simulation model SimAdapt that was developed by Rebaudo et al. (2013) for NetLogo 5.0.3 (Wilenski, 1999).

\section{Purpose}

The aim of the model is to compare effects of continuous habitat loss and fragmentation on population demographic estimates - in particular population abundance - and population genetic diversity and differentiation. The model was designed to test the hypothesis that these effects can be detected earlier in measures of genetic variation than in demographic properties, which will have important consequences for the identification of areas of highest conservation concern.

State variables and scales

\section{Low-level entities}

The model comprises two entities: individuals and grid cells. Individuals are characterized by state variables updated each time step: identity number, location, dispersal capacity, degree of directional persistence, list of neutral markers, generation, sample ID, and parents.

The grid cells represent the landscape in which the individuals evolve. Each cell is characterized by its state, which describes the environmental condition driving individual dispersal and population dynamics: a barrier variable representing the cost to move through a certain cell (habitat_barrier), a resource variable representing the carrying capacity of a cell (habitat_resource), and a type variable describing the habitat characteristics (habitat_type).

\section{High-level entities}

The variable values of single grid cells shape the quality of a binary landscape (Fig. A4.2), i.e. cells are either habitat or matrix cells with habitat cells having a carrying capacity and lower resistance values to move through. 
Contiguous habitat cells are defined as patches and individuals on the same patch are defined as a population.

Population dynamics are modeled as discrete time steps. Each time step in the model corresponds to one generation, i.e. generations are nonoverlapping. The world extent was set 50 x 50 grid cells resulting in a total of 2500 cells.

\section{Process overview and scheduling}

The model combines two submodels: a population-genetic submodel and a cellular automaton, landscape submodel (Fig. A4.1). The population-genetic submodel processes include dispersal and reproduction in this given order for each given individual taken in a random order. Time is modeled as discrete time steps. At the end of one time step, all individuals die, and the next time step begins with their offspring. The information about location and genetic markers of the reproducing generation is stored in an output file. All individual state variables are updated asynchronously as they are taken in a random order.

The landscape model runs asynchronously with the population genetic submodel. Depending on the number of generations, landscapes disturbances events are executed to introduce habitat loss and fragmentation.

\section{Design concepts}

Emergence: Population dynamics arise from the behavior of individuals, which is entirely represented by empirical rules describing dispersal rates as probabilities.

Predictions: The dispersal of individuals can be considered as a tactic prediction where dispersal to another cell will give to the population a better probability of survival by influencing genetic variation.

Sensing: As part of the dispersal procedure, individuals perceive the location of potential destination in their neighborhood. Within their last dispersal steps, individuals have a two cells radius perception of surrounding habitat, which enables them to perceive and move to nearby habitat.

Interaction: Individuals interact directly for reproduction and indirectly for mediating resources (carrying capacity).

Stochasticity: The mating of individuals in a given cell is modeled randomly to reproduce variability. Except for the last steps (see above), individuals 
disperse randomly among possible destinations without having a perception of surrounding habitat.

Collectives: Habitat cells that are connected to other habitat cells are defined as patch. Individuals belonging to the same patch are defined as a population. Observation: The following information for each individual was collected after each reproduction process (i.e. each time step): spatial location ( $\mathrm{x}-$ and $\mathrm{y}$ - coordinates), generation (i.e. no. of ticks), neutral markers, and parents. Output files also included information about underlying landscape files such as amount of remaining habitat $(A)$ and degree of fragmentation $(p)$.

\section{Initialization and related submodels}

Every simulation starts with setting the initial values of the state variables ( setup, see Table A4.1). Three external habitat layers of the initial full-habitatlandscape are loaded (submodel load_landscape), where each cell is of type habitat (habitat_type.txt) with a carrying capacity of either 20, 10 or 5 (habitat_resource.txt) and a resistance value of 1 (habitat_barrier.txt). According to Rebaudo et al. (2013), if no files are provided, the model will run with default values of 1, 100 and 10, respectively. Each file is organized with coordinates in the first two columns (abscissa, ordinate) and landscape characteristic (values for habitat type, resource, barrier) in the third. Individuals are homogeneously distributed over the landscape with each cell containing 20, 10 or 5 individuals (submodel setup_individuals) depending on the carrying capacity. For each individual 30 neutral loci (num_microsats), i.e. microsatellites, are created. Alleles are initialized randomly and consequently vary among simulations. They are chosen from a normal distribution with a standard deviation of $1\left(s d_{-} H\right)$, which corresponds to an expected heterozygosity around $70 \%$ and a number of possible alleles $z$ around 10 (see SimAdapt documentation of Rebaudo et al., 2013, pp. 12). The underlying population genetic principles are based on Hartl and Clark (2007), Wade (2001) and Trajstman (1973).

\section{Input}

There are no input data.

\section{Submodels}

Dispersal: The decisions whether to move or not was set to different dispersal probabilities of either $0.05,0.1$, or 0.5 . For this, a random number between 0 
and 1 is drawn and values below the dispersal probability caused movement. Dispersing individuals could move from one cell to another located in its Moore neighborhood (8 nearest neighboring cells). The landscape resistance of the two different habitat types (habitat vs. matrix) determined the dispersal distance. Each individual was characterized by a movement capacity of either 25 , $20,15,10$, or 5 steps and each cell was characterized by a resistance value with matrix cells having higher resistance than habitat cells. We chose resistance values of 5 for matrix and 1 for habitat. In every step, the resistance value was subtracted from the movement capacity. Each individual moved until its capacity was reached.

Dispersal behavior followed a correlated random walk (CRW, Kareiva and Shigesada, 1983) where dispersal directions of subsequent steps are correlated. The initial direction was chosen randomly between 0 to $360^{\circ}$. Directions for subsequent steps are selected from a wrapped Cauchy distribution with a mean direction equal to the previous one (Batschelet, 1981; Haefner and Crist, 1994). The concentration around the mean direction is determined by $\rho$, where $\rho=0$ results in a random walk and $\rho=1$ results in a perfect straight line. According to Zollner and Lima (1999) we set $\rho$ to 0.99 , since nearly straight dispersal promise higher dispersal success than uncorrelated walks (Haefner and Crist, 1994, Fletcher, 2006; Bartoń et al., 2009). In the last steps, i.e. before the individual reached its movement capacity, the individual was given a perceptual range of a two-cell radius. If there was habitat within this radius, the individual would move to this cell instead of passing nearby habitat and terminating movement in the matrix.

Individuals are not allowed to leave the world. When disperses experience the world's barriers, they turn around, i.e. face the opposite direction, and select a random heading between $90^{\circ}$ to the left or right, and continue to move.

Reproduction: The reproduction submodel is based on the assumption that all individuals have an equal probability of mating, given that they are located in a habitat cell with at least one additional conspecific. This excludes individuals in the matrix from reproduction. The number of descendants is defined by a logistic growth function (Ricker, 1954):

$$
N_{\mathrm{t}+1}=N_{\mathrm{t}} e^{r\left(N_{\mathrm{t}} / K\right)}
$$

where $N_{\mathrm{t}}$ is the number of individuals in a given cell before reproduction, $r$ is the defined intrinsic growth rate of 0.5 ( $r \_$growth), and $K$ is the carrying ca- 
pacity defined by the habitat resources landscape layer (habitat_resource.txt). The numbers of offspring calculated with the logistic growth function are stored in a list (listNt1) together with the $\mathrm{x}$ - and $\mathrm{y}$ - coordinate of the habitat cell of the reproducing individuals. All the gametes produced by the reproducing generation constitute a gamete pool. In the code, this gamete pool is implemented as another list (gam_pool) in which markers of each individual on the same habitat cell are stored.

Mortality: At the end of each generation, individuals died and the next generation was created with new genotypes generated from the gene pool of individuals from the previous generation that had reproduced. Note that information about number of offspring in the new generation and markers of the potential parents are stored in lists and are not deleted.

New generation: The creation of new individuals and assignment of genotypes is executed $N_{\mathrm{t}}+1$ times which is taken from a list created in the reproduction submodel (listNt1). For each new created individual two different individuals and their genetic markers are randomly drawn as parents from the gamete pool $\left(g a m \_p o o l\right)$. The transmission of genetic characteristics follows Mendel inheritance laws and allows free combination between loci. For creating new markers, one allele per parent is randomly drawn from the list and possibly transformed reflecting mutation. Mutations occur with a probability of $10^{-4}$ and is based on a stepwise mutation model as defined by Hamilton (2009), replacing allele $z$ by allele $z+1$ or by allele $z-1$.

Sampling and output: Sampling starts at generation 100 when the population is in equilibrium. After the 100th generation each individual ( $n$ ind) on every patch ( $n \_$points) and in every following generation is sampled and outputted in a csv file. Note that sampling only proceeds in habitat cells, because matrix cells are empty at this stage after clearing the old generation. The output file of a given landscape scenario comprises the following variables: individual ID, $\mathrm{x}$ - and $\mathrm{y}$ - coordinates, population size, generation, amount of remaining habitat (rem.Hab, see description below), neutral markers, mother ID, and father ID.

Update landscape: The first 100 generations run on the initially loaded uniform full-habitat landscape (100\% of habitat) to reach genetic equilibrium. After the 100th generation, landscape disturbance events are introduced every following generation by loading new landscape files containing 10\% less habitat amount than the previous landscape (Fig A4.3). Loading new files continues until a predefined maximum value of habitat loss (max.loss) is reached. This 
parameter could take either the value 50, 40, 30, 20, or $10 \%$. When reaching max.loss, simulation is proceeded on the corresponding landscape file until the final generation is reached.

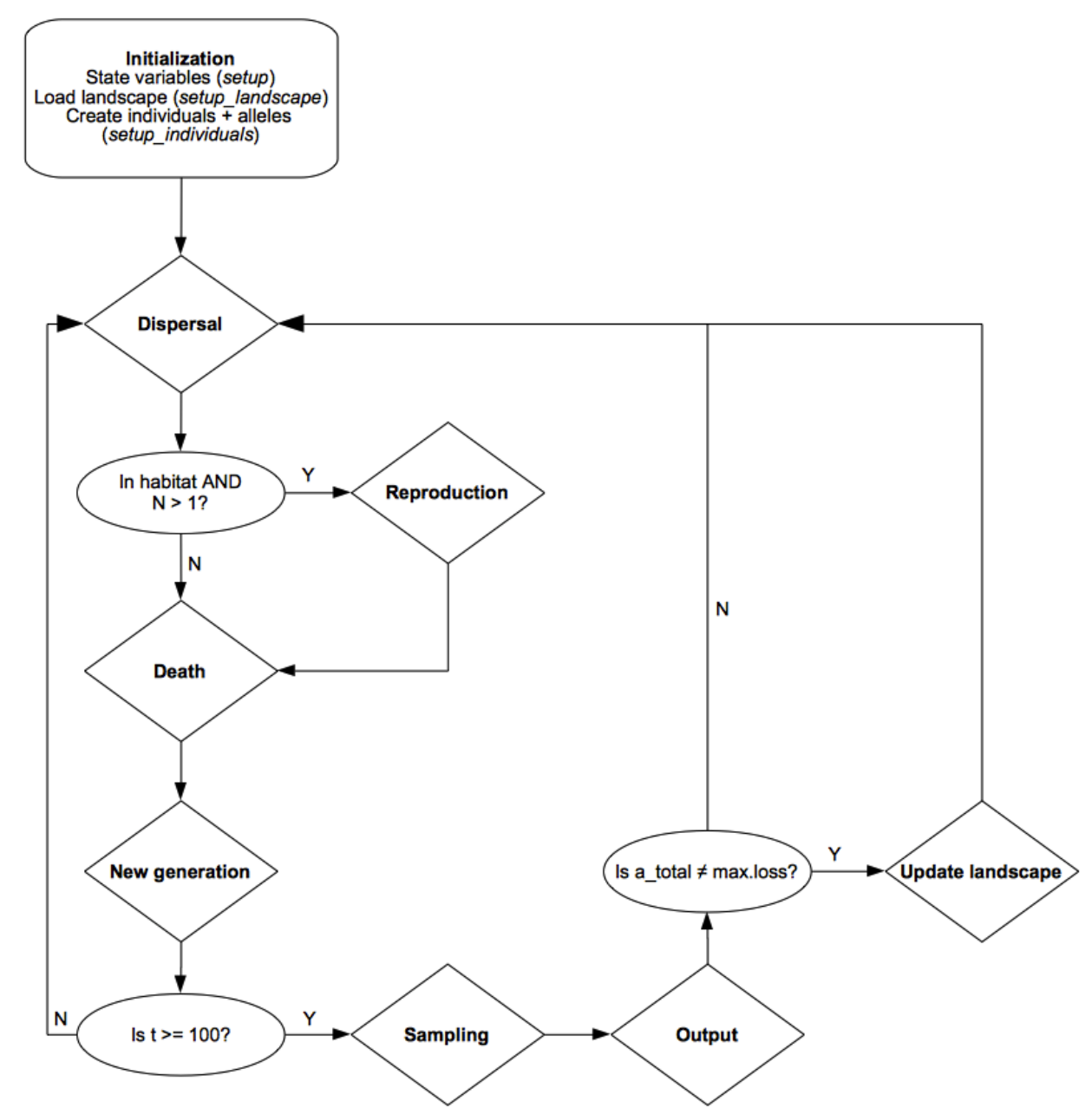

Figure A4.1: Initialization, procedures and conditional executions of a simulation run. Submodels are illustrated in rhombus, conditional expressions in circles. $Y$ : yes, $N$ : no, $t$ : time steps (ticks), a_total: habitat amount of the actual landscape file, max.loss: maximum amount of habitat loss a landscape experienced (terminates loading of new landscape files). After reaching max.loss, simulation will continue on the same landscape loaded one time step before. 


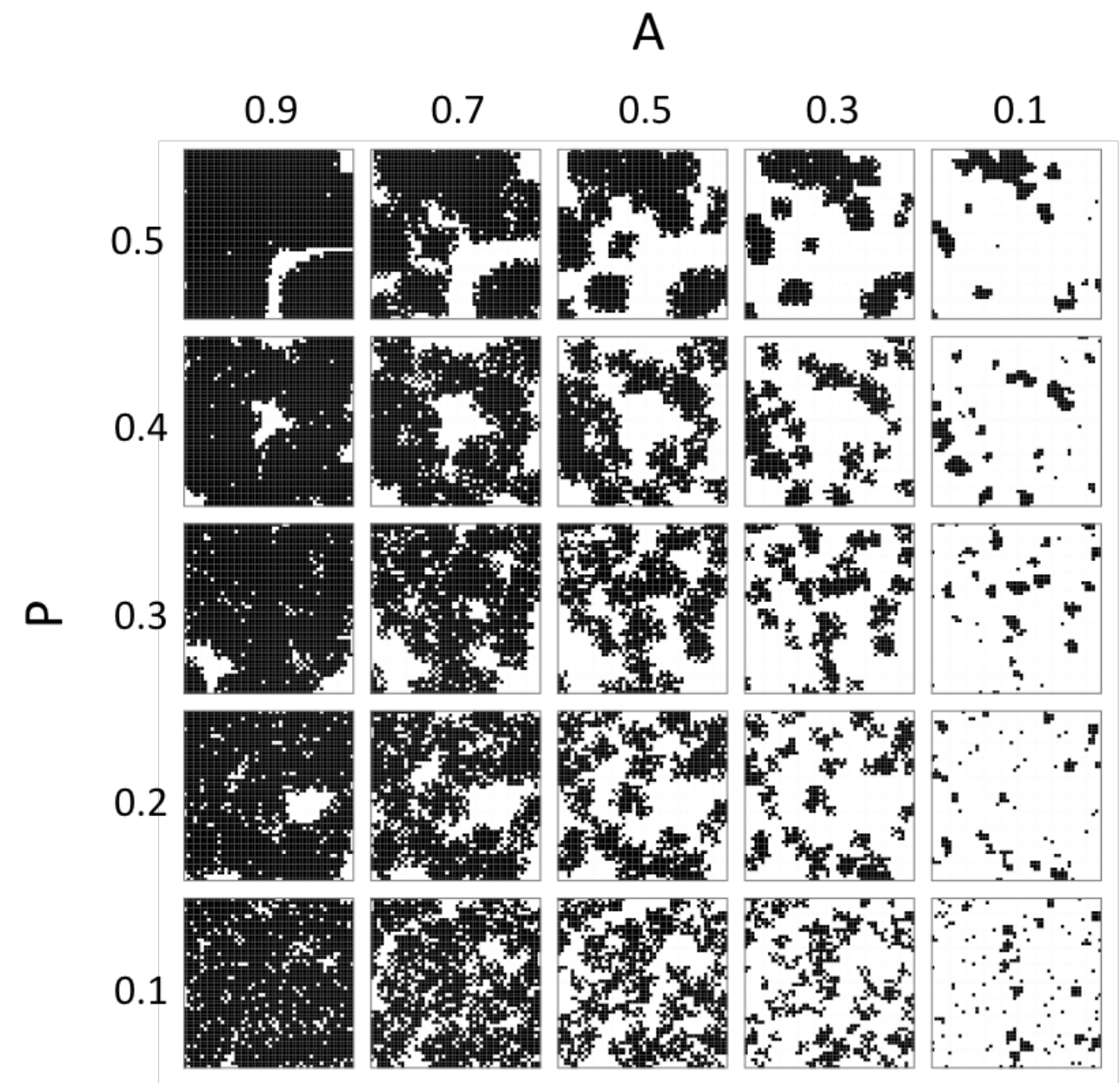

Figure A4.2: Simulated binary landscapes with varying habitat amount $(A)$ and configuration $(p)$. Black cells represent habitat and white cells represent matrix. This figure shows one replicate of all $\mathrm{p}$ values and five example values of $A$. Landscapes with $A=100,80,60,40$ or $20 \%$ habitat amount are not shown. For each combination, we produced 10 replicates using different random number seed. 


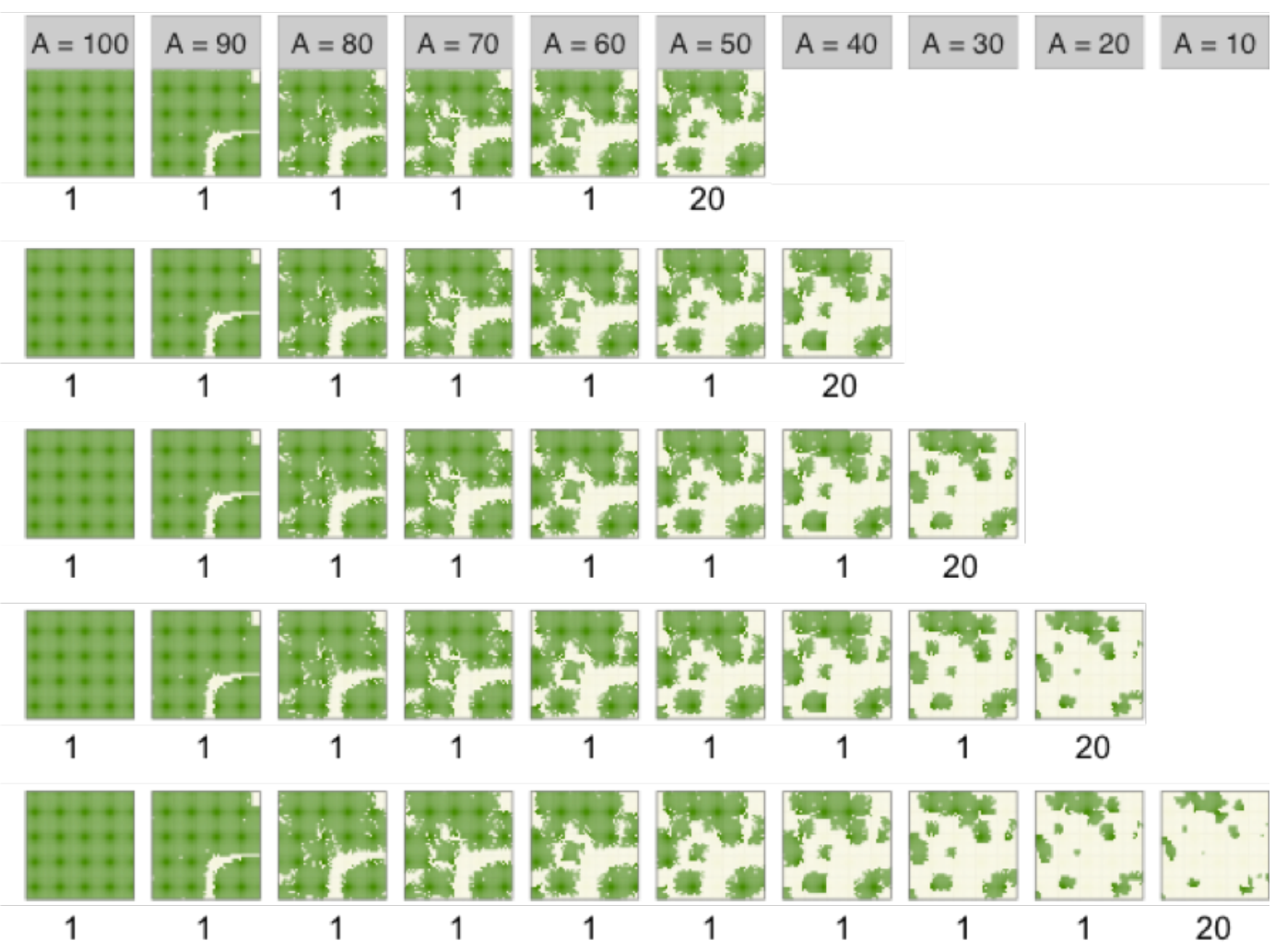

Figure A4.3: Habitat loss scenarios. Habitat was reduced in $10 \%$ increments every generation, until reaching the minimum value either of $50,40,30,20$, or $10 \%$ of remaining habitat. After reaching this minimum value, simulations continued for 20 generations in order to examine changes of response variables over time. 


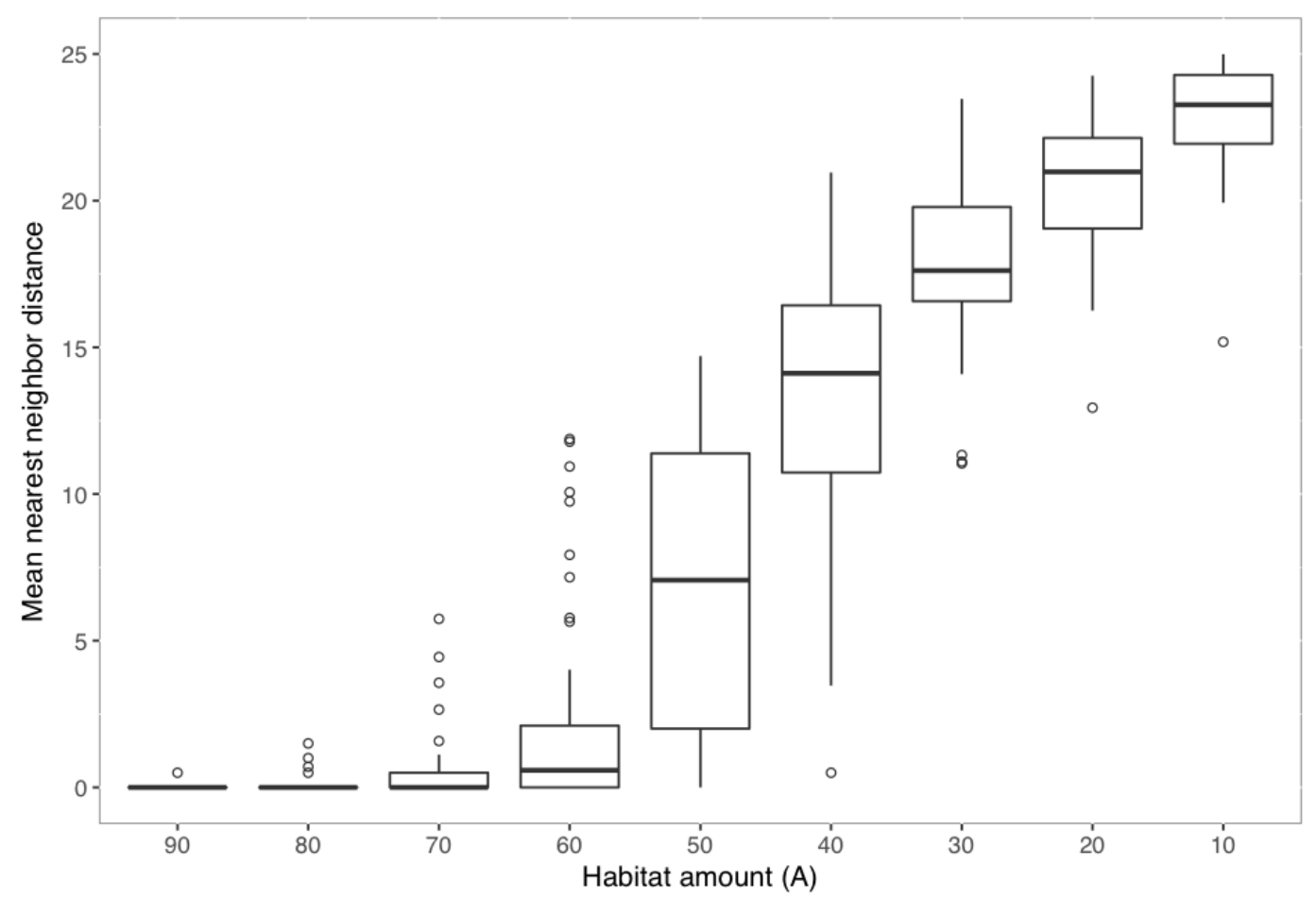

Figure A4.4: Nearest neighbor distances between habitat patches along the habitat loss gradient for all $p$ values. 
Table A4.1: Overview of processes, parameters and values of parameters in the SimAdapt model.

\begin{tabular}{|c|c|}
\hline Parameters & Values \\
\hline \multicolumn{2}{|l|}{ Setup } \\
\hline Number of individuals in each cell ( $\left.n b_{-} a g e n t\right)$ & 5,10, or 20 \\
\hline Distribution in every cell (everywhere) & On \\
\hline Number of microsatellite loci (num_microsat) & 30 \\
\hline $\begin{array}{l}\text { Standard deviation of the normal distribution } \\
\text { defining the heterozygosity rate \& no. of } \\
\text { different alleles }\left(s d_{H}\right)\end{array}$ & 1.0 \\
\hline Number of generations (var_num_generations) & 128 \\
\hline \multicolumn{2}{|l|}{ Dispersal } \\
\hline Dispersal probability (disp_proba) & $0.5,0.1,0.05$ \\
\hline Dispersal distance $\left(d i s p \_d i s t\right)$ & $25,20,15,10$, or 5 \\
\hline Degree of correlated random walk ( $h a b C R W$ ) & 0.9 \\
\hline \multicolumn{2}{|l|}{ Reproduction } \\
\hline $\begin{array}{l}\text { Growth parameter of the logistic growth model } \\
\left(r \_ \text {growth }\right)\end{array}$ & 0.5 \\
\hline $\begin{array}{l}\text { Probability of stepwise mutation } \\
(\text { mutation_rateN) }\end{array}$ & $10^{-4}$ \\
\hline \multicolumn{2}{|l|}{ Sampling and output } \\
\hline $\begin{array}{l}\text { Output file containing: turtleID, } \mathrm{x}-\text { and } \mathrm{y}- \\
\text { coordinate, neutral markers, parents (CSV) }\end{array}$ & On \\
\hline Switch to sampled populations (sample_pop?) & On \\
\hline $\begin{array}{l}\text { Type of sampling method (WR: with } \\
\text { replacement, WOR: without replacement) }\end{array}$ & WR \\
\hline $\begin{array}{l}\text { No. of localizations per habitat type for } \\
\left.\text { sampling ( } n \_ \text {point }\right)\end{array}$ & 2500 \\
\hline $\begin{array}{l}\text { No. of individuals per localization for sampling } \\
\left(n \_ \text {ind }\right)\end{array}$ & 20,10, or 5 \\
\hline \multicolumn{2}{|l|}{ Landscape disturbance } \\
\hline Habitat amount of a landscape ( $a \_$total) & $100-10$ (increments of 10$)$ \\
\hline $\begin{array}{l}\text { Maximum amount of habitat loss to terminate } \\
\text { loading of new habitat files (rem.Hab) }\end{array}$ & $50-10$ (increments of 10$)$ \\
\hline
\end{tabular}


Table A4.2: Mean values for abundance $(a b)$, allelic richness $(A R)$, and Jost'D $(D)$, $95 \%$ confidence intervals ( $L=$ lower, $U=$ upper), and their relative changes over proceeding habitat loss compared to their initial values (at 100\% habitat amount).

\begin{tabular}{|c|c|c|c|c|c|c|}
\hline Amount & $a b$ & $a b_{L}$ & $\mathrm{ab}_{U}$ & rel_ab & rel_ab $\mathrm{ab}_{L}$ & rel_ab $\mathrm{b}_{U}$ \\
\hline 100 & 8340.99 & 7173.04 & 9609.68 & 0.00 & 0.00 & 0.00 \\
\hline 90 & 8283.41 & 6883.99 & 9655.17 & -0.72 & -1.08 & -0.43 \\
\hline 80 & 8189.82 & 6922.30 & 9378.56 & -1.93 & -3.01 & -1.07 \\
\hline 70 & 8090.20 & 6710.79 & 9483.30 & -3.25 & -4.93 & -2.01 \\
\hline 60 & 8006.43 & 6685.30 & 9242.76 & -4.38 & -6.36 & -2.52 \\
\hline 50 & 7550.73 & 6305.68 & 8857.75 & -11.19 & -15.82 & -6.51 \\
\hline 40 & 7545.56 & 6422.97 & 8856.82 & -11.31 & -16.31 & -6.70 \\
\hline 30 & 7650.09 & 6372.56 & 9028.80 & -10.04 & -16.64 & -5.27 \\
\hline 20 & 4952.52 & 4003.21 & 5905.06 & -41.84 & -46.52 & -37.97 \\
\hline 10 & 2367.73 & 1923.08 & 2774.31 & -72.14 & -74.88 & -69.97 \\
\hline Amount & $\mathrm{AR}$ & $\mathrm{AR}_{L}$ & $\mathrm{AR}_{U}$ & rel_AR & rel_AR $\mathrm{AR}_{L}$ & rel__ $\mathrm{AR}_{U}$ \\
\hline 100 & 3.49 & 3.44 & 3.52 & 0.00 & 0.00 & 0.00 \\
\hline 90 & 3.49 & 3.44 & 3.52 & -0.03 & -0.05 & -0.02 \\
\hline 80 & 3.48 & 3.44 & 3.52 & -0.11 & -0.14 & -0.07 \\
\hline 70 & 3.48 & 3.44 & 3.51 & -0.19 & -0.26 & -0.14 \\
\hline 60 & 3.48 & 3.44 & 3.51 & -0.29 & -0.38 & -0.20 \\
\hline 50 & 3.46 & 3.42 & 3.50 & -0.78 & -1.06 & -0.57 \\
\hline 40 & 3.45 & 3.41 & 3.49 & -1.10 & -1.47 & -0.82 \\
\hline 30 & 3.43 & 3.39 & 3.47 & -1.70 & -2.17 & -1.29 \\
\hline 20 & 3.26 & 3.21 & 3.31 & -6.52 & -7.46 & -5.63 \\
\hline 10 & 2.71 & 2.65 & 2.78 & -22.19 & -23.74 & -20.65 \\
\hline Amount & $\mathrm{D}$ & $\mathrm{D}_{L}$ & $\mathrm{D}_{U}$ & rel_D & rel_ $\mathrm{D}_{L}$ & rel_ $\mathrm{D}_{U}$ \\
\hline 100 & 0.07 & 0.05 & 0.08 & 0.00 & 0.00 & 0.00 \\
\hline 90 & 0.07 & 0.05 & 0.08 & 0.97 & 0.66 & 1.37 \\
\hline 80 & 0.07 & 0.05 & 0.08 & 3.18 & 2.26 & 4.11 \\
\hline 70 & 0.07 & 0.05 & 0.08 & 5.82 & 4.31 & 7.62 \\
\hline 60 & 0.07 & 0.06 & 0.08 & 9.02 & 6.40 & 11.91 \\
\hline 50 & 0.07 & 0.06 & 0.09 & 26.63 & 17.75 & 35.94 \\
\hline 40 & 0.08 & 0.07 & 0.09 & 39.61 & 27.45 & 55.49 \\
\hline 30 & 0.09 & 0.07 & 0.10 & 66.97 & 44.80 & 88.87 \\
\hline 20 & 0.15 & 0.13 & 0.17 & 229.68 & 167.22 & 299.62 \\
\hline 10 & 0.37 & 0.35 & 0.39 & 840.49 & 612.72 & 1065.48 \\
\hline
\end{tabular}


Table A4.3: Mean values for Jost'D $(D)$, allelic richness $(A R)$, and abundance $(a b)$ within the last 20 generations following habitat loss, and their relative changes and $95 \%$ confidence intervals ( $L=$ lower, $U=$ upper) over different habitat loss scenarios compared to the first generation after habitat loss had stopped.

\begin{tabular}{|c|c|c|c|c|c|c|c|c|c|c|}
\hline rem.Hab & Gen & rel_D & $\mathrm{D}_{L}$ & $\mathrm{D}_{U}$ & rel_AR & $\mathrm{AR}_{L}$ & $\mathrm{AR}_{U}$ & rel_ab & $\mathrm{ab}_{L}$ & $\mathrm{ab}_{U}$ \\
\hline 10 & 0 & 0 & 0 & 0 & 0 & 0 & 0 & 0 & 0 & 0 \\
\hline 10 & 1 & 15.76 & 12.04 & 19.94 & -1.98 & -2.36 & -1.66 & -5.26 & -7.17 & -3.43 \\
\hline 10 & 2 & 30.93 & 23.28 & 39.64 & -3.72 & -4.38 & -3.14 & -8.55 & -11.64 & -5.7 \\
\hline 10 & 3 & 44.72 & 33.52 & 57.37 & -5.26 & -6.19 & -4.46 & -10.85 & -14.3 & -7.18 \\
\hline 10 & 4 & 57.04 & 42.94 & 72.91 & -6.66 & -7.83 & -5.65 & -12.56 & -17.36 & -8.43 \\
\hline 10 & 5 & 67.9 & 51.01 & 86.34 & -7.89 & -9.23 & -6.67 & -13.87 & -19.22 & -9.22 \\
\hline 10 & 6 & 77.83 & 57.9 & 99.51 & -9.07 & -10.33 & -7.88 & -14.91 & -20.54 & -10.02 \\
\hline 10 & 7 & 86.61 & 61.88 & 112 & -10.15 & -11.82 & -8.73 & -15.74 & -22.16 & -9.51 \\
\hline 10 & 8 & 94.64 & 69.92 & 121.21 & -11.17 & -13.24 & -9.65 & -16.43 & -22.77 & -10.3 \\
\hline 10 & 9 & 101.8 & 78.04 & 131.1 & -12.1 & -14.25 & -10.44 & -16.97 & -24.2 & -11.06 \\
\hline 10 & 10 & 108.38 & 80.47 & 141.09 & -12.98 & -14.89 & -11.13 & -17.41 & -25.07 & -10.72 \\
\hline 10 & 11 & 114.54 & 83.68 & 148.87 & -13.81 & -15.78 & -11.84 & -17.78 & -25.3 & -10.94 \\
\hline 10 & 12 & 119.93 & 91.11 & 157.21 & -14.56 & -16.83 & -12.44 & -18.1 & -26.33 & -11.51 \\
\hline 10 & 13 & 124.66 & 88.87 & 163.72 & -15.24 & -17.71 & -13.18 & -18.37 & -26.55 & -11.83 \\
\hline 10 & 14 & 129.14 & 92.16 & 171.04 & -15.91 & -18.34 & -13.79 & -18.58 & -26.99 & -12.01 \\
\hline 10 & 15 & 133.64 & 97.28 & 174.49 & -16.55 & -19.07 & -14.39 & -18.78 & -26.18 & -11.44 \\
\hline 10 & 16 & 137.79 & 101.33 & 182.45 & -17.17 & -19.64 & -14.79 & -18.94 & -27.99 & -12.35 \\
\hline 10 & 17 & 141.41 & 101.84 & 177.12 & -17.74 & -20.51 & -15.45 & -19.1 & -27.01 & -11.49 \\
\hline 10 & 18 & 145.03 & 104.11 & 187.08 & -18.29 & -20.83 & -15.81 & -19.23 & -27.58 & -12.25 \\
\hline 10 & 19 & 148.17 & 105.07 & 191.94 & -18.81 & -21.52 & -16.34 & -19.36 & -27.89 & -11.96 \\
\hline 20 & 0 & 0 & 0 & 0 & 0 & 0 & 0 & 0 & 0 & 0 \\
\hline 20 & 1 & 14.01 & 10.69 & 17.50 & -0.89 & -1.11 & -0.71 & -3.74 & -5.23 & -2.54 \\
\hline 20 & 2 & 28.33 & 21.02 & 36.68 & -1.73 & -2.14 & -1.36 & -6.25 & -8.41 & -4.2 \\
\hline 20 & 3 & 42.02 & 30.93 & 53.17 & -2.52 & -3.09 & -2.03 & -8.1 & -11.19 & -5.39 \\
\hline 20 & 4 & 55.07 & 40.68 & 71.15 & -3.26 & -4.04 & -2.63 & -9.52 & -13.09 & -6.23 \\
\hline 20 & 5 & 67.59 & 49.94 & 87.29 & -3.96 & -4.94 & -3.06 & -10.62 & -15.39 & -6.87 \\
\hline 20 & 6 & 79.36 & 57.93 & 102.62 & -4.61 & -5.78 & -3.7 & -11.53 & -16.35 & -7.58 \\
\hline 20 & 7 & 90.39 & 66.69 & 115.49 & -5.24 & -6.48 & -4.09 & -12.28 & -17.62 & -7.96 \\
\hline 20 & 8 & 100.28 & 73.49 & 128.54 & -5.82 & -7.2 & -4.66 & -12.9 & -18.34 & -7.34 \\
\hline 20 & 9 & 109.23 & 79.29 & 144.18 & -6.36 & -7.92 & -5.09 & -13.42 & -18.9 & -8.51 \\
\hline 20 & 10 & 117.65 & 85.66 & 155.48 & -6.88 & -8.41 & -5.48 & -13.88 & -19.46 & -8.34 \\
\hline 20 & 11 & 126 & 94.8 & 164.16 & -7.39 & -8.98 & -6.01 & -14.28 & -20.27 & -8.53 \\
\hline 20 & 12 & 133.08 & 98.87 & 168.49 & -7.87 & -9.54 & -6.49 & -14.62 & -21.52 & -8.77 \\
\hline 20 & 13 & 139.76 & 104.34 & 177.93 & -8.32 & -10.23 & -6.7 & -14.9 & -21.6 & -9.16 \\
\hline 20 & 14 & 146.02 & 107.92 & 188.33 & -8.75 & -10.77 & -7.15 & -15.16 & -22.37 & -9.3 \\
\hline 20 & 15 & 152.13 & 113.67 & 199.07 & -9.18 & -11.35 & -7.31 & -15.37 & -21.9 & -9.36 \\
\hline 20 & 16 & 157.82 & 116.57 & 205.44 & -9.58 & -11.65 & -8 & -15.55 & -22.62 & -8.95 \\
\hline 20 & 17 & 163.18 & 122.93 & 208.35 & -9.96 & -11.71 & -8.15 & -15.74 & -21.83 & -9.6 \\
\hline 20 & 18 & 168.88 & 125.75 & 218.71 & -10.35 & -12.62 & -8.56 & -15.87 & -23.52 & -9.14 \\
\hline 20 & 19 & 173.63 & 129.44 & 220.64 & -10.7 & -12.75 & -8.83 & -16 & -23.96 & -9.87 \\
\hline
\end{tabular}


Table A4.3 - Continued from previous page

\begin{tabular}{|c|c|c|c|c|c|c|c|c|c|c|}
\hline rem.Hab & Gen & rel_D & $\mathrm{D}_{L}$ & $\mathrm{D}_{U}$ & rel_AR & $\mathrm{AR}_{L}$ & $\mathrm{AR}_{U}$ & rel_ab & $\mathrm{ab}_{L}$ & $\mathrm{ab}_{U}$ \\
\hline 30 & 0 & 0 & 0 & 0 & 0 & 0 & 0 & 0 & 0 & 0 \\
\hline 30 & 1 & 11.49 & 8.62 & 14.65 & -0.47 & -0.58 & -0.37 & -2.96 & -4.02 & -2.03 \\
\hline 30 & 2 & 23.08 & 17.47 & 29.25 & -0.92 & -1.12 & -0.75 & -5 & -7.03 & -3.4 \\
\hline 30 & 3 & 34.65 & 26.83 & 43.97 & -1.36 & -1.69 & -1.05 & -6.53 & -9 & -4.32 \\
\hline 30 & 4 & 45.92 & 33.84 & 59.53 & -1.78 & -2.24 & -1.41 & -7.71 & -10.81 & -5.08 \\
\hline 30 & 5 & 57.09 & 40.8 & 75 & -2.19 & -2.68 & -1.74 & -8.65 & -12.93 & -5.65 \\
\hline 30 & 6 & 67.49 & 48.26 & 87.46 & -2.58 & -3.23 & -2.1 & -9.41 & -13.44 & -6.22 \\
\hline 30 & 7 & 77.5 & 56.61 & 101.47 & -2.95 & -3.74 & -2.34 & -10.05 & -14.36 & -6.21 \\
\hline 30 & 8 & 87.17 & 62.81 & 114.34 & -3.32 & -4.21 & -2.62 & -10.6 & -15.02 & -6.79 \\
\hline 30 & 9 & 96.73 & 69.84 & 125.3 & -3.69 & -4.63 & -2.89 & -11.05 & -15.63 & -6.6 \\
\hline 30 & 10 & 105.25 & 77.86 & 134.34 & -4.03 & -5.08 & -3.15 & -11.45 & -16.27 & -6.98 \\
\hline 30 & 11 & 113.38 & 84.37 & 149.09 & -4.36 & -5.45 & -3.32 & -11.81 & -17.58 & -7.46 \\
\hline 30 & 12 & 121.21 & 89.47 & 158.85 & -4.67 & -5.9 & -3.63 & -12.13 & -17.61 & -7.28 \\
\hline 30 & 13 & 128.59 & 96.2 & 161.63 & -4.98 & -6.35 & -3.9 & -12.4 & -18.56 & -7.46 \\
\hline 30 & 14 & 136.34 & 96.67 & 178.35 & -5.29 & -6.79 & -4.07 & -12.65 & -17.96 & -7.48 \\
\hline 30 & 15 & 143.44 & 109.01 & 187.69 & -5.58 & -7.18 & -4.34 & -12.88 & -19.36 & -7.67 \\
\hline 30 & 16 & 150.16 & 108.4 & 196.43 & -5.86 & -7.46 & -4.52 & -13.09 & -19.26 & -7.79 \\
\hline 30 & 17 & 156.26 & 115.59 & 203.45 & -6.13 & -7.86 & -4.66 & -13.26 & -18.88 & -7.72 \\
\hline 30 & 18 & 162.25 & 117.77 & 205.96 & -6.4 & -8.04 & -4.97 & -13.43 & -19.97 & -7.85 \\
\hline 30 & 19 & 168.07 & 118.63 & 217.26 & -6.64 & -8.29 & -5.18 & -13.58 & -20.2 & -8.6 \\
\hline 40 & 0 & 0 & 0 & 0 & 0 & 0 & 0 & 0 & 0 & 0 \\
\hline 40 & 1 & 8.29 & 6.33 & 10.59 & -0.34 & -0.43 & -0.26 & -2.57 & -3.58 & -1.7 \\
\hline 40 & 2 & 16.24 & 12.05 & 20.96 & -0.65 & -0.81 & -0.52 & -4.44 & -6.25 & -2.77 \\
\hline 40 & 3 & 23.91 & 18.04 & 30.18 & -0.95 & -1.18 & -0.75 & -5.85 & -8.08 & -3.74 \\
\hline 40 & 4 & 31.19 & 22.92 & 41 & -1.24 & -1.54 & -0.95 & -6.93 & -9.61 & -4.48 \\
\hline 40 & 5 & 38.5 & 28.55 & 48.99 & -1.51 & -1.95 & -1.18 & -7.79 & -11.28 & -4.96 \\
\hline 40 & 6 & 44.77 & 32.67 & 56.81 & -1.77 & -2.23 & -1.38 & -8.48 & -11.9 & -5.18 \\
\hline 40 & 7 & 50.92 & 37.3 & 66.52 & -2.01 & -2.5 & -1.53 & -9.04 & -13 & -5.33 \\
\hline 40 & 8 & 57 & 42.36 & 72.59 & -2.25 & -2.86 & -1.7 & -9.52 & -13.98 & -5.52 \\
\hline 40 & 9 & 62.34 & 45.53 & 81.03 & -2.48 & -3.1 & -1.94 & -9.92 & -14.06 & -6.11 \\
\hline 40 & 10 & 67.91 & 48.49 & 90.52 & -2.71 & -3.52 & -2.13 & -10.26 & -14.75 & -6.21 \\
\hline 40 & 11 & 72.53 & 53.63 & 94.37 & -2.92 & -3.7 & -2.24 & -10.56 & -15.97 & -6.16 \\
\hline 40 & 12 & 77.06 & 56.95 & 103.48 & -3.12 & -4.02 & -2.34 & -10.83 & -15.79 & -6.26 \\
\hline 40 & 13 & 81.63 & 60.56 & 102.77 & -3.32 & -4.29 & -2.56 & -11.07 & -16.65 & -6.65 \\
\hline 40 & 14 & 86.19 & 62.09 & 110.46 & -3.52 & -4.51 & -2.65 & -11.29 & -16.83 & -6.63 \\
\hline 40 & 15 & 90.78 & 68.26 & 116.46 & -3.71 & -4.78 & -2.86 & -11.48 & -17.05 & -6.82 \\
\hline 40 & 16 & 94.81 & 72.63 & 121.28 & -3.9 & -5.07 & -2.99 & -11.66 & -17.09 & -6.99 \\
\hline 40 & 17 & 98.24 & 72.59 & 127.94 & -4.07 & -5.24 & -3.08 & -11.82 & -18.49 & -7.04 \\
\hline 40 & 18 & 102.02 & 77.31 & 130.45 & -4.24 & -5.44 & -3.3 & -11.95 & -18.13 & -7.11 \\
\hline 40 & 19 & 106.02 & 77.55 & 137.4 & -4.41 & -5.9 & -3.33 & -12.09 & -17.9 & -7.26 \\
\hline 50 & 0 & 0 & 0 & 0 & 0 & 0 & 0 & 0 & 0 & 0 \\
\hline 50 & 1 & 6.58 & 4.80 & 8.56 & -0.26 & -0.34 & -0.2 & -2.4 & -3.35 & -1.55 \\
\hline 50 & 2 & 12.65 & 9.01 & 16.46 & -0.51 & -0.65 & -0.39 & -4.14 & -5.77 & -2.83 \\
\hline 50 & 3 & 18.52 & 13.66 & 24.15 & -0.74 & -0.96 & -0.57 & -5.44 & -7.77 & -3.52 \\
\hline 50 & 4 & 23.95 & 17.36 & 31.45 & -0.95 & -1.22 & -0.75 & -6.43 & -9.06 & -3.85 \\
\hline 50 & 5 & 28.95 & 20.88 & 38.41 & -1.15 & -1.49 & -0.89 & -7.2 & -10.11 & -4.63 \\
\hline
\end{tabular}


Table A4.3 - Continued from previous page

\begin{tabular}{lllllllllllll}
\hline rem.Hab & Gen & rel_D & $\mathrm{D}_{L}$ & $\mathrm{D}_{U}$ & $\mathrm{rel} \mathrm{AR}_{-} \mathrm{AR}_{L}$ & $\mathrm{AR}_{U}$ & $\mathrm{rel}_{-} \mathrm{ab}_{2}$ & $\mathrm{ab}_{L}$ & $\mathrm{ab}$ \\
\hline 50 & 6 & 33.57 & 14.04 & 43.51 & -1.33 & -1.75 & -1.03 & -7.83 & -11.19 & -5.07 \\
50 & 7 & 37.64 & 27.65 & 50.07 & -1.51 & -1.96 & -1.16 & -8.33 & -11.92 & -5.29 \\
50 & 8 & 41.35 & 30.14 & 54.94 & -1.67 & -2.17 & -1.31 & -8.75 & -12.87 & -5.24 \\
50 & 9 & 45.22 & 33.43 & 59.19 & -1.83 & -2.38 & -1.43 & -9.11 & -13.13 & -5.4 \\
50 & 10 & 48.55 & 35.92 & 63.51 & -1.97 & -2.52 & -1.49 & -9.4 & -13.61 & -6.04 \\
50 & 11 & 51.58 & 37.95 & 68.43 & -2.12 & -2.75 & -1.6 & -9.66 & -14.4 & -5.92 \\
50 & 12 & 54.88 & 40.29 & 69.95 & -2.26 & -2.88 & -1.72 & -9.89 & -14.97 & -6 \\
50 & 13 & 58.04 & 42.93 & 76.29 & -2.41 & -3.16 & -1.84 & -10.08 & -14.52 & -6.14 \\
50 & 14 & 60.95 & 44.84 & 79.85 & -2.54 & -3.34 & -1.93 & -10.27 & -15.13 & -6.04 \\
50 & 15 & 63.86 & 48.51 & 83.24 & -2.67 & -3.58 & -1.98 & -10.43 & -15.95 & -6.13 \\
50 & 16 & 66.35 & 48.15 & 87.47 & -2.79 & -3.74 & -2.12 & -10.59 & -16.12 & -6.19 \\
50 & 17 & 69.17 & 50.78 & 89.69 & -2.92 & -3.95 & -2.19 & -10.72 & -16.25 & -6.65 \\
50 & 18 & 71.6 & 52.86 & 93.55 & -3.03 & -3.93 & -2.26 & -10.84 & -15.95 & -6.43 \\
50 & 19 & 73.77 & 55.34 & 97.36 & -3.14 & -4.23 & -2.41 & -10.95 & -16.24 & -6.65 \\
& & & & & & & & & &
\end{tabular}

\section{References}

Bartoń, K. A., Phillips, B. L., Morales, J. M., and Travis, J. M. (2009). The evolution of an 'intelligent' dispersal strategy: Biased, correlated random walks in patchy landscapes. Oikos, 118(2):309-319.

Batschelet, E. (1981). Circular Statistics in Biology. Academic Press, London.

Fletcher, R. J. (2006). Emergent properties of conspecific attraction in fragmented landscapes. American Naturalist, 168(2):207-219.

Grimm, V., Berger, U., Bastiansen, F., Eliassen, S., Ginot, V., and et al. (2006). A standard protocol for describing individual-based and agent-based models. Ecological Modelling, 198(1-2):115-126.

Grimm, V., Berger, U., DeAngelis, D. L., Polhill, J. G., Giske, J., and Railsback, S. F. (2010). The ODD protocol: A review and first update. Ecological Modelling, 221(23):2760-2768.

Haefner, J. W. and Crist, T. O. (1994). Spatial Model of Movement and Foraging in Harvester Ants (Pogonomyrmex) (I): The Roles of Memory and Communication.

Hamilton, M. B. (2009). Population Genetics. Wiley-Blackwell, West Sussex.

Hartl, D. and Clark, A. G. (2007). Principles of Population Genetics. Sinauer Associates, Sunderland, MA.

Kareiva, P. M. and Shigesada, N. (1983). Analyzing insect movement as a correlated random walk. Oecologia, 56(2-3):234-238.

Rebaudo, F., Le Rouzic, A., Dupas, S., Silvain, J. F., Harry, M., and Dangles, O. (2013). SimAdapt: An individual-based genetic model for simulating landscape management impacts on populations. Methods in Ecology and Evolution, 4(6):595-600. 
Ricker, W. E. (1954). Stock and Recruitment. Journal of the Fisheries Research Board of Canada, 11(5):559-623.

Trajstman, A. C. (1973). The necessity of the Poisson distribution for the equivalence of some random mating models. Mathematical biosciences, 17:1-10.

Wade, M. J. (2001). Epistasis, complex traits, and mapping genes. Genetica, 112-113(i):5969.

Wilenski, U. (1999). NetLogo. http://ccl.northwestern.edu/netlogo/. Center for Connected Learning and Computer-Based Modeling, Northwestern University, Evanston, IL.

Zollner, P. A. and Lima, S. L. (1999). Search Strategies for Landscape-Level Interpatch Movements. Ecology, 80(3):1019-1030. 



\section{CHAPTER 5}

\section{General discussion}

This thesis studies the effects and consequences of landscape characteristics on individual dispersal and resulting dispersal pattern. Specifically, it deals with an integration of dispersal as a behavioral process of individuals into studies that examine landscape influences on gene flow, population distribution and population persistence. This last chapter discusses the main findings of the previous chapters and provides an outlook on how we can gain a deeper understanding of dispersal in heterogeneous landscapes and derive comprehensive inferences on resulting dispersal pattern.

\section{Environmental drivers of individual dispersal}

Studies that examine landscape effects on species distribution and genetic variation often make simplified assumptions on the underlying dispersal process. Although dispersal encompasses three interrelated stages that are influenced by different environmental factors (Clobert et al. 2009, Matthysen, 2012), it is often integrated as one single parameter (i.e., either emigration, movement or settlement). Consequently, only environmental factors relevant for this single stage (i.e., either local or landscape-wide factors) are considered and related to dispersal pattern.

As shown in chapter 2, the distribution of brown bears (Ursus arctos) in the Central-European Alps is determined by different environmental factors. Brown bear settlement was well explained by local landscapes factors, i.e., habitat suitability and habitat similarity, whereas habitat reachability, determined by the influence of landscape resistance on movement, was probably not the main driver of dispersal in brown bears. 
The focus on single landscape factors or dispersal stages, such as landscape resistance that is often used in studies on gene flow and population connectivity (e.g., landscape genetics or landscape ecology), could lead to false or incomplete inferences on how the landscape is affecting dispersal. For example, studies revealing that the landscape is permeable for movement of the study species, would conclude that dispersal is not negatively affected by the landscape. However, this conclusion could be inaccurate when the local habitat important for settlement does not fit the needs of an individual for survival and reproduction, and thus constraints effective dispersal.

Ideally, the first step of any study on landscape effects on dispersal pattern should be to test several hypotheses on several environmental factors that could be meaningful to the study species during the three steps of dispersal. Species relocation data in combination with spatial modeling, such as resource or step selection functions (Boyce et al., 2002; Thurfjell et al., 2014), offer the opportunity to link multiple possible environmental factors to the dispersal stages and to explore their potential effect on individual dispersal decisions. Advancing GPS tracking technologies can provide us with huge amounts of relocation data (Cagnacci et al. 2010). Their increasing spatial and temporal resolutions allow us to gain a detailed understanding on how individuals interact with their environment, making GPS tracking a promising tool for studying different dispersal stages separately. However, the assignment of relocation data to certain behavioral states, such as dispersal movements or resource use within home ranges, can be challenging.

Topology-based methods, such as the step-length thresholding used in chapter 2, are less data demanding and are analytically most straightforward when movement pattern have to be determined, such as in our analysis. Several alternative and more sophisticated methods are available to determine behavioral states in relocation data (Edelhoff et al., 2016). For example, behavioral change point analyses can detect changes among successive relocations (Gurarie et al. 2009) and state-space models are able to identify underlying behavioral processes or "hidden states" (Patterson et al. 2008). While these alternative approaches could offer detailed insights into individual movement behavior, they have higher data demands and partly are challenging to apply to empirical data (Edelhoff et al. 2016). Consequently, the choice of method to detect different behaviors in relocation data depends on the quality and quantity of the data and the details required to answer our research questions. However, all of these methods provide the opportunity to relate behavior-specific 
data to environmental factors, making them valuable tools for understanding dispersal behavior in heterogeneous landscapes in the future.

In sum, the combination of different environmental factors derived from a detailed focus on individual dispersal behavior can lead to a more comprehensive understanding of dispersal and interpretation of resulting dispersal pattern. The knowledge we gain from these analyses can also improve conservation management decisions. For instance, resistance maps that are informed by movement behavior are expected to improve the effectiveness of conservation corridors (e.g., Abrahms et al., 2017, Scharf et al., 2018), whereas essential local drivers for settlement can yield important information for effective habitat restoration or rewildering projects.

\section{Integrating dispersal behavior into landscape genetics}

Landscape genetic studies offer a great potential to understand environmental effects on dispersal within and among populations and for predicting its ecological and evolutionary consequences (Manel et al., 2003, Storfer et al., 2007).However, most landscape genetic studies assume that the resistance of the landscape between populations is the solely environmental factor on dispersal and resulting gene flow. Although the landscape structure and composition between populations can be an important driver of movement (Storfer et al., 2010; Zeller et al., 2012), the local landscape characteristics such as habitat suitability or habitat similarity within home ranges also have important effects on the decisions to leave the natal site (i.e., to emigrate) and to select a new site for reproduction (i.e. to settle) as shown in chapter 2.

Chapter 3 demonstrates that it is conceptually plausible and statistically possible to integrate multiple possible links of landscape heterogeneity and effective dispersal in landscape genetic analyses. By considering several environmental factors acting on the three stages of dispersal simultaneously, landscape genetic analyses may become an even more powerful tool to understand the landscape effects shaping dispersal pattern. A remaining challenge for this or any other approach that focuses on environmental effects on dispersal will be to identify the environmental factors that are meaningful to the study species. Stronger ties with other research disciplines, such as movement ecology and behavioral ecology, will overcome this challenge by providing detailed information on individual behavior towards landscape heterogeneity. For example, the identification of the correct drivers could be delineated a priori based on the species' ecology and for each dispersal stage separately by using 
and also refining approaches similar to those suggested in chapter $\mathbf{2}$.

\section{Detecting negative landscape effects on dispersal}

Effective conservation of species threatened by habitat loss and fragmentation requires reliable indicators that are able to detect negative effects prior to extinction. However, currently used indicators have several drawbacks. Simple habitat thresholds might be appealing, but do not indicate actual habitat loss effects, which is often needed to convince stakeholders to initiated conservation management. In contrast, sophisticated early warning signals of upcoming critical thresholds (e.g., Dakos et al., 2012, Scheffer et al., 2009) could be alternatively used to simple habitat threshold rules, but require long-term demographic data, which can be challenging and costly to obtain in applied settings.

As demonstrated in chapter 4 , genetic data have the potential to provide valuable, alternative early warning indicator for conservation. The genetic diversity within populations and the genetic differentiation among them showed non-linear threshold responses during ongoing habitat loss similar to population abundance. Most importantly and contrasting to abundance, the responses of genetic variation were constant across model species and indicated negative effects of indirect habitat loss on population connectivity prior to remarkable changes in population abundance. Thus, when the extinction risk is estimated from abundance data alone, we neglect the indirect negative effects of habitat loss and fragmentation on dispersal and resulting gene flow, which could lead to an overestimation of the species persistence potential.

When integrated into a spatial, comparative framework that compares genetic diversity and differentiation of populations in degraded landscapes to control landscapes (e.g., protected landscapes), genetic data can improve our ability to identify areas of high conservation concern and to decide where conservation action have the greatest potential to be effective.

\section{Outlook}

It is possible to integrate individual dispersal behavior into studies dealing with landscape effects on the distribution of species and genetic variation (Chapter 2 - Chapter 4). In order to gain a deep understanding on dispersal - landscape relationships, future research should further create synergies between different research disciplines, focusing on different organizational levels and 
applications, such as behavioral and movement ecology, landscape and population genetics, landscape and (meta-) population ecology (e.g., Habel et al., 2015; Cayuela et al., 2018).

We are technically well equipped to follow species throughout life and gain important information on why, how, where and when they move in space and time and interact with their environment (Nathan et al., 2008, Cagnacci et al. 2010). Increasing high-quality remote sensed data at fine resolutions in combination with field data can provide detailed information on species specific landscape heterogeneity over large geographical extents (Hansen et al. 2013; Raab, 2019). Landscape genomics using novel technologies, such as next generation sequencing, opens up new avenues to relate genetic variation of whole genomes to fine-scale environmental data derived from remote sensing. Increasing computational power will facilitate to actually handle and analyze these large, spatially explicit data sets in a reasonable amount of time (e.g., Kidd and Ritchie, 2006, Paul and Song, 2012). Finally, next generation individual - based models using standardized and re-usable submodels that represent different dispersal behaviors and mechanisms will improve our ability to reproduce and explain the dispersal patterns we observe at the population or community level and to predict future response to environmental change (Travis et al., 2012, Grimm et al., 2017).

In sum, combining genetic data with high resolution aerial images and relocation data, and incorporating behavioral ecology, enables us to evaluate habitat loss effects on various taxa and to identify the appropriate habitat important for maintaining effective individual dispersal. The integration of several interacting components of dispersal in heterogenous landscapes and creative data analysis arising from interdisciplinary synergies may facilitate the understanding of the causes, mechanisms, and spatiotemporal patterns of dispersal and its role in various ecological and evolutionary processes, which ultimately could improve conservation management effectiveness. 


\section{References}

Abrahms, B., Sawyer, S. C., Jordan, N. R., McNutt, J. W., Wilson, A. M., and Brashares, J. S. (2017). Does wildlife resource selection accurately inform corridor conservation? Journal of Applied Ecology, 54(2):412-422.

Boyce, M. S., Vernier, P. R., Nielsen, S. E., and Schmiegelow, F. K. A. (2002). Evaluating resource selection functions. Ecological Modelling, 157(2-3):281-300.

Cagnacci, F., Boitani, L., Powell, R. A., and Boyce, M. S. (2010). Animal ecology meets GPS-based radiotelemetry: A perfect storm of opportunities and challenges. Philosophical Transactions of the Royal Society B: Biological Sciences, 365(1550):2157-2162.

Cayuela, H., Rougemont, Q., Prunier, J. G., Moore, J. S., Clobert, J., Besnard, A., and Bernatchez, L. (2018). Demographic and genetic approaches to study dispersal in wild animal populations: A methodological review. Molecular Ecology, 27(20):3976-4010.

Clobert, J., Le Galliard, J.-F., Cote, J., Meylan, S., and Massot, M. (2009). Informed dispersal, heterogeneity in animal dispersal syndromes and the dynamics of spatially structured populations. Ecology Letters, 12(3):197-209.

Dakos, V., Carpenter, S. R., Brock, W. A., Ellison, A. M., Guttal, V., and et al. (2012). Methods for detecting early warnings of critical transitions in time series illustrated using simulated ecological data. PLoS ONE, 7(7):e41010.

Edelhoff, H., Signer, J., and Balkenhol, N. (2016). Path segmentation for beginners: an overview of current methods for detecting changes in animal movement patterns. Movement Ecology, 4(1):21.

Grimm, V., Ayllón, D., and Railsback, S. F. (2017). Next-Generation Individual-Based Models Integrate Biodiversity and Ecosystems: Yes We Can, and Yes We Must. Ecosystems, $20(2): 229-236$.

Gurarie, E., Andrews, R. D., and Laidre, K. L. (2009). A novel method for identifying behavioural changes in animal movement data. Ecology Letters, 12(5):395-408.

Habel, J. C., Zachos, F. E., Dapporto, L., Rödder, D., Radespiel, U., Tellier, A., and Schmitt, T. (2015). Population genetics revisited - towards a multidisciplinary research field. Biological Journal of the Linnean Society, 115(1):1-12.

Hansen, M. C., Potapov, P. V., Moore, R., Hancher, M., Turubanova, S. A., Tyukavina, A., Thau, D., Stehman, S. V., Goetz, S. J., Loveland, T. R., Kommareddy, A., Egorov, A., Chini, L., Justice, C. O., and Townshend, J. R. G. (2013). High-Resolution Global Maps of 21st-Century Forest Cover Change. Science, 342:850-854.

Kidd, D. M. and Ritchie, M. G. (2006). Phylogeographic information systems: Putting the geography into phylogeography. Journal of Biogeography, 33(11):1851-1865.

Manel, S., Schwartz, M. K., Luikart, G., and Taberlet, P. (2003). Landscape genetics: combining landscape ecology and population genetics. Trends in Ecology and Evolution, 18(4):189-197. 
Matthysen, E. (2012). Multicausality of dispersal: a review. In Clobert, J., Baguette, M., Benton, T., and Bullock, J., editors, Dispersal Ecology and Evolution, pages 3-18. Oxford University Press, Oxford.

Nathan, R., Getz, W., Revilla, E., Holyoak, M., Kadmon, R., Saltz, D., and Smouse, P. (2008). A movement ecology paradigm for unifying organismal movement research. Proceedings of the National Academy of Sciences of the United States of America, 105(49):19052-19059.

Patterson, T. A., Thomas, L., Wilcox, C., Ovaskainen, O., and Matthiopoulos, J. (2008). State-space models of individual animal movement. Trends in Ecology and Evolution, $23(2): 87-94$.

Paul, J. S. and Song, Y. S. (2012). Blockwise HMM computation for large-scale population genomic inference. Bioinformatics, 28(15):2008-2015.

Raab, C. B. (2019). Combining remote sensing data at different spatial, temporal and spectral resolutions to characterise semi-natural grassland habitats for large herbivores in a heterogeneous landscape. Phd thesis, Georg-August-Universität Göttingen.

Scharf, A. K., Belant, J. L., Beyer, D. E., Wikelski, M., and Safi, K. (2018). Habitat suitability does not capture the essence of animal-defined corridors. Movement Ecology, $6(1): 1-12$.

Scheffer, M., Bascompte, J., Brock, W. A., Brovkin, V., Carpenter, S. R., and et al. (2009). Early-warning signals for critical transitions. Nature, 461(7260):53-59.

Storfer, A., Murphy, M., Evans, J., Goldberg, C., Robinson, S., Spear, S., Dezzani, R., Delmelle, E., Vierling, L., and Waits, L. (2007). Putting the "landscape" in landscape genetics. Heredity, 98(3):128-142.

Storfer, A., Murphy, M. a., Spear, S. F., Holderegger, R., and Waits, L. P. (2010). Landscape genetics: where are we now? Molecular Ecology, 19(17):3496-3514.

Thurfjell, H., Ciuti, S., and Boyce, M. S. (2014). Applications of step-selection functions in ecology and conservation. Movement Ecology, 2(1):1-12.

Travis, J. M., Mustin, K., Bartoń, K. A., Benton, T. G., Clobert, J., and et al. (2012). Modelling dispersal: An eco-evolutionary framework incorporating emigration, movement, settlement behaviour and the multiple costs involved. Methods in Ecology and Evolution, $3(4): 628-641$

Zeller, K. A., McGarigal, K., and Whiteley, A. R. (2012). Estimating landscape resistance to movement: a review. Landscape Ecology, 27(6):777-797. 



\section{Danksagung}

Diese Arbeit wäre nicht ohne die Unterstützung, Ideen, Diskussionen, Meetings und die Geduld vieler anderer Menschen möglich gewesen. Besonders danken möchte ich:

- Prof. Dr. Niko Balkenhol für die Chance und seinen Einsatz, ein Teil der Abteilung Wildtierwissenschaften zu werden, für die Betreuung dieser Arbeit, seine Kreativität und für die Herausforderungen.

- Ein großer Dank gilt auch Prof. Dr. Matthias Waltert und Dr. Christian Roos für ihre Bereitschaft, die Zweit-/ und Drittbetreuung zu übernehmen.

- Ein besonders großer Dank geht an Johannes Signer für seine großartige Unterstützung und seine Passion für R. Ich habe dadurch so unglaublich viel gelernt!

- Ich danke meinen ehemaligen Bürokollegen Kathrin Mayer, Trishna Dutta, Maarten Hofmann, Hendrik Edelhoff, Scott Appleby und dem Team der Wildtierwissenschaften insgesamt für eine unglaublich tolle, freundschaftliche und produktive Arbeitsatmosphäre.

- Ich danke Katharina Westekemper für das Korrekturlesen und die mentale, teils zuckerhaltige Unterstützung kurz vor der Abgabe.

- Ich danke meinen Eltern dafür, es mir ermöglicht zu haben, diesen beruflichen Weg einzuschlagen.

- Ich danke Mechthild und Bernard für ihren großartigen Einsatz, uns zu unterstützen und Freiräume zu schaffen. Danke für euer Vertrauen und eure Zuneigung.

- Ein besonderer Dank geht an meine Kinder. Es ist so schön, dass es euch gibt!

- Mein allergrößter Dank geht an meinen Partner Serjoscha, ohne den diese Arbeit nicht möglich gewesen wäre. Danke für deine Liebe, deine Geduld, dein Vertrauen und deine Unterstützung! 



\section{Thesis Declaration}

I hereby confirm that I have written this doctoral thesis independently, that I have not used other sources or facilities other than the ones mentioned, that I have not used unauthorized assistance and that I have not submitted this thesis previously in any form for another degree at any university or institution.

Femke Pflüger

Göttingen, 14 August 2020 